\title{
WestVirginiaUniversity
}

THE RESEARCH REPOSITORY @ WVU

Graduate Theses, Dissertations, and Problem Reports

2014

\section{The Use of Hand Bacteria as a Human Biometric Identifier}

\author{
Amanda Holbert
}

Follow this and additional works at: https://researchrepository.wvu.edu/etd

\section{Recommended Citation}

Holbert, Amanda, "The Use of Hand Bacteria as a Human Biometric Identifier" (2014). Graduate Theses, Dissertations, and Problem Reports. 5811.

https://researchrepository.wvu.edu/etd/5811

This Thesis is protected by copyright and/or related rights. It has been brought to you by the The Research Repository @ WVU with permission from the rights-holder(s). You are free to use this Thesis in any way that is permitted by the copyright and related rights legislation that applies to your use. For other uses you must obtain permission from the rights-holder(s) directly, unless additional rights are indicated by a Creative Commons license in the record and/ or on the work itself. This Thesis has been accepted for inclusion in WVU Graduate Theses, Dissertations, and Problem Reports collection by an authorized administrator of The Research Repository @ WVU. For more information, please contact researchrepository@mail.wvu.edu. 
The Use of Hand Bacteria as a Human Biometric Identifier

\begin{abstract}
Amanda Holbert
Thesis submitted

to the Benjamin M. Statler College of Engineering and Mineral Resources at West Virginia University
\end{abstract}

in partial fulfillment of the requirements for the degree of

Master of Science in Electrical Engineering

Jeremy Dawson, Ph.D., Chair

Donald Adjeroh, Ph.D.

Lawrence Hornak, Ph.D.

Letha Sooter, Ph.D.

Lane Department of Computer Science and Electrical Engineering

Morgantown, West Virginia

2014

Keywords: Ethnicity, identification of persons, molecular biometrics, skin bacteria Copyright 2014 Amanda Holbert 


\section{Abstract \\ The Use of Hand Bacteria as a Human Biometric Identifier}

Amanda Holbert

Molecular and bio-molecular biometrics are an advancing field that involves the analysis of a person's unique biological markers at a molecular level to ascertain identity. Bacteria communities found on the skin of the human hand have shown to be highly diverse and to have a low percentage of similarity between individuals. The goal of this research effort is to see if a person's demographics, primarily ethnicity, share a relationship with the bacteria communities that exist on their hand. A sample collection was carried out in which the left and right inner palms of 250 individuals were swabbed to obtain a total of 500 bacteria samples. Of these, 104 samples covering a range of age, gender, and ethnicity of the participants, were sequenced using 150 paired-end multiplex reads on an Illumina MiSeq. The reads contained the third hypervariable region DNA of the microbial 16S rRNA gene commonly used for microbial identification. Sequences were analyzed using a combination of commercial and custom bioinformatics tools. Results indicated that women that participated in the sample collection had a $15.7 \%$ higher diversity of bacteria at the genus level than men. Using a support vector machine with a $60 \%$ train and $40 \%$ test approach, ethnicities of individuals who provided samples could be classified with a range of 64-93\% accuracy depending on the method used. Principal coordinate plots generated by using the unique fraction (UniFrac) algorithm devised by Lozupone et al at University of Colorado at Boulder showed that similar clustering appeared with people of Turkish, Asian Indian, and Middle Eastern descent and less clustering with people of Caucasian and African American descent. Although focused on a small subset of the human population with no temporal variance in bacterial diversity explored, these results provide a basis for performing identification based on human bacteria that can be expanded upon using time varying sampling and other regions of the 16S rRNA gene. 


\section{Acknowledgments}

I would first like to thank my advisor Dr. Jeremy Dawson for all of his help since my under grad years. I am grateful that he encouraged me to stay and complete my Masters. The last two years have been very beneficial for my transformation to the real world. Thanks to Jeremy, I had several opportunities to meet and connect with many important members in the biometrics community. These opportunities have given me a better path of what my future goals are.

I would like to thank Dr. Letha Sooter for her help and faith in me over the last few years. She has been very helpful in teaching me the reasons and means of many procedures in her lab. I would also like to thank Letha for not giving me that last strike in her lab and allowing me to finish this project.

I would like to thank Dr. Don Adjeroh and Dr. Larry Hornak for their suggestions and help with this project.

I would like to thank Holly Whitelam for all her help during her summer fellowship. She was a joy to work with and made the lengthy and tedious lab work not seem so bad. I wish she could have stayed longer but am glad to still be able to call her a very close friend.

I would like to thank my friends, a.k.a. my coworkers, for the laughs, the fun times, and even some of the not so fun times in our lab over the years.

Finally, I would like to thank my family for their support and positive words. It is because of them that I was able to get this far in my college career. I love you all so much. 


\section{Table of Contents}

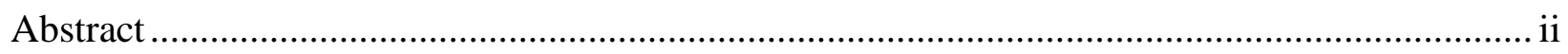

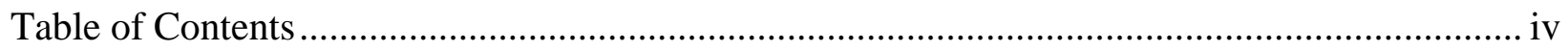

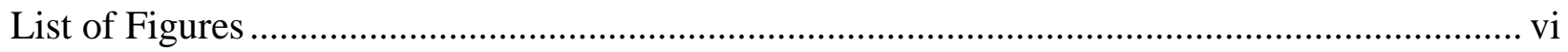

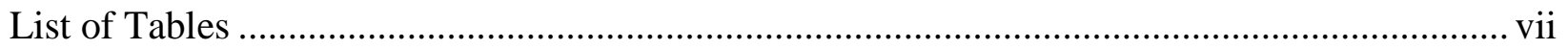

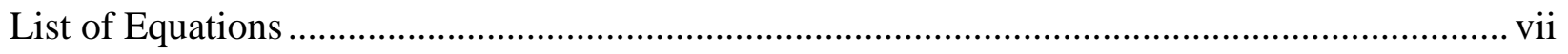

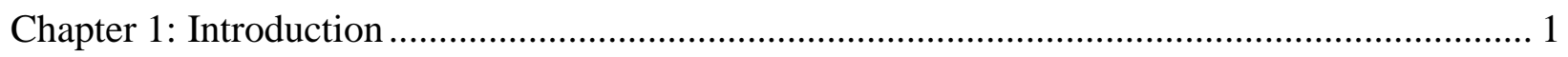

1.1 Human Bacteria and Bacteria-Based Identification .......................................................... 6

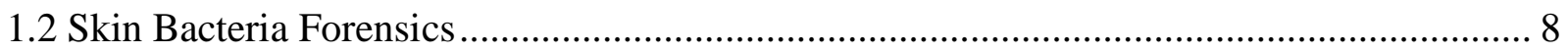

1.3: Problem Statement and Thesis Organization .............................................................. 10

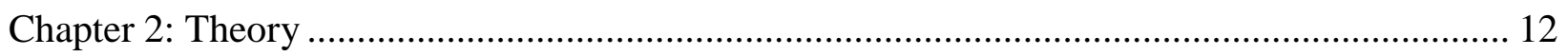

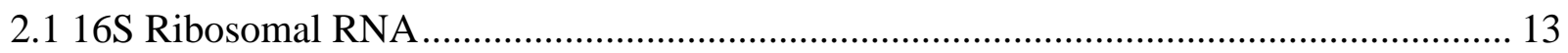

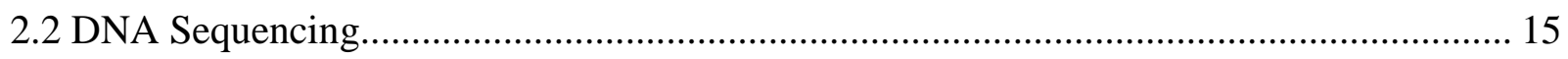

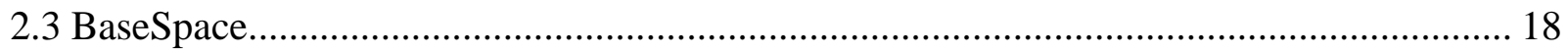

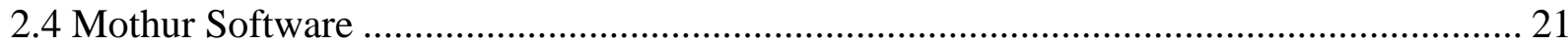

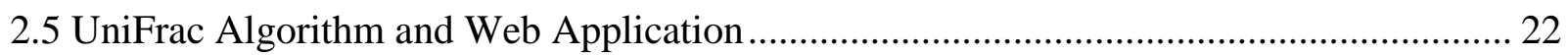

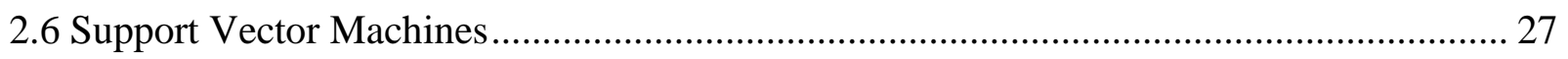

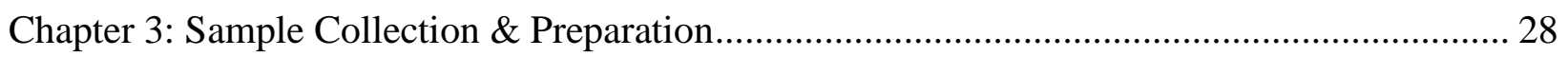

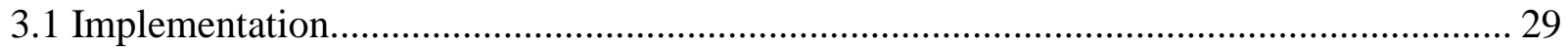

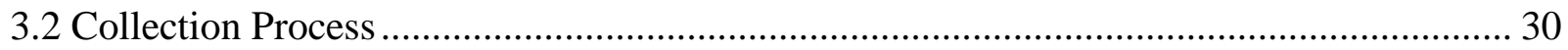

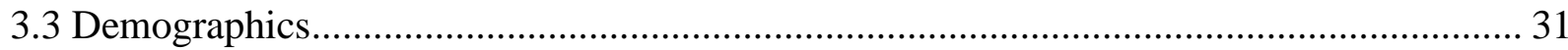

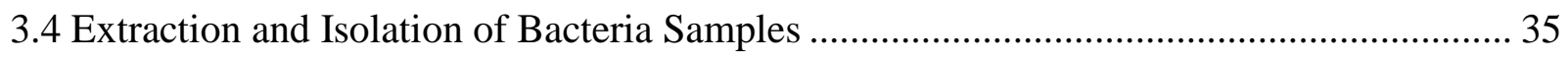

3.5 Escherichia coli Control and Modification of Isolation Kit.............................................. 39

3.6 Amplification of the V3 Region and Library Generation ................................................... 42

Chapter 4: Data Extraction \& Analysis ................................................................................... 46

4.1 First Bioinformatics Method ........................................................................................... 47

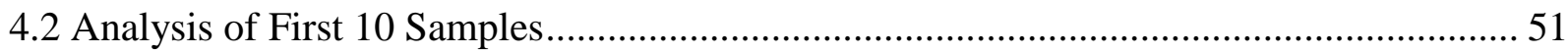

4.3 Additional Bioinformatics Method by WVU Genomics Facility ....................................... 54

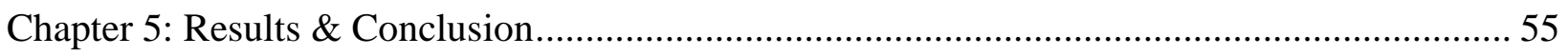

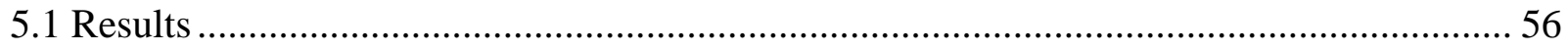




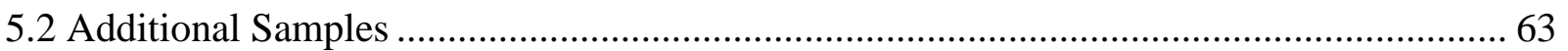

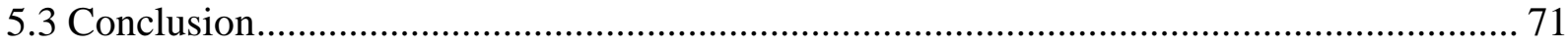

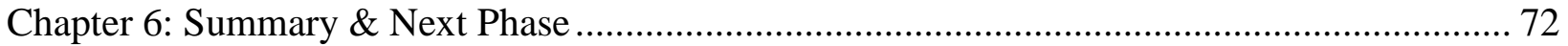

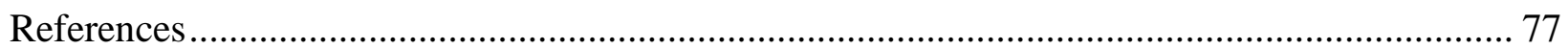

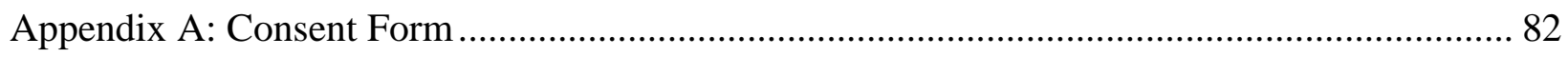

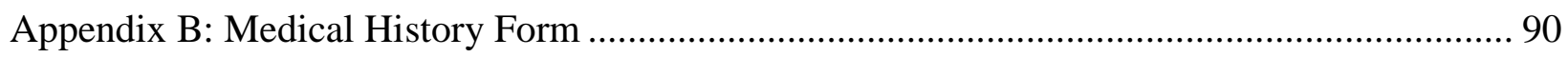

Appendix C: UltraClean ${ }^{\circledR}$ Plant DNA Isolation Kit, Instruction Manual .................................... 105

Appendix D: Gel/PCR DNA Fragments Extraction Kit, IBI Scientific …………..................... 120

Appendix E: Quality Scores for Next-Generation Sequencing .............................................. 124 


\section{List of Figures}

Figure 2.1: Assembly of the 70S ribosome found in Bacteria ................................................... 14

Figure 2.2: Breakdown of the conserved and variable regions of the 16S rRNA gene ............... 15

Figure 2.3: Cost and technology evolution of DNA sequencing and synthesis............................. 16

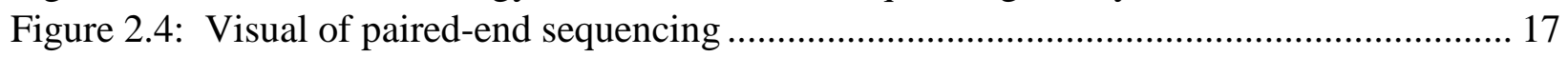

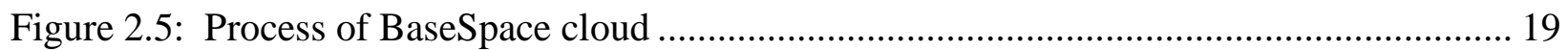

Figure 2.6: Snippet of a forward and reverse FASTQ file........................................................ 19

Figure 2.7: Snippet of the breakdown of classification confidence percentage .......................... 20

Figure 2.8: Snippet of a classification file that provides a summary for a sample ....................... 21

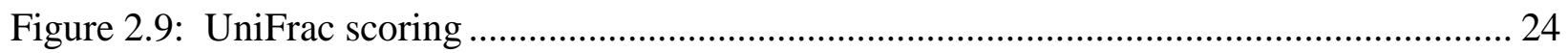

Figure 2.10: Visual of how the environment file is created for UniFrac application ................... 25

Figure 2.11: (Left) Sample clustering tree (Right) Sample PCoA plot. ......................................... 26

Figure 3.1: Ethnicity of participants from collection of 255 individuals.................................... 32

Figure 3.2: Ethnicity of participants used for the bacterial identification subset group.............. 33

Figure 3.3: Distribution of gender and ethnicity of total collection. ............................................ 33

Figure 3.4: Participant's gender and ethnicity of the subset group.............................................. 34

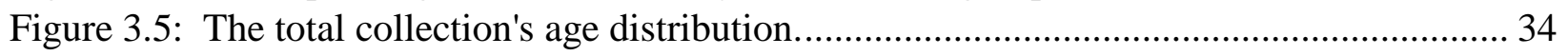

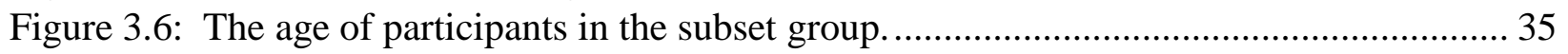

Figure 3.7: Collection tube prior to DNA isolation and after isolation ....................................... 36

Figure 3.8: After isolation, the 16S region of the sample was amplified and then cleaned........ 38

Figure 3.9: Samples are cleaned, and quality and concentration are determined ........................ 39

Figure 3.10: Gel from four unamplified E. coli samples .......................................................... 41

Figure 3.11: Gel from amplified E. coli samples...................................................................... 41

Figure 3.12: Examples of good, marginal, and bad quality samples ......................................... 45

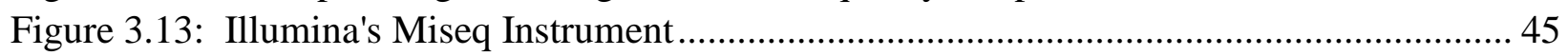

Figure 4.1: Diagram of bioinformatics tools and methods used to analyze bacteria data ........... 48

Figure 4.2: Percentage of OTUs that made up the sample at the genus level.............................. 49

Figure 4.3: Diagram on how the samples went from sequence to a phylogenetic tree................. 51

Figure 4.4: Environment UniFrac distance matrices ............................................................. 52

Figure 4.5: Sample clustering on first 10 samples using weighted UniFrac measurements........ 53

Figure 4.6: Weighted Principal Coordinate Analysis plot for first 10 samples ............................ 53

Figure 5.1: Clustering of Middle Eastern, Asian Indian and Turkish ethnicities .......................... 57

Figure 5.2: Dissimilarity between Asian Indian and Asian ethnicities........................................ 58

Figure 5.3: No Caucasian or African American clustering, slight Hispanic clustering................ 58

Figure 5.4: No apparent clustering between groups when based off of age ................................. 59

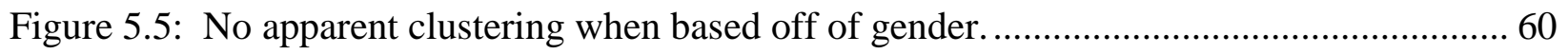

Figure 5.6: Percentage of the five most common OTUs found using the first method ................ 62

Figure 5.7: Percentage of the five most common OTUs found using the second method ........... 62

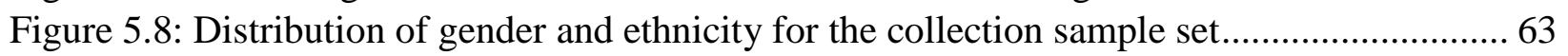

Figure 5.9: Additional samples, primarily Caucasian, were added to the sample set..................... 64

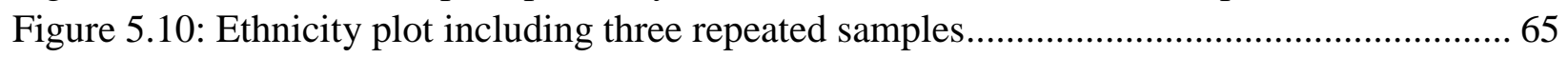

Figure 5.11: Unweighted UniFrac distance matrix from 107 samples ........................................ 66 


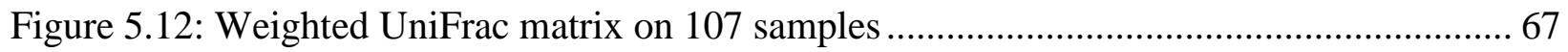

Figure 5.13: No apparent clustering based off of participant's gender .................................... 68

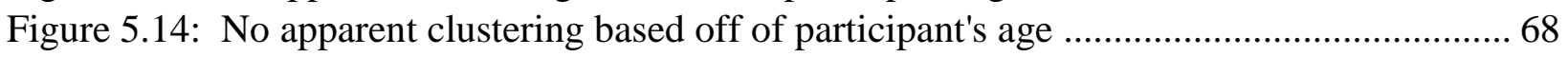

Figure 5.15: SVM error rates based off of the 11 most common OTUs ................................. 69

Figure 6.1: Review of clustering comparisons between some of the ethnicities...................... 74

Figure 6.2: $70 \mathrm{~S}$ broken into $16 \mathrm{~S}, 23 \mathrm{~S}$ and $5 \mathrm{~S} .16 \mathrm{~S}$ broken down into regions......................... 75

\section{List of Tables}

Table I: Bacteria Specific 16S rRNA and V3 Region PCR Primer and Sequence.................... 43

Table II: Accuracy Rate of Support Vector Machine Classification Method............................. 61

Table III: SVM error rates from the visual in Figure 5.1 ................................................ 70

Table IV: SVM error rates for top 5 best performances of each ethnicity ............................... 70

\section{List of Equations}

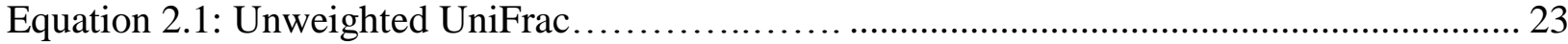

Equation 2.2: Weighted UniFrac................................................................. 23

Equation 2.3: Support Vector Machine .................................................................................. 27

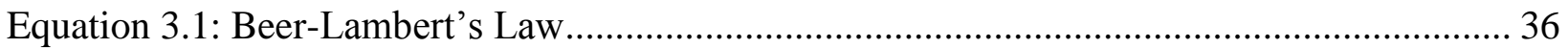


Chapter 1:

Introduction 


\section{Biometrics Methodologies}

Biometrics is the measurement of human characteristics and traits for identification and verification purposes. A biometric identifier is a measureable physical or behavioral characteristic that is universally found, and, unique and permanent to an individual. These offer a reliable way of identifying that person and can be easily captured and usually quick to evaluate. Physical traits are traits such as fingerprints, palm prints, hand geometry, and face and iris recognition; gait and voice are examples of behavioral biometrics. Biometric identifiers are becoming more preferred and used for authentication management because these traits are harder to manipulate, share, forget or lose unlike passwords and identification cards. Unlike forensics, which is applied by gathering information from past events or situations such as criminal activity, biometrics deals with preevent situations like gaining access to a restricted location or verifying one's identity. Fingerprints, face, iris, and voice recognition are currently among some of the most common biometric traits being used today. These traits are usually easily attainable, and the majority of the biometric systems used to obtain this data are fast, cost-effective, and user-friendly [1].

Biometrics has made major advancements in the last decade, such as multi-modality sensors with high image quality, low false match rate (FMR) recognition algorithms, and increase in overall end-to-end system speed [2]. Even with better technology, there are still biometric challenges that are difficult to overcome. For example, biometric traits such as fingerprints, facial features and gait can be medically altered [3]. Fingerprints can be scarred, surgically switched, or replaced by another part of the person's skin or even by another person's skin. Deformities, degenerative diseases, or a major injury to a limb can cause the need for orthopedic attention such 
as surgery which could alter an individual's gait. More than 23 million surgical and nonsurgical cosmetic procedures were performed worldwide in 2013 according to International Society of Aesthetic Plastic Surgery [4]. These procedures, especially ones that affect the jaw line, cheeks and the shape and size of the face, have a big effect on facial recognition systems. Another factor often affecting the collection of these biometric traits is lighting and environment settings. For example, the majority of face recognition computing only performs well in settings with controlled lighting and background, and standard face presentation [5] (i.e. frontal pose, no expression). Iris and fingerprint quality is also reliant on controlled settings [1]. Low quality iris images can occur when the sensor is out of focus, when there is eye movement (causing blurred images) and occlusion (caused by eyelids, lashes, etc.). Low quality fingerprint images can occur when the skin on the finger is too dry or when there is too much moisture.

\section{Soft Biometrics}

One subset of the previous traditional biometrics are soft biometrics. These traits are usually established over time and may lack uniqueness, permanence and may not be universally available like traditional biometrics [6]. Soft biometrics, like traditional biometrics, can be based off of physical or characteristic features. Physical features are traits such as a person's height, weight; skin color, hair color, eye color and scars or marks. Behavioral and adhered characteristic features are traits such as a person's keystroke, handwriting, clothing, accessories, and tattoos. Soft biometrics may be used to aid traditional biometrics to differentiate someone by downsizing a data set of a group of people and reducing computational time, but are not reliable enough to be used to identify someone alone. 


\section{Molecular and Soft Bio-Molecular Biometrics}

Molecular biometrics and soft bio-molecular biometrics is an emerging subset of biometrics that uses unique molecular and biological markers to perform human identification. Classes such as deoxyribonucleic acid (DNA) would be considered molecular biometrics, while body odor and human microbes are soft bio-molecular biometrics. DNA has already been widely used for identification in forensics (law enforcement, booking) and non-forensics purposes (border crossing, familial identification). Both purposes generally involve gathering a DNA sample by taking a buccal swab which collects cells from the inside of the individual's cheeks. This sample is used to generate a profile of the subject based on 13 short tandem repeats (STRs) that are found in the DNA. DNA is ideal for identification purposes in that it can be gathered from not only cheek cells, but from skin cells, hair cells, and any other area of the body.

DNA and soft bio-molecular traits are also beneficial from the traditional biometric traits in that they are not as easily affected by physical alterations, are harder to spoof and they do not require specific lighting or conditions to be collected. Recent technical advancements in portable rapid DNA systems have pushed DNA processing times from weeks and hours down below one hour. These systems are currently being used in trial applications in booking stations across the US. Molecular markers can also be used to differentiate between identical twins. It used to be assumed that identical twins had identical DNA, but recent discoveries show that they can be distinguished by examining single nucleotide polymorphisms (SNPs) within the DNA [7]. 
Along with differentiating genomic DNA, twins also possess different bacterial colonies. Among the general human population, bacterial colonies have been shown to be unique on the skin and throughout the body [8]. The activity of these bacteria is also what helps contribute to unique odor components of the human body. Sweat which is originally odorless is consumed by skin bacteria which then produces a byproduct. This byproduct is what causes a person's odor. These skin bacteria can be as dense as $10^{7}$ bacteria cells per square centimeter [9]. Although skin bacteria is not as ecologically rich as compared to the bacteria found in the mouth or intestines, it has been shown to have a higher diversity. Individuals share more of the same type of bacterial communities found in their mouth and intestines than compared to the communities found on their skin [10] [11]. This diversity is large enough that skin bacteria has been evaluated for forensic identification applications [12]. Studies have been able to match bacteria swabbed from an individual's hand to the bacteria found on that individual's personal belongings. They can be easily be collected from a surface that has been touched, or from simply swabbing a section of the skin. Bacteria are also more robust to environmental exposure. From the same study [12], bacteria swabbed were left untouched in an open container for two weeks before processing, the overall structure and composition of the individual's profile was left unchanged. This study demonstrated that bacterial DNA is less prone to degradation than nuclear DNA in human cells.

Previously, because of lengthy processing time, cost of equipment, and training necessary to prepare samples and evaluate data, these molecular markers had not been seriously considered for biometrics. However, thanks to advancements in technology, such as next-generation sequencing and more rapid DNA systems, emerging technologies are offering faster sequencing and processing time for larger amounts of DNA and other biological samples. Within 5-10 years, 
these systems will enable new forms of molecular biometrics, either as stand-alone methods of identification or in a supplemental role to existing, mature biometric identification systems.

\subsection{Human Bacteria and Bacteria-Based Identification}

\section{Gut Bacteria}

The microbes residing in the gut have a profound influence on human physiology and nutrition. Gut microbes are so essential to the body for digestion, immune response and creating enzymes that they are considered a virtual organ [13]. Like any organ, an individual's genetic makeup as well as the environmental conditions that they live in, and the individual's age directly affect an organ. These conditions also hold true about an individual's gut microbes, which are also directly affected [14] [15]. These results suggest that the gut bacteria in the human body are similar to the individual's genetic traits [11]. Although results show there is a high affiliation between gut bacteria and an individual's genetic makeup, which would lead to a great biometric recognition, the collection of gut bacteria is not easily accessible. The collection of gut bacteria is primarily obtained via fecal samples, this method is not as amenable to biometric applications as bacteria collected from the skin.

\section{Oral Bacteria}

The microbes that reside in the oral cavity are a diverse, abundant and complex community but are also one of the more stable bacterial regions of the human microbiome [11]. The ethnicity 
of an individual has been able to be determined based off of specific bacterial communities found in the oral cavity [16]. Analysis of oral bacterial communities collected from 192 individuals who were either non-Hispanic black, non-Hispanic white, Chinese or Latino proved to predict the individuals' ethnicity with a $62 \%$ accuracy. These results were found by analyzing variable regions V1-V3 and V7-V9 of the bacterial 16S rRNA gene were sequenced using multiplexed 16S pyrotag sequencing. The prediction of individual ethnicity was determined by using a Random Forest machine-learning classifier. Observations showed that the ethnicity of an individual was best observed by the bacteria that were more influenced by the individual's genetics rather than the bacteria that were associated with the individual's food intake or hygiene. Although collection of oral bacteria is also a potential biometric application, oral bacterial swabbing could be considered an invasive form of collection when considering typical usage such as daily access control.

\section{Skin Bacteria}

The microbes that reside on the human skin were once thought of as being harmful to the body, but with advances in research and projects such as the Human Microbiome Project [11], a better understanding of skin bacteria has been revealed [17]. These microbes have shown to help the human body and the skin's immune system by preventing transient pathogens from colonizing on the skin surface [9] [17]. Also from the Human Microbiome Project results revealed that the skin contains a high diversity of bacteria. Unlike the gut and oral bacterial diversity, the skin bacterial diversity is more diverse between different skin environments. This means there is more variation between different skin locations, unlike the oral and gut which have the same diversity 
within those regions. This high degree of variation, as well as the non-invasive nature of collection compared to gut and oral bacteria, makes skin bacteria a potential use for a biometric application.

\subsection{Skin Bacteria Forensics}

The palm of the hand is a skin region that is known to contain a high level of bacterial diversity due to its frequent exposure to different surfaces and environments. Even with exposure to varying conditions such as temperature fluctuations, soaps, lack of constant moisture, and ultraviolet radiation, an individual's hand bacterial communities have been shown to contain the same amount of bacterial consistency over time [10] [18] [19]. In a study performed by the Fierer group at the University of Colorado at Boulder, who analyzed the 16S rRNA gene via multiplex pyrosequencing [10], it was observed that the diversity of skin bacterial communities found on the palm surfaces of individuals was quite large. A total of 4,742 different phylotypes were identified across the 102 sample set. The study also revealed that women had a higher level of bacterial diversity than that of men and that certain bacterial groups are more abundant on one gender compared to the other. Although some of the bacteria groups were found on all hands, the bacteria samples still revealed to be extremely different. The similarities between two individuals displayed only a $13 \%$ similarity and only a $17 \%$ similarity between an individual's left and right hand. These similarity scores were calculated by using the unique fraction (UniFrac) measurement [20] [21]. UniFrac measures the phylogenetic distance between sets of bacteria groups in a single rooted phylogenetic tree. This tree contains bacteria from two or more different samples or environments, the more unique the samples are than the higher uniqueness score is assigned between those two 
samples. In this case, a sample would be all the bacteria collected from one hand. More details on this UniFrac algorithm is explained in Chapter 2.

The bacteria found on the hand has also been used as a forensic tool to link individuals to their personal belongings [12]. Bacteria that were swabbed from individuals' fingertips and their keyboard keys, along with additional keyboards from other individuals and random public keyboards, showed that the bacterial communities on a subject's fingertips and the communities on their keyboard were far more similar to each other than the communities found on other individuals' fingertips and keyboards. Additionally, this study [12] collected skin bacteria samples that were either stored immediately at $-20^{\circ} \mathrm{C}$ or left in open containers at approximately $20^{\circ} \mathrm{C}$ for two weeks. The results displayed slight difference during analysis and the bacteria samples left in open containers were still able to be matched to the individuals that they were collected from. This revealed that skin bacterial communities can reside unchanged on touched objects for a lengthy amount of time.

Since study [12] showed that bacteria can reside on surfaces for at least two weeks, it is not unexpected that people in the same household would have more shared bacteria than individuals outside of the household [22]. Observations on 17 families equaling to 159 individuals in study [22] found that there are higher similarities between family members in the same household than to other individuals outside of the family. These observations were gathered by identifying the bacteria by using the second hypervariable (V2) region of the bacterial 16S rRNA gene using multiplex DNA sequencing with Illumina. After bacterial identification the statistics were calculated by using the UniFrac algorithm that has been previously mentioned. Although 
observations indicated there are more shared bacteria with members in the same household, it also showed that there is still a sufficient amount of uniqueness between the individuals with an average of around $60 \%$ uniqueness.

\section{3: Problem Statement and Thesis Organization}

The main goal of this research is to establish a basis for the use of hand bacteria as a biometric identifier by analyzing the third hypervariable region (V3) of the bacterial 16S ribosomal RNA (rRNA) gene collected from the palm of a hand. The V3 region can be used to distinguish a large population of bacteria down to the genus level [23]. After identifying the bacteria species present in the skin bacteria samples, the goal is to discover if this information will produce similar results in uniqueness and gender diversity to previous studies, primarily studies [12] and [22]. It is also

desired to discover if a person's demographics (their ethnicity, gender, and age) shares a relationship with the cohabiting skin bacterial communities. The main tasks associated with these goals are:

1. Data Collection: Swabbing left and right inner palms of participants to collect skin bacteria

2. Sample Preparation: Isolating DNA from bacteria samples and amplifying target region

3. Genomic Sequencing: Performing $150 \mathrm{bp}$ paired-end multiplexed sequencing

4. Bioinformatics Analysis: Classifying and analyzing sequence data with open-source software 
Knowing that processing large amounts of data can be done in a reasonable amount of time due to technology advancements and that skin bacteria have been proven to be unique enough to be used on a forensic level, it is also desired to see if bacterial colonies collected from the human hand are unique enough to be used as a biometric identifier.

\section{Thesis Organization}

Chapter 2 explains the principle and reasoning on why the bacteria region of interest is important and valuable, and what tools were decided on to be the best to process and analyze this area. Chapter 3 describes in detail the process of the sample collection and the preparation that occurred to extract the best data for analysis. Chapter 4 covers the bioinformatics pipelines that were described in the second chapter and how these tools were used to analyze the data. Chapter 4 also covers the initial results from the first data set analyzed. Chapter 5, the results and conclusion chapter, covers the findings from the remaining processed data and the conclusions that were made about this data and finally Chapter 6 covers the thesis summary and the next phases for this area of work. 
Chapter 2: Theory 
This chapter begins by giving a background understanding of molecular compounds in bacteria which helps describes the purpose and importance of the region of interest for identifying bacteria. This chapter also covers how this area will be processed, and what bioinformatics tools will be used to analyze the processed data.

\subsection{S Ribosomal RNA}

Ribosomes are complex structures found in all living organisms. In bacteria cells, ribosomes consist of two subunits called the 30S subunit and the 50S subunit that make up the 70S ribosome (Fig. 2.1). The ' $\mathrm{S}$ ' in $30 \mathrm{~S}$, $50 \mathrm{~S}$ and $70 \mathrm{~S}$ stands for Svedberg unit. A Svedberg unit is a non-SI unit for sedimentation rate and is a measure of time. This rate measures how fast a particle takes to travel and settle to the bottom of a test tube under centrifugal force. One Svedberg unit equals $10^{-13}$ seconds [24]. So the larger the $\mathrm{S}$ number is the larger the particle. The small ribosomal subunit, the $30 \mathrm{~S}$ subunit, which reads in RNA contains a gene called the 16S ribosomal RNA (16S rRNA) gene. The DNA that encodes for this gene is approximately 1,500-1,600 base pairs in length. This gene exists in nearly all bacteria and is a highly conserved region, meaning it rarely is transferrable between other bacterial species. Although it is highly conserved, it still exhibits enough variability to reveal informative differences between different bacterial species. The function of this gene itself has also not changed over time, showing that random sequence changes are an accurate measure of evolution [25] [26]. All of these factors make this gene a widely used area for studying bacterial phylogeny and taxonomy. 
The 16S rRNA is made up of nine different hypervariable regions (Fig. 2.2). These hypervariable regions show considerable sequence diversity among different bacterial species and are commonly used for bacteria classification. Although not one region can distinguish the difference between all bacteria, nor can any one region identify down to the species or sub-species level, certain regions do provide more information than others for specific bacterial identification tasks. In this thesis, just the V3 region was analyzed for bacterial identification. This region is located around nucleotides 433-497 (approximately 60 bps in length) of the 16S rRNA and is one of the most suitable and most popular regions for identifying majority of bacterial species down to the genus level [23]. This region was combined with other regions in a couple of the previous studies for bacterial classification. To recap, the forensics and handedness study [10] [12] analyzed the whole $16 \mathrm{~S}$ region, which contains all nine variable regions, the cohabiting family members study [22] used just the V2 region, which has also shown similar results in classification and the study involving oral bacteria [16] used combinations of V1-V3 and the V7-V9 regions.

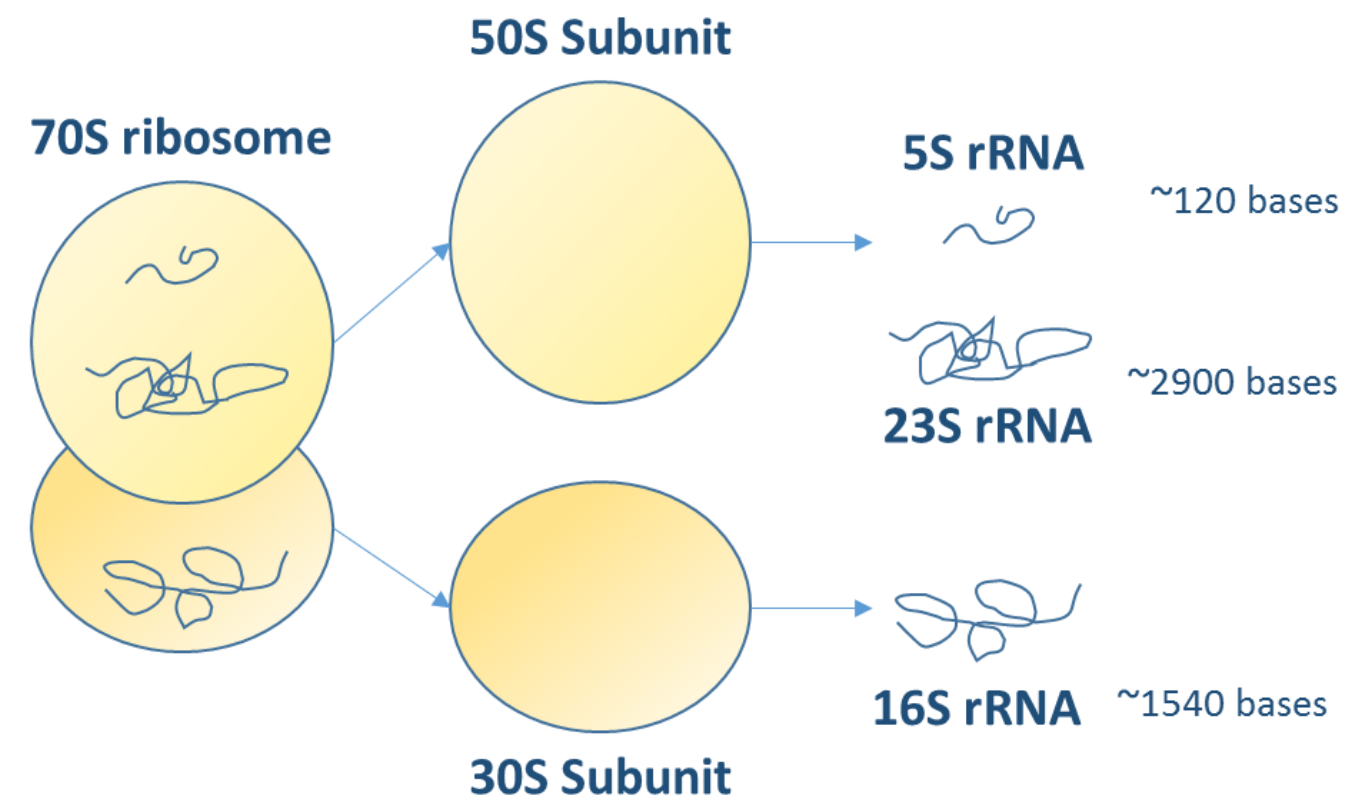

Figure 2.1: Assembly of the 70S ribosome found in Bacteria 


\begin{tabular}{|c|c|c|c|c|c|c|c|c|}
\hline (29-99 & |c: & 433-497 & ـ & 822-879 & 986-1043 & 1117-1173 & $1243-1294$ & (1435. \\
\hline V1 & V2 & V3 & V4 & V5 & V6 & V7 & V8 & V9 \\
\hline
\end{tabular}

\section{Variable Regions: $\square$ Conserved Regions:}

Figure 2.2: Breakdown of the conserved and variable regions of the 16S rRNA gene. ${ }^{1}$

\subsection{DNA Sequencing}

To be able to use the V3 region for classification, the DNA that encodes it must be sequenced. Sequencing is any process that determines the precise order of the four nucleotides (Adenine 'A', Thymine ' $\mathrm{T}$ ', Guanine ' $\mathrm{G}$ ', and Cytosine ' $\mathrm{C}$ ') within a given DNA strand. Sequencing technology has advanced significantly since the early 1970s when the first DNA strands were sequenced [27]. The first-generation iterations of sequencing systems were very costly and could cost more than a $\$ 1$ per base pair (nucleotide pair) to sequence (Fig. 2.3). In 1987, the first automatic sequencing machine, the AB370, could only detect 96 bases at a time, had a read length of 600 bases, and could process about 500K bases in a day [28]. To put this in perspective, a typical bacterial genome has between $~ 140 \mathrm{kbp}$ [29] to 13 Mbps [30] while a human genome has a length greater than 3 Bbps. With rapid advancements in technology, the development of a new generation of sequencers (NGS) dubbed the 'next-generation' fulfilled the need to lower the cost of sequencing and produce larger and faster throughput by having the ability to parallel process sequences. These new instruments can now sequence up to $600 \mathrm{~Gb}$ per run (Illumina HiSeq 2000) with read lengths of up to 900 bases in less than 3 hours (Sanger 3730xl) [28].

\footnotetext{
${ }^{1}$ Modified from www.alimetrics.net
} 


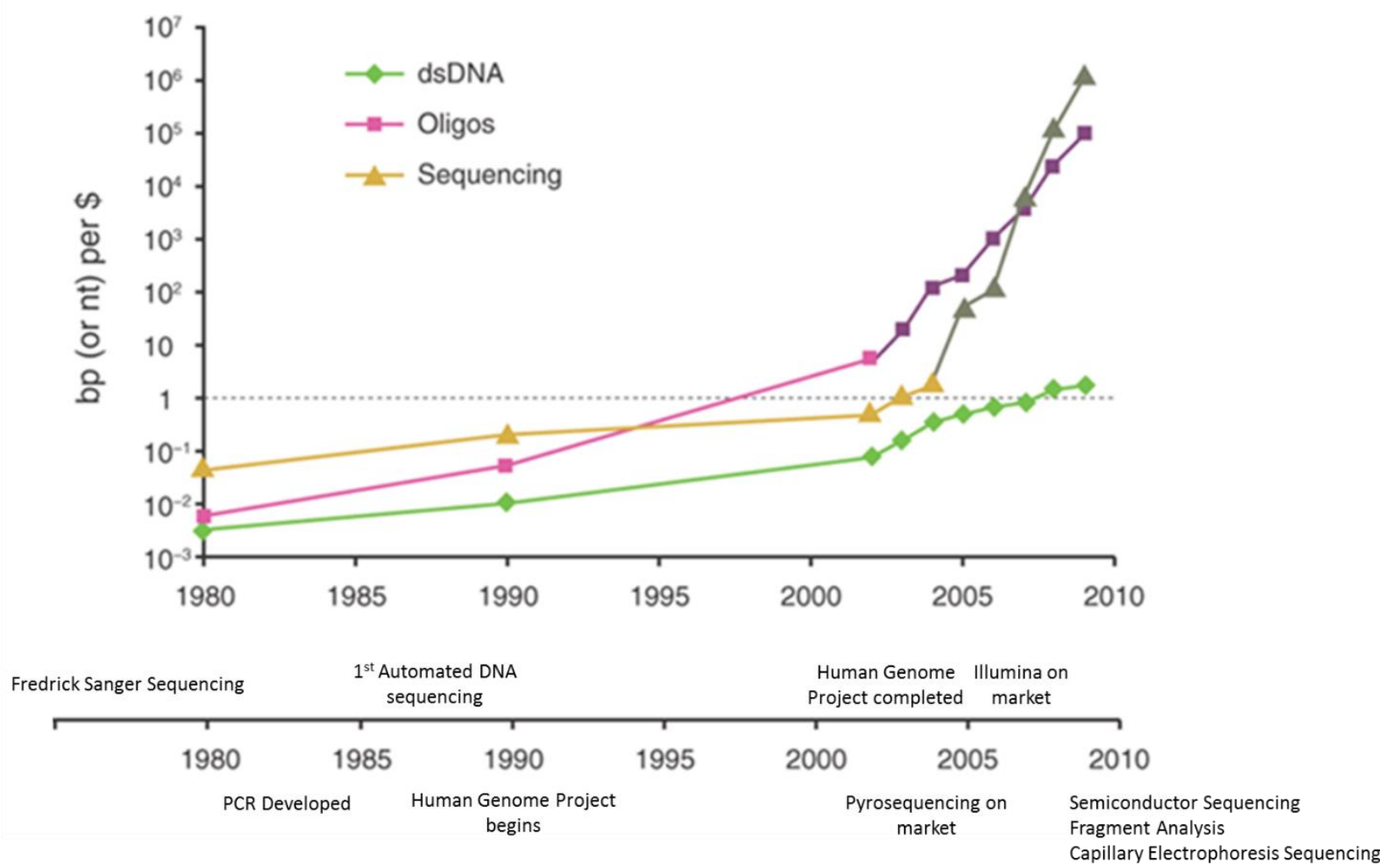

Figure 2.3: Cost and technology evolution of DNA sequencing and synthesis over a 30 year span. The change in color represents the introduction of NGS. Graph modified from Carr et al [31].

Even with these great improvements, classification accuracies of the data are still highly dependent on the quality and length of the DNA target region and the instrument being used. Common NGS methods include pyrosequencing by 454 Life Sciences (released in 2004), sequencing by ligation by Sequencing by Oligo Ligation Detection (SOLiD) but was purchased by Applied Biosystems in 2006, and sequencing by synthesis by Illumina (released in 2006) [28]. These methods all have their advantages and disadvantages. For instance, pyrosequencing can still be expensive, but it is fast and can do long read lengths (approx. $700 \mathrm{bps}$ ). With about $1 \mathrm{M}$ reads per run, ligation is a slower method, but cheaper and reads very short sequences (approx. 50) With around 1B reads per run, sequencing by synthesis is also considered expensive but can accomplish read lengths between 50-300 bps with around $600 \mathrm{~Gb}$ of output per run [32] [33]. 
For this project, sequencing by synthesis by Illumina, which is also the most common technique used worldwide, was chosen to sequence the V3 region of the bacteria samples. As previously stated, Illumina is most accurate in classification for shorter read lengths (50-300 bps) like the V3 region. Illumina's Miseq instrument is the only next-generation sequencer that can integrate amplification, sequence, and perform data analysis (base calling, alignment, variant calling, and reporting) all in one instrument [34]. It can also output up to 15B nucleotides of 300 bp paired-end reads in less than 3 days. Paired-end sequencing is the process of sequencing both ends of the same DNA fragment where with single-end sequencing is the process of only sequencing one end of the same fragment. Paired-end reads create high-quality alignable sequences because there is overall more coverage of the fragment. Originally paired-end sequencing did not overlap. Although a section of the fragment would be missing there would still be information about the orientation and the segment missing because of the two reads. With the new changes, the Miseq can sequence more length to the reads which causes the forward and reverse read to overlap in information, as shown in Fig. 2.4. This allows the two sequences to be stitched together and create one complete read.

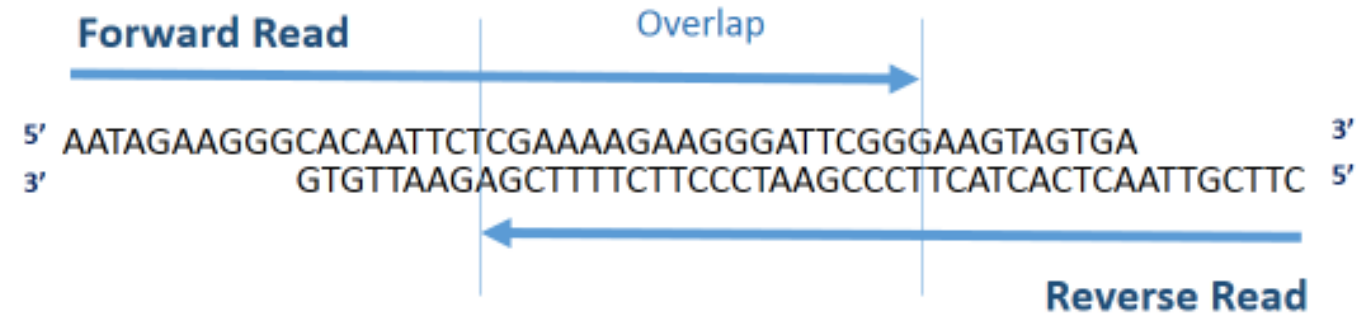

\section{New Complete Read}

5'AATAGAAGGGCACAATTCTCGAAAAGAAGGGATTCGGGAAGTAGTGAGTTAACGAAG 3'

Figure 2.4: Visual of paired-end sequencing. Both strands of a DNA fragment are read to $x$ amount of base pairs. This outputs two reads, a forward and reverse read. These overlapping sequences are then used to make a new compete read of the DNA fragment. 


\subsection{BaseSpace}

The Miseq and other Illumina instruments not just sequence data but offer tools to analyze, archive, and share the data generated by the instrument. BaseSpace is known as Illumina's genomics computing environment for next-generation sequencing data analysis. It can be offered in both cloud and as an onsite format. Since the data for this project was going to be sequenced at a different location, the sequencing cloud would be the best option in receiving the bacteria DNA data. With BaseSpace, the data from the Miseq instrument is streamed and transformed into files that can be accessed by anyone who has been given permission to that particular project. The data from a sample set is uploaded to BaseSpace as a .BLC file. This .BLC file can be converted and demultiplexed into individual sample files called FASTQ files (Fig. 2.5). FASTQ files are a textbased file that contains all the sequences that was gathered from one sample. For the data presented in this thesis, one sample would be all the bacteria DNA that was able to be sequenced from one hand. The FASTQ file has four lines of text for each sequence as displayed in Fig. 2.6. The first line is the sequence name or also called the sequence identifier, the second is the sequence read itself, the third line is just a plus sign, and the fourth is the Phred quality score (more on this in Appendix E) symbol which represents each nucleotide base in the sequence from the second line. The quality scores are in ASCII format and a character is assigned to each letter in the sequence. The better the sequence quality the higher the ASCII character will be. 

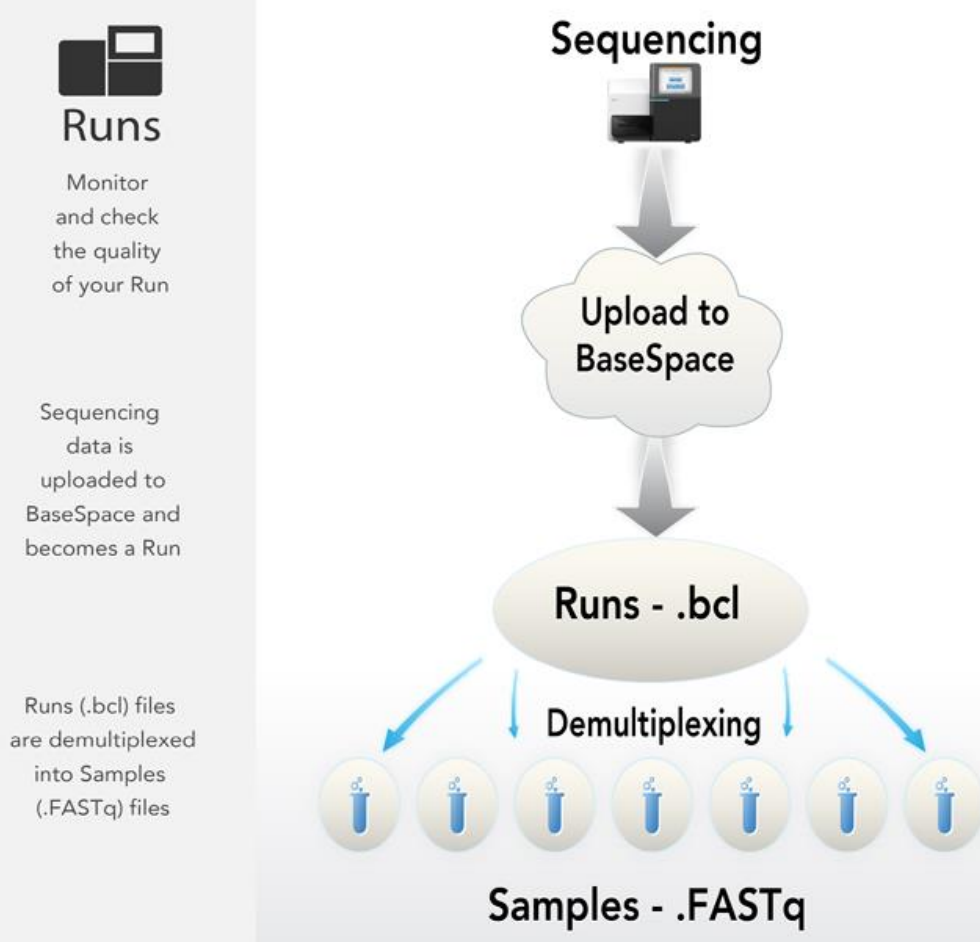

Figure 2.5: Process of BaseSpace cloud. Pooled samples are sequenced on sequencer then uploaded to BaseSpace where they are sorted and classified ${ }^{2}$.

Run 1 Sample (Forward FASTQ read)

@M00780:42:000000000-A679Y:1:1101:15511:1725 1:N:0:1

CCTACGGGAGGCAGCAGTGGGGAATATTGCACAATGGGCGGAAGCCTGATGCAGCAACGCCGCGTGCGGGATGACGGCCTTCGGGTTGTAAACCGCTTTCGC

AAAAAAAD111>FAEABF10ECOOB1DF2B1F10FAEAB/A//AAGGFE@111BFCFB@EGGE/EE??/E/?ABHCC/<CHHGC/F/<C11DDF/>CGG1<.><.GB

\section{Run 2 Sample (Reverse FASTQ read)}

@M00780:42:000000000-A679Y:1:1101:15511:1725 2:N:0:1

GTTAGCCGGTGCTTCTTTACCCATTACCGTCACTCACGCTTCGTCACAGGCGAAAGCGGTTTACAACCCGAAGGCCGTCATCCCGCACGCGGCGTTGCTGCATCAG

$+$

HFHHFGHGGGEEHHFDGHH1GFGHHHHHGGGGGHGHHHHFFGCFECEGFF/EEGG/CAEGG?C1>1GEEEGGCCHHCCGC??FGGGGGGCC?@C<C@COCO/0<;0

Figure 2.6: Snippet of a forward and reverse FASTQ file. The first line is the sequence identifier; the second is the sequence read, the third a plus sign, and the last line is the quality score of each base in ASCII format

\footnotetext{
${ }^{2}$ Image from http://developer.basespace.illumina.com/docs/content/documentation/getting-started/overview
} 
After the FASTQ files are created, BaseSpace has a 16S metagenomics workflow that identifies the bacteria sequences using a high-performance implementation of the ribosomal database project (RDP) classifier, which is a Naïve Bayesian taxonomic classification algorithm [35]. This classification process involves matching short subsequences of the sequences (called words) to a set of $16 \mathrm{~S}$ reference sequences that come from a version of GreenGenes database. The accumulated word matches for each sequence are used to assign reads at a particular taxonomic classification. Classification can be determined down to the genus level depending on the quality of the sequence. This information is stored in a text file (*.txt.gz) for each sample. From this information another text file is created for each sample called a classification file. This file is a summary that provides the total number of classification clusters for each sample at each taxonomy level. An example of each file is shown in Fig. 2.6 and 2.7 respectively [36] [37].

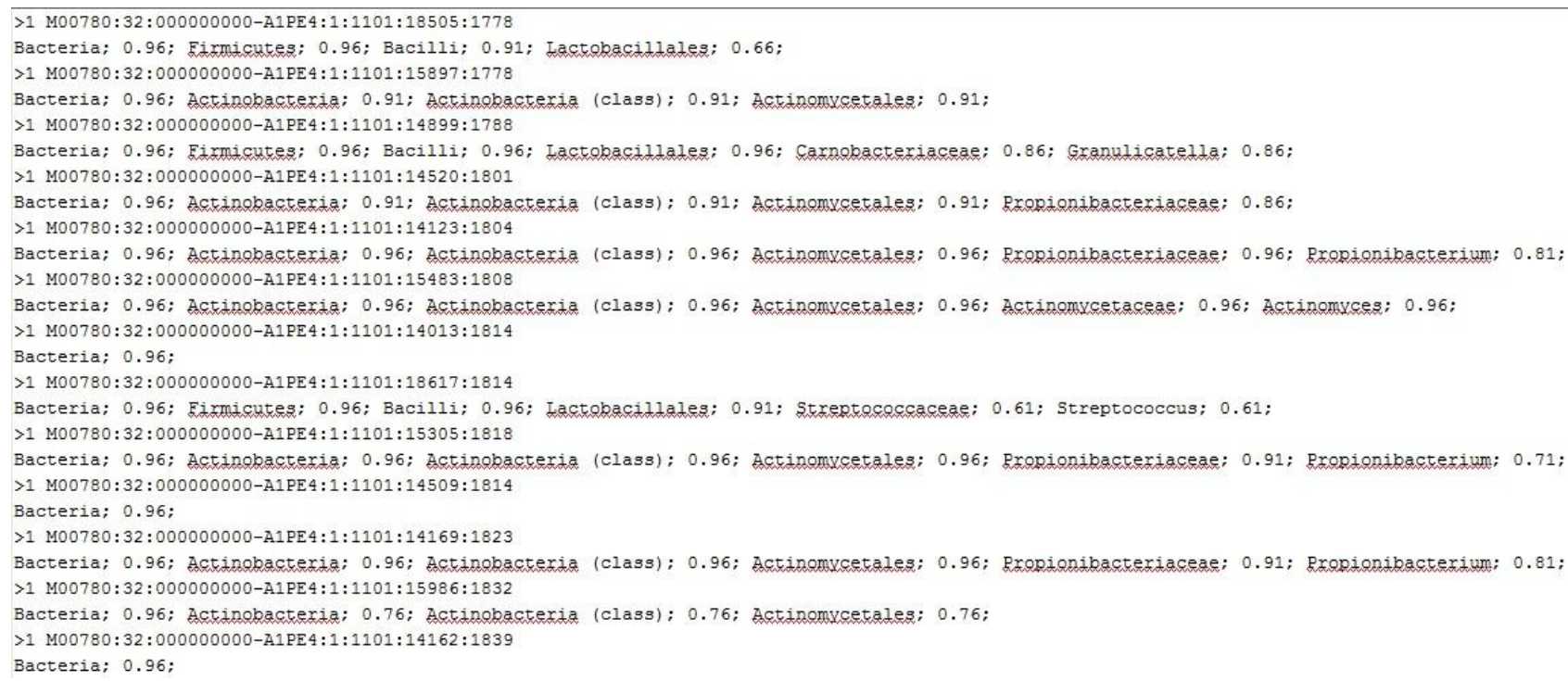

Figure 2.7: Snippet of the breakdown of classification confidence percentage 


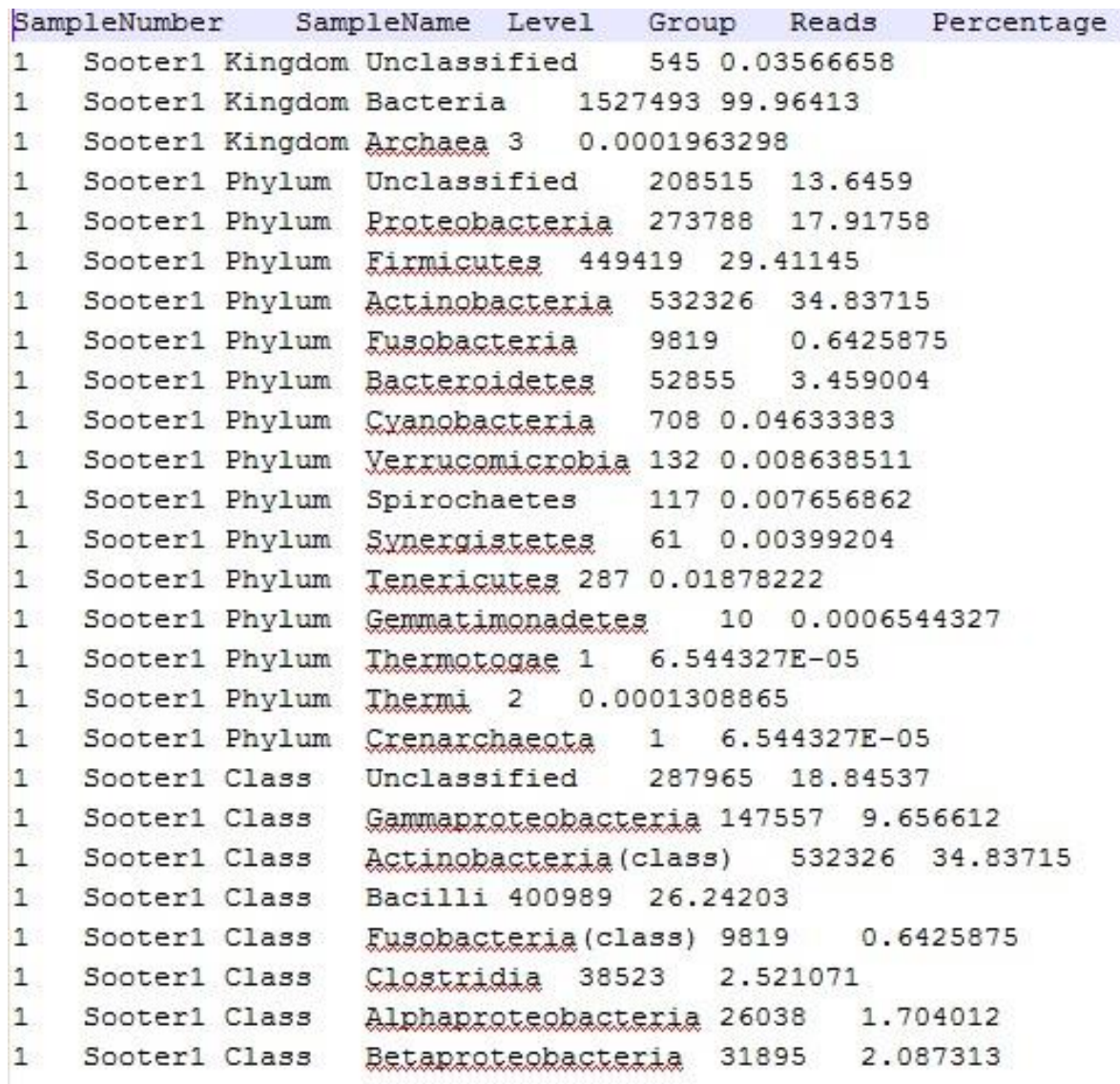

Figure 2.8: Snippet of a classification file that provides a summary for a sample. The file provides information on how many OTUs were identified and their percentage at each taxonomy level.

\subsection{Mothur Software}

Mothur is a single piece of open-source, expandable software that seeks to fill the bioinformatics needs in the microbial ecology community. The software was developed by a software development team from the University of Michigan in the microbiology and immunology department. Mothur is most often used as a bioinformatics tool for analyzing 16S rRNA gene sequences and can be easily used to analyze the data generated from Illumina's Miseq and other instruments. It comes in multiple executable formats along with graphical user interfaces (GUI) 
for Mac OSX, Linux, and Windows. After installation, Mothur provides a numerous amount of sequence processing commands.

These set of tools allow the user to run sequence analysis pipelines that can carry out different approaches such as operational taxonomic unit (OTU) based and hypothesis testing. OTU-based testing enables the user to analyze the frequency distribution of sequences using a variety of methods. These methods provide quantifying of ecological features such as richness, diversity, and similarity. The hypothesis testing command provide different methods that allows the user to determine whether there is sufficient evidence that the structure of the data is more extreme than expected by chance and in contrast to OTU based, do not indicate a level of similarity. These commands all have their own wiki page that allows the user to better understand the purpose of a command, what variables are needed and what the output will be [38].

\subsection{UniFrac Algorithm and Web Application}

UniFrac is a dissimilarity algorithm implemented by Lozupone et al. that uses phylogenetic information to compare the $\beta$-diversity [39] between microbial communities collected from two different environments [20]. $\beta$-diversity differs from $\alpha$-diversity in that $\beta$-diversity looks at the differences between species from different environments while $\alpha$-diversity looks at the differences between species within an environment. For example, skin is an environment that often contains a rich microbial $\beta$-diversity, while the throat and gut would be considered a rich $\alpha$-diversity environment. The UniFrac algorithm measures the uniqueness between environments by looking at the branch lengths within a single rooted phylogenetic tree. The phylogenetic tree must contain 
species from at least two environments (Fig. 2.9). A phylogenetic tree is a diagram that shows the evolutionary relationships among various species based off of their genetic makeup. A branch leading to an operational taxonomic unit (OTU) that is found in both environments is marked as "shared" and branches leading to an OTU which is only found in one of the environments is marked as "unshared". If all branches are unique between two environments then the distance score for those two environments would be 1.0. If the two given environments were identical, then they would receive a score of 0 . UniFrac can be applied in two forms, unweighted and weighted. The unweighted UniFrac algorithm looks at just the qualitative difference between OTUs, while the weighted UniFrac algorithm takes in consideration of OTU abundance (quantitative). If there are twice as many OTUs in one environment compared to another environment then the smaller environment would be weighted twice as much as the other environment.

$$
\begin{array}{ll}
\text { unweighted Unifrac value }=\sum_{i}^{N} b_{i} *\left|A_{i}-B_{i}\right|, & \text { Equation } 2.1 \\
\text { weighted Unifrac value }=\sum_{i}^{N} b_{i} *\left|\frac{A_{i}}{A_{T}}-\frac{B_{i}}{B_{T}}\right|, & \text { Equation } 2.2
\end{array}
$$

Equation 2.1 describes the unweighted UniFrac algorithm where $\mathrm{N}$ is the total number of branches in the tree, $b_{i}$ is the length of branch $i, A_{i}$ and $B_{i}$ are the number of descendants of branch i from environment A and B respectively. Equation 2.2 is the weighted UniFrac algorithm which takes in account for OTU abundance. $\mathrm{A}_{\mathrm{T}}$ and $\mathrm{B}_{\mathrm{T}}$ are the total number of sequences from environment $A$ and $B$. In order to control for unequal sampling effort, $A_{i}$ and $B_{i}$ are divided by $A_{T}$ and $\mathrm{B}_{\mathrm{T}}$. 

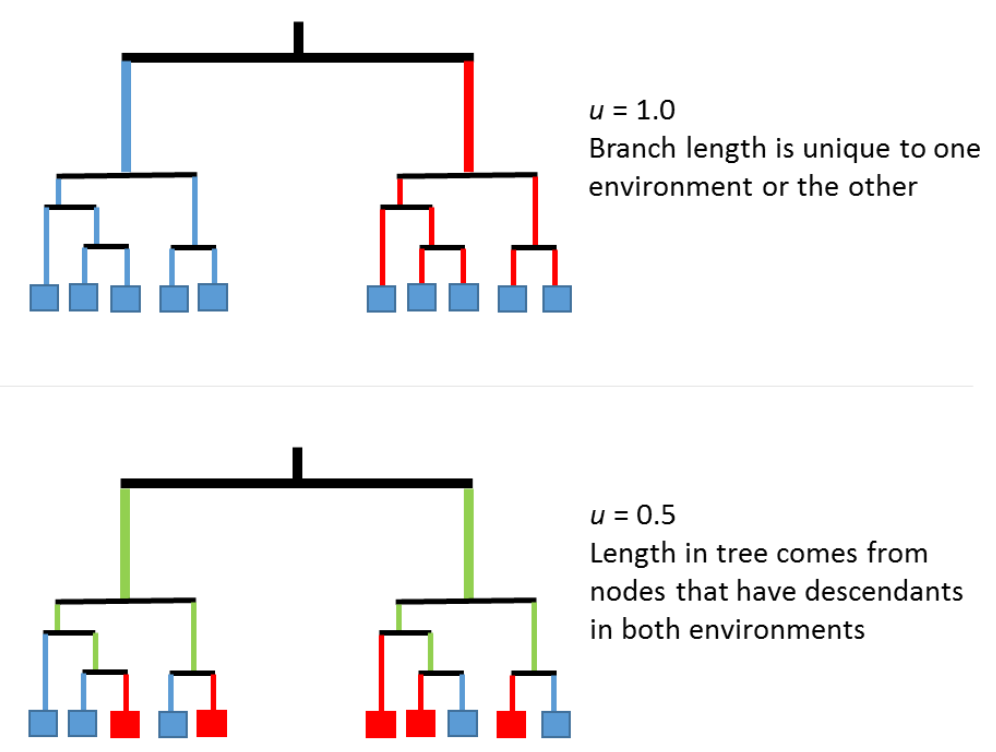

Figure 2.9: UniFrac scoring, red and blue branches indicate different samples. Green branches represent shared branches. If two samples are identical than the UniFrac score would be 0.0.

UniFrac is also a web application that provides additional sets of tools for comparing microbial communities using the dissimilarity scores generated from the algorithm. The UniFrac web application allows the user to not only determine if the environments in the tree have significantly different microbial communities, but to also see if there are certain factors that cluster the communities in the environments and to provide graphical visualization of the different environments amongst each other. The application allows the user to perform these analyses on up to $100 \mathrm{~K}$ unique sequences, up to 200 unique environments, and to perform significance test based on up to $1 \mathrm{~K}$ tree permutations [40] [41].

The application requires three input files from the user. The first is the phylogenetic tree which is required to be constructed in Newick format. This format is a common method for constructing phylogenetic trees and consists of commas and parentheses to separate out the distances and OTU names. This tree can be created by using open source applications such as the Mothur software that was previously described. The tree also must contain a minimum of three 
different environments. For this research, one environment would be the bacterial communities collected from one hand swab. Along with the tree file, a text file containing what OTU sequences came from which environment and how many times each OTU occurred in each environment is needed. Fig. 2.10 gives a visual of how this file is created. This allows the application to distinguish the difference between the samples in the tree and lastly, another text file that shows relationships between the samples that the user would like to see in comparison against such as the location or temperature of that location that the microbes were collected. For this study, categories for comparison would be the demographic information that was gathered from the individuals during the collection.

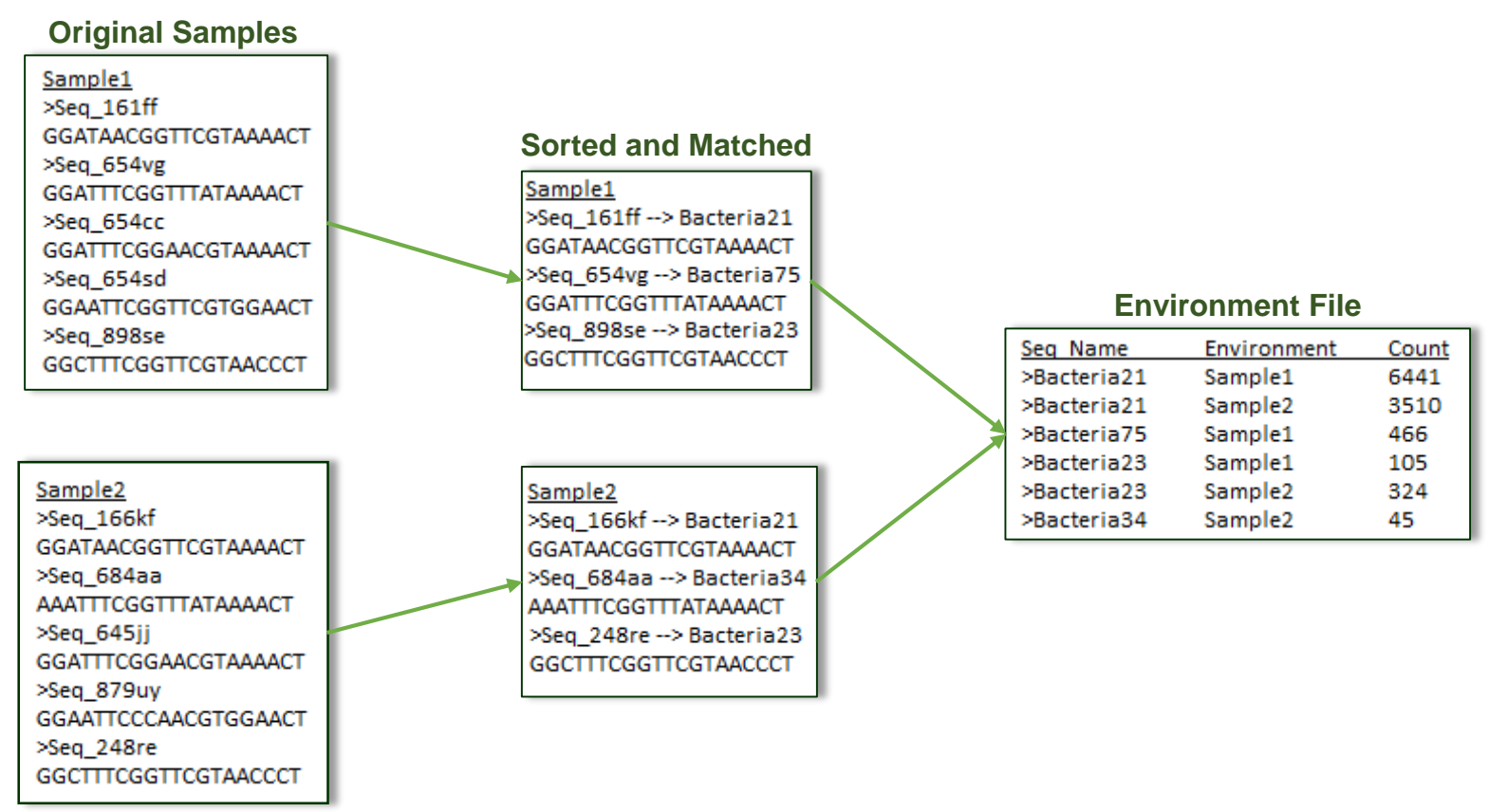

Figure 2.10: Visual of how the environment file is created for UniFrac application

Fig. 2.9 gives a visual of sample phylogenetic tree that contains two completely unique samples (left side) and another that has a 50\% similarity (right side). The distance matrix can then be used to perform two other options that show a better visual of how the samples compare against one another. The first is a clustering option that creates a new phylogenetic tree based on the 
phylogenetic lineages that the samples contain. For this, if the distance score between two samples were low than these samples would cluster closer to each other in the tree than if the distance between them was greater. The second option is a diagram called a principal coordinate analysis (PCoA) plot that takes the distance matrix and creates a new Euclidean matrix to plot the samples as points. This diagram uses the category file to show how the different groups or demographics relate to one another. Fig. 2.11 shows sample plots for both of these options.
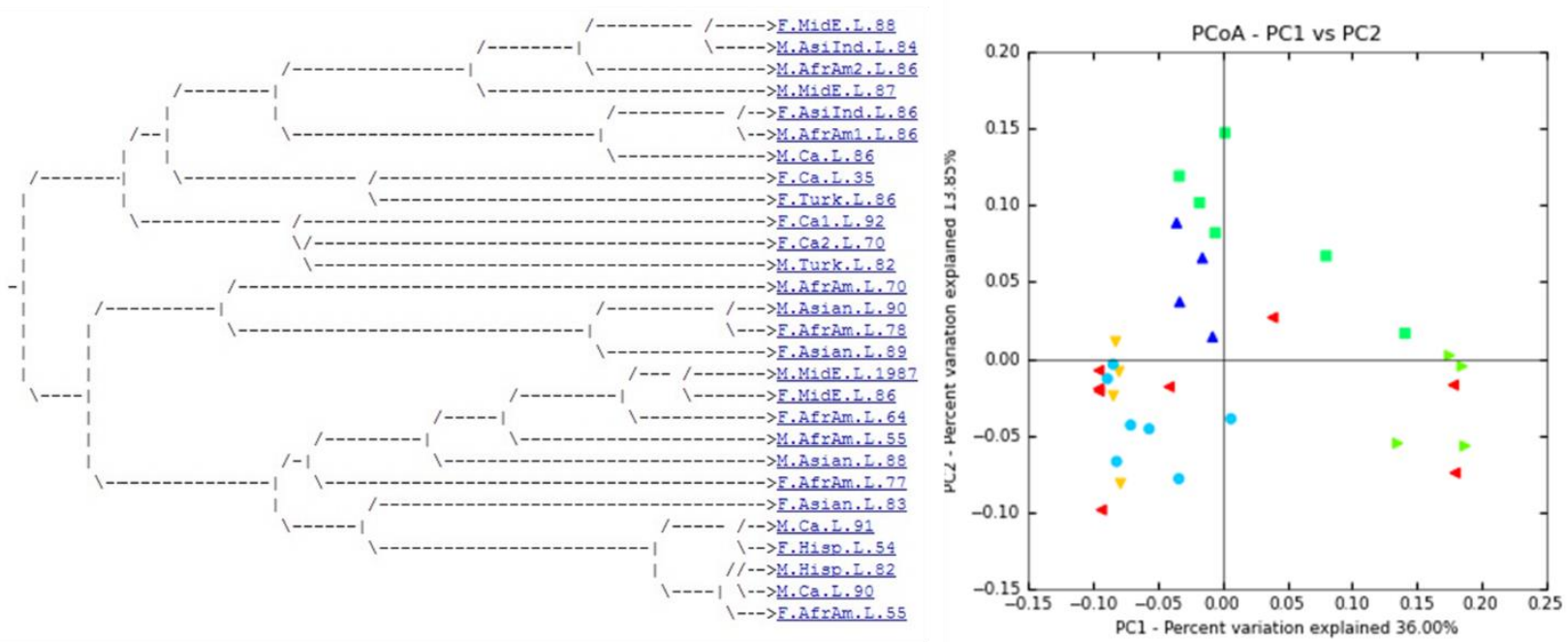

Figure 2.11: (Left) Sample clustering tree (Right) Sample PCoA plot. 


\subsection{Support Vector Machines}

In machine learning, support vector machines (SVM) are a form of supervised learning models. SVM's are used for recognizing patterns in data taken from two categories. These patterns are then used to classify the data into either one or the other category. To use SVM, the classifier has to be trained on a sample subset of the data, this allows the classifier to know what patterns belongs to what category. The classifier uses an optimization method [42] to identify support vectors $s_{i}$, weights $a_{i}$, and bias $b$ that classify vectors $x$ using the following equation,

$$
c=\sum_{i} a_{i} k\left(s_{i}, x\right)+b, \quad \text { Equation } 2.3
$$

where $k$ is a kernel function, in the case of a linear kernel, $k$ is the dot product. If $c \geq 0$, then $x$ is classified as a member of the first category, otherwise it is classified as a member of the second category. This SVM classifier structure created from the training set is used to predict the classification of the remaining vectors $x$ called the test set. 
Chapter 3: Sample Collection \&

Preparation 
This chapter begins by covering the process in obtaining approval from the Institutional Review Board (IRB). Next, it goes over a detailed description on what information and biometrics were gathered from participants and what procedures were used to collect this data. Lastly, this chapter provides charts showing the demographics of the total sample set and the subset of individuals used for the bacterial identification.

\subsection{Implementation}

The hand bacteria project was part of a larger research effort that had two specific goals. The first goal was to evaluate the regions of human genomic DNA that encode for facial features such as eye color, hair color, nose, ear lobe shape, and etc. and use this information to construct a pseudo-code image the individual. The second goal, which is the basis of this thesis, was to evaluate the bacterial colonies that are found on the human hand as used as a biometric identifier. An additional sub goal was to see if hand bacteria had any relations to health and medical conditions.

To accomplish these goals a sample collection protocol was developed to gather blood samples, hand swabs, facial images and medical history information of at least 200 individuals, male and female of diverse ethnicity, that were of the age 18 or older. Obtaining this large collection size would allow for a better data set which in hopes would then allow for a better insight into how the samples compare against one another and also provide a better understanding on how the information can be used for identification and health purposes. The following section covers details of the collection process that was approved under IRB no. H-23693. 


\subsection{Collection Process}

Data collection began in September of 2012 and lasted for approximately three months. Participants were contacted via email based on previous studies where they opted for future contact about new data collections, and were provided a website and phone number so that they could contact and schedule their appointment. The collection was carried out at West Virginia University's Health Sciences Center. This location houses the WVU's Student Medical Center and is connected to the Ruby Memorial Hospital, which is WVU largest hospital facility. This location allowed access to fast medical assistance in case of an emergency during a participant's appointment. Once a participant arrived to the collection site they were given a consent form where a co-investigator explained what would be occurring during the collection. A copy of this form is provided in Appendix A. Once the participant completed the consent form they were then enrolled into a database where a random number was assigned to them and additional demographics and physical appearance information was gathered. Once enrolled, the participant filled out three questionnaires that asked about the individual's medical history, their handedness, and hand washing. These questionnaires are located in Appendix B.

Next 2-D face images were taken. The participant was asked to stand in front of a gray backdrop and face a commercial digital camera. During the pictures participants were asked to not show any facial expressions. Five different images were taken at five different angles, the angles were at $-90^{\circ}, 45^{\circ}, 0^{\circ}$ (frontal pose), $45^{\circ}$, and $90^{\circ}$. After the images were gathered the participant was then taken into a connecting room to have their hands swabbed and blood drawn. The first procedure was the swabbing of the hands. This was done by taking the end of a cotton swab that 
was dipped into a double distilled water solution containing $0.15 \mathrm{M} \mathrm{NaCl}$ and $0.1 \%$ polysorbate 20 (also known as Tween 20), which is a non-toxic cleaner that helps lift the bacteria from the skin [43]. The cotton swab had been sterilized prior to collection by being wrapped in aluminum foil and autoclaved. The personnel swabbed the entire inside of the participant's hand while rotating the cotton tip. After swabbing, the head of the tip was placed inside a $2 \mathrm{ml}$ bead solution tube from an Ultraclean Plant DNA Isolation Kit (MO BIO Laboratories, Carlsbad, CA, USA), (Appendix C) and then cut with sterilized scissors. A new cotton swab then used for the other hand. When finished, the same procedure was followed as with the first sample. The tubes were then stored at $-80^{\circ} \mathrm{C}$ until DNA extraction. After the bacteria samples were collected the personnel changed gloves and collected blood from the crease in the participants arm. This was done via venipuncture using BD Vacutainer push button blood collection set that came with pre-attached holder and a BD Vacutainer stretch latex free tourniquet. Approximately 6-8 $\mathrm{ml}$ of blood was drawn and stored in BD Vacutainer $2 \mathrm{ml}$ EDTA plus blood collection tubes. These tubes were then stored at $4^{\circ} \mathrm{C}$ until DNA extraction took place. This blood and the facial images would be used in trying to create a pseudo code image of the individual based off of specific regions found in the DNA. If blood was not able to be drawn from the participant but the participant allowed the personnel to attempt once in each arm then the participant would still receive the $\$ 40$ gift for completing the collection.

\subsection{Demographics}

At the end of the collection period there was a total of 255 individuals who took part in the study. This number was increased from the original 200 due to not being able to receive blood samples from roughly 30 of the participants. This was due to individuals having small veins, or 
veins that were not close to the surface of the skin making it difficult for the personnel to find. The following charts provide a break-down of the demographics of the cohort of 255 participants, as well as those of the 51 people whose bacteria samples were processed and sequenced.

\section{Participants by Ethnicity(\%)}

$\square$ Caucasian
$\square$ Asian
$\square$ Asian Indian
$\square$ African American
$\square$ African
$\square$ Middle Eastern
$\square$ Hispanic
$\square$ Other

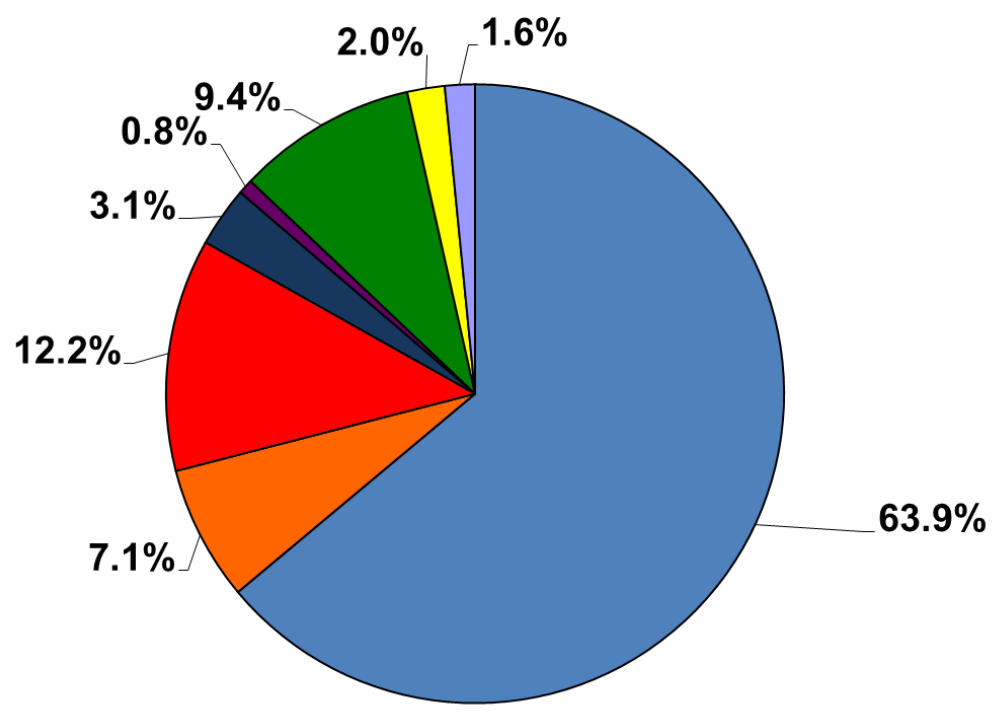

Figure 3.1: Ethnicity of participants from collection of 255 individuals. 


\section{Participants by Ethnicity(\%)}

\begin{tabular}{l}
\hline वaucasian \\
$\square$ Asian \\
$\square$ Asian Indian \\
$\square$ African American \\
$\square$ African \\
$\square$ Middle Eastern \\
$\square$ Hispanic \\
$\square$ Turkish
\end{tabular}

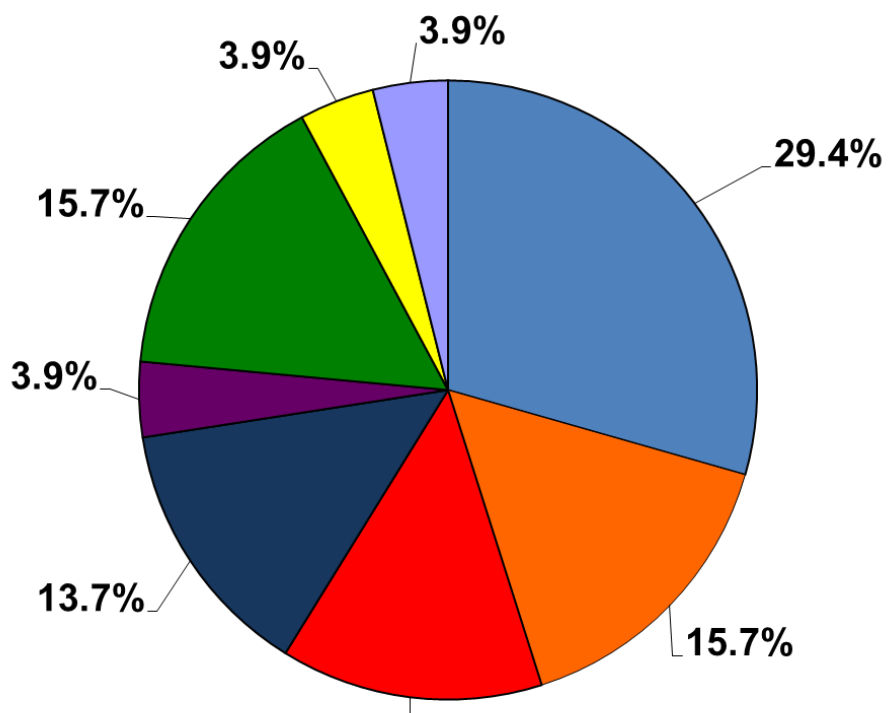

$13.7 \%$

Figure 3.2: Ethnicity of participants used for the bacterial identification subset group.

\section{Demographics by gender and ethnicity}

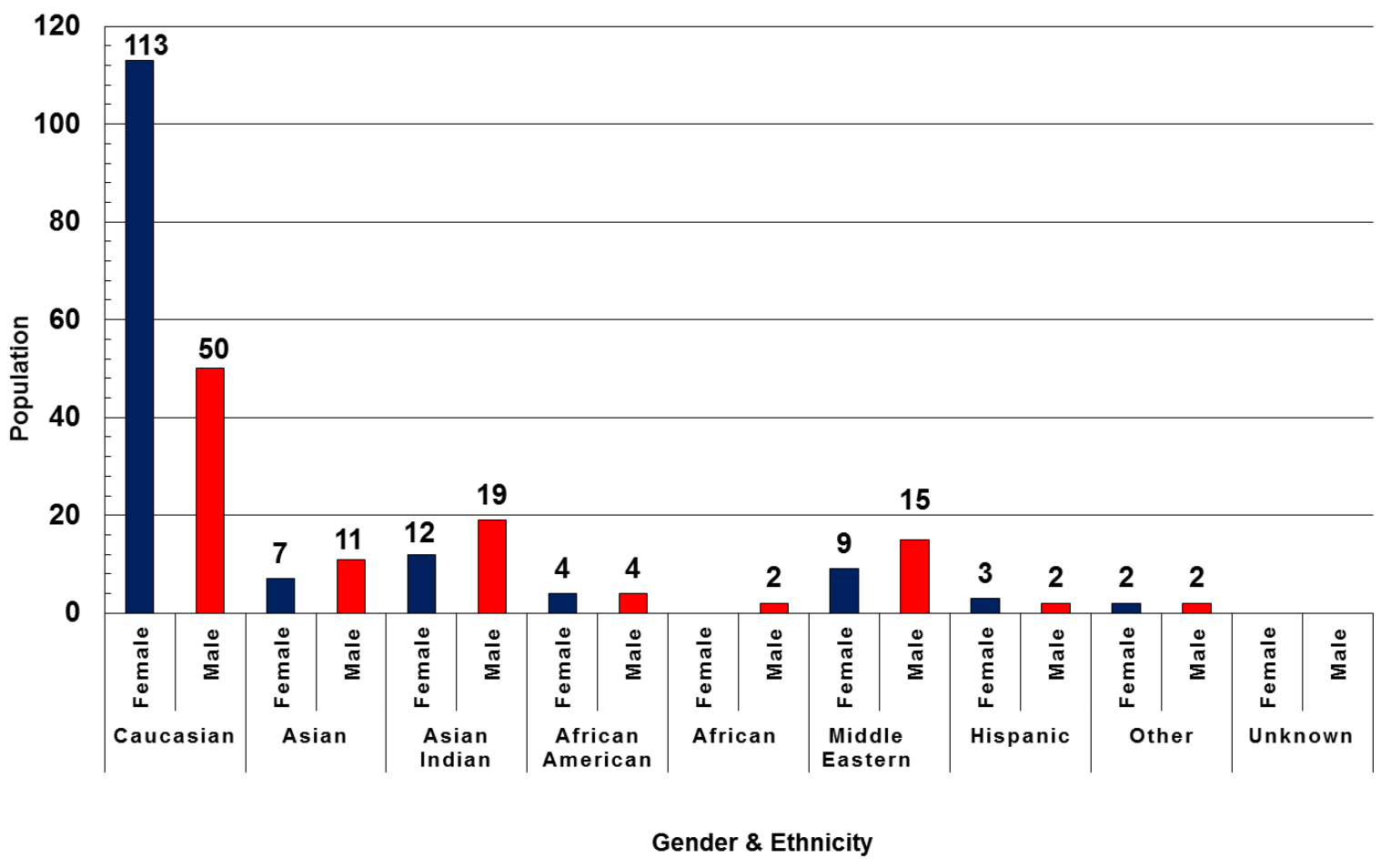

Figure 3.3: Distribution of gender and ethnicity of total collection. 


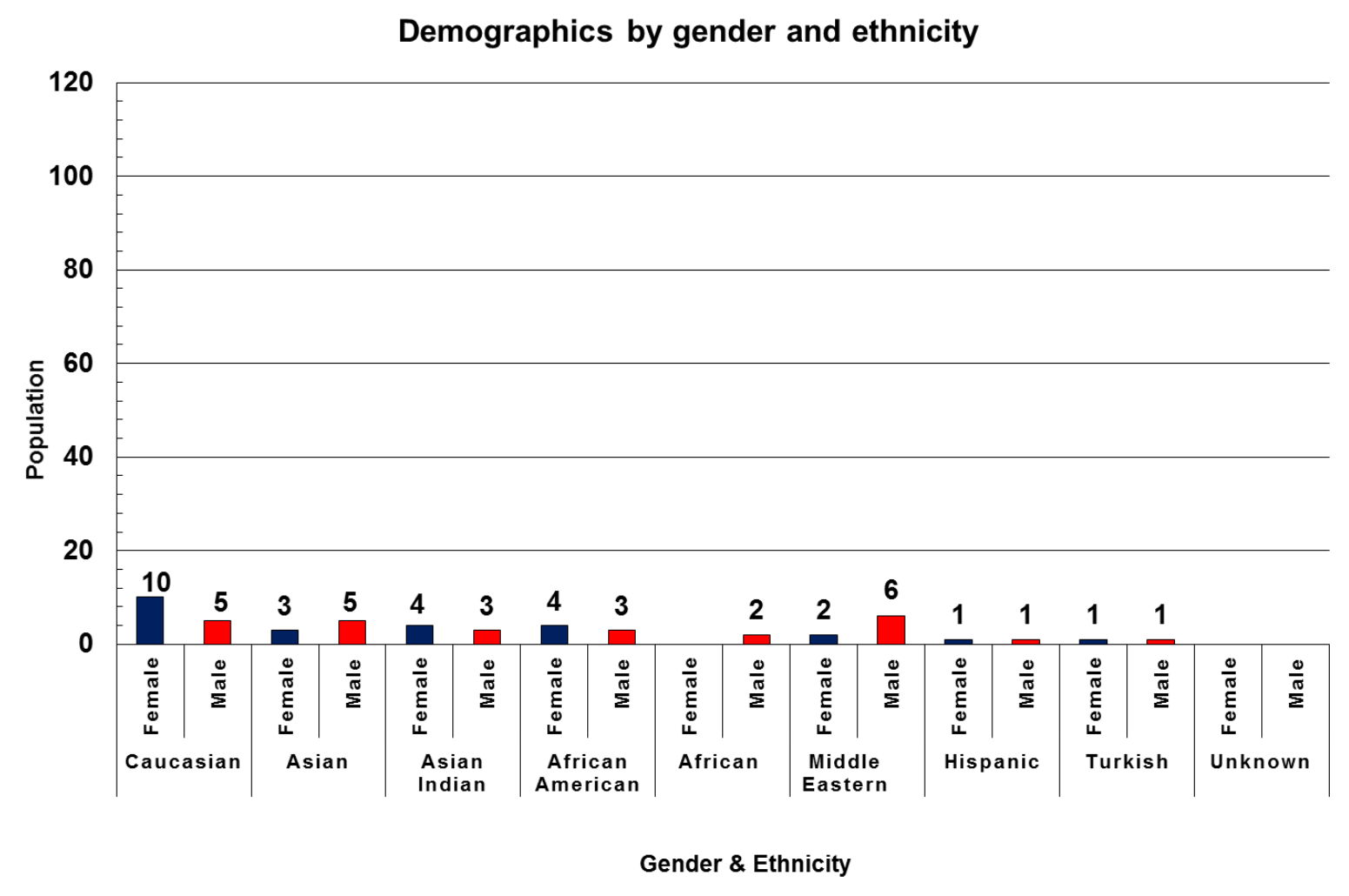

Figure 3.4: Participant's gender and ethnicity of the subset group.

\begin{tabular}{|l|}
$\square 18-19$ years old \\
$\square 20-29$ years old \\
$\square 30-39$ years old \\
$\square 40-49$ years old \\
$\square 50-59$ years old \\
$\square 60-69$ years old \\
$\square 70-79$ years old
\end{tabular}

\section{Participants by age group (\%)}

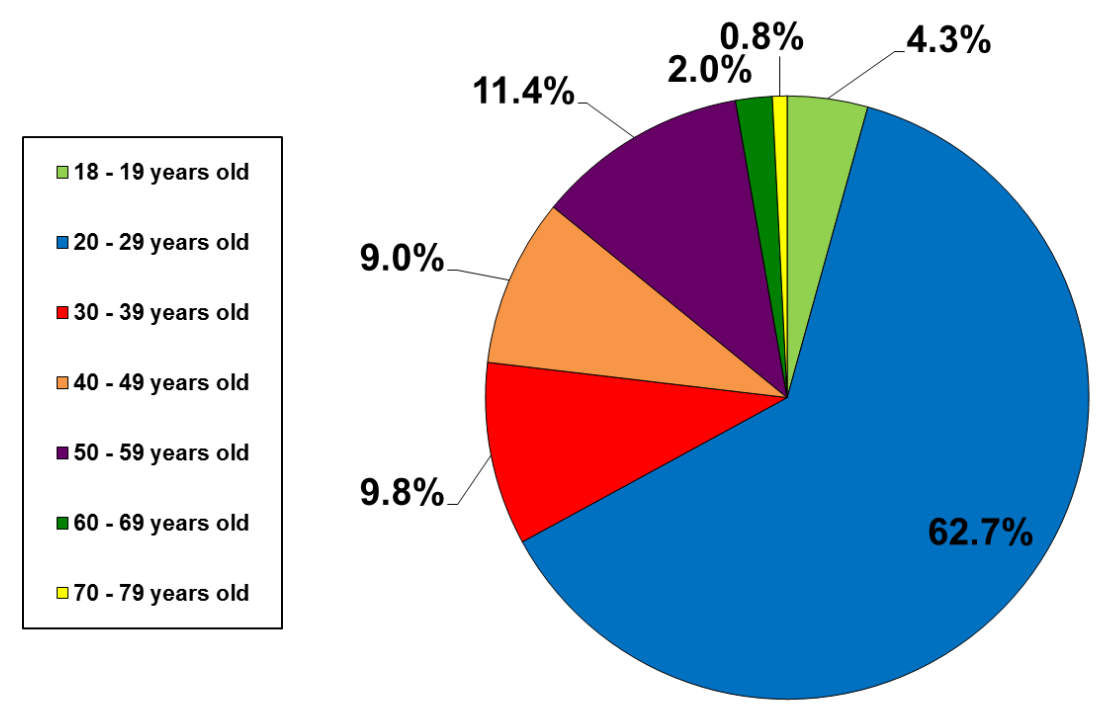

Figure 3.5: The total collection's age distribution. 
Participants by age group (\%)
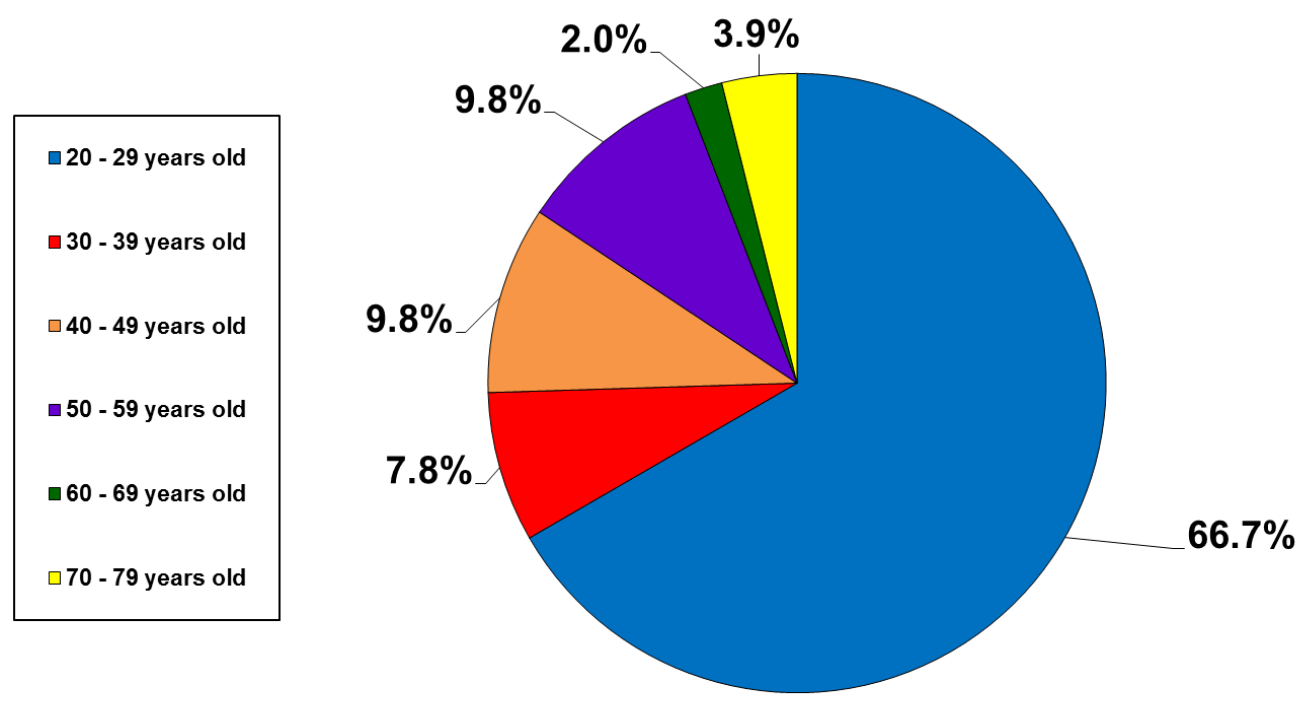

Figure 3.6: The age of participants in the subset group.

Over half of the participants who took part in the collection were Caucasian and between the ages of 20-29. This is consistent with the ethnic and age distribution of the student and staff population at WVU. The subset used for sequencing was intentionally selected to contain wellbalanced variation of ethnicity and gender. A well-balanced distribution of participant age was harder to obtain due to fulfilling the variation of ethnicity and having a small sample set in the older age groups.

\subsection{Extraction and Isolation of Bacteria Samples}

Before DNA extraction began on the collected hand bacteria samples, practice samples were used to ensure maximum DNA extraction would be achieved. These samples were collected from in-house staff members. Isolation was first completed by following the Ultraclean® Plant 
DNA Isolation Kit Protocol as written with no additional changes [44]. This kit was the same kit that contained the $2 \mathrm{ml}$ bead solution tubes that were used during the collection. Fig. 3.7 shows the before and beginning results of the DNA isolation. In the right image, a solution was used to separate the DNA from the remaining "junk" in the sample. The clear supernatant on top contains the DNA while the white pellet in the bottom contains unwanted remains. After isolation the DNA concentration was measured using a NanoDrop 1000 spectrophotometer (Thermo Fisher Scientific, Waltham, MA, USA). The concentrations were based on an absorbance at $260 \mathrm{~nm}$ and the concentrations of each sample was determined using the Beer-Lambert Law [45],

$$
c=(A * \varepsilon) / b, \quad \text { Equation } 3.1
$$

where $c$ is the nucleic acid concentration in $\mathrm{ng} / \mu \mathrm{l}, A$ is the absorbance in $\mathrm{AU}, \mathcal{E}$ is the wavelengthdependent extinction coefficient in $\mathrm{ng}-\mathrm{cm} / \mu \mathrm{l}$ and $b$ is the path length measured in $\mathrm{cm}$.
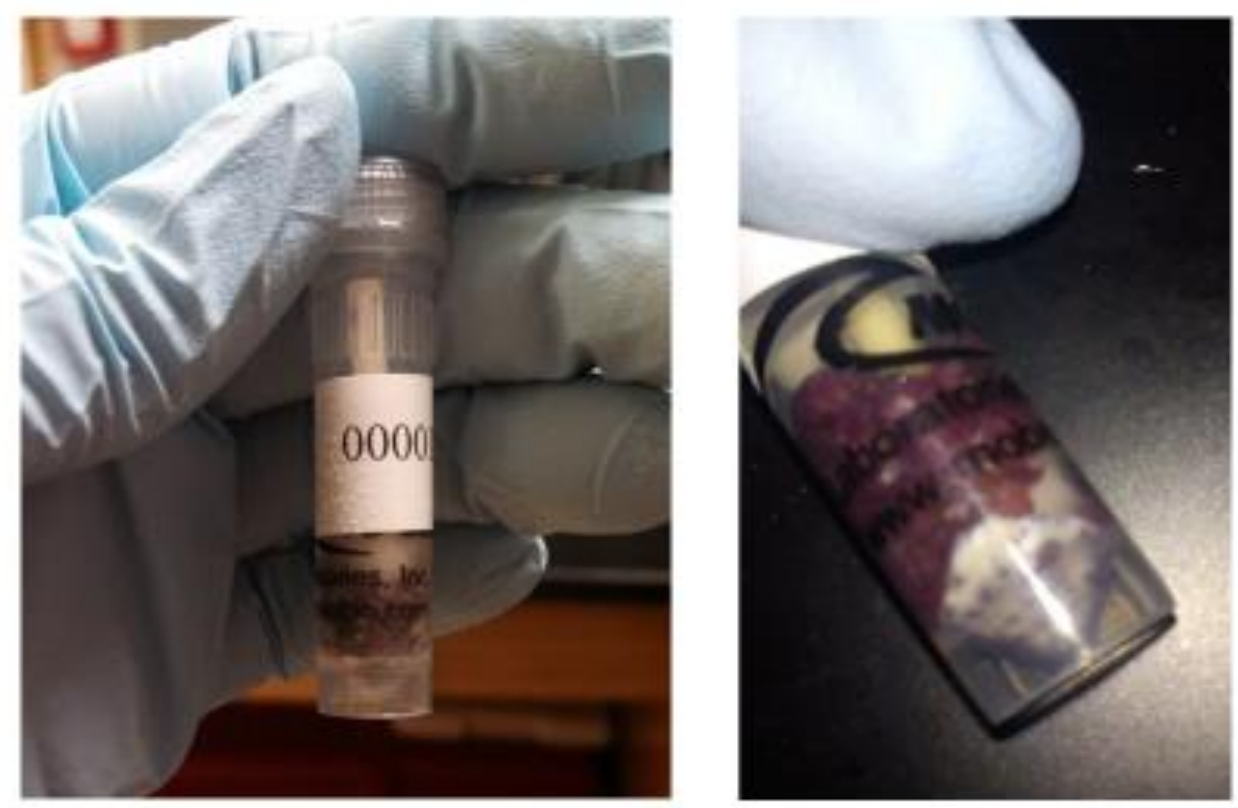

Figure 3.7: (Left) Collection tube prior to DNA isolation. (Right) Collection tube during isolation, contains separated DNA supernatant and pellet of unwanted remains. 
The concentration results seemed low (below $0.4 \mathrm{ng} / \mu \mathrm{l}$ ), but polymerase chain reaction (PCR) amplification of the 16S rRNA gene was still carried out on the samples to see if enough of the target region was present. To amplify the target region, primer set E8F and E1541R was used. These primer sequences are located just inside the target region [46]. Primers were synthesized by Eurofins Genomics (Huntsville, AL, USA). Using a $50 \mu 1$ polymerase chain reaction (PCR) reaction mixture, each mixture consisted of:

- $24.5 \mu 1$ of $\mathrm{ddH}_{2} \mathrm{O}$

- $10 \mu 1$ of DNA template

- $10 \mu 1$ of 5x HF Buffer (contains $\mathrm{MgCl}_{2}$ ) (New England Biolabs, Ipswich, MA, USA)

- $1 \mu 1$ of $20 \mu \mathrm{M}$ of each reverse and forward primer

- $2.5 \mu 1$ of dimethyl sulfoxide (DMSO)

- $0.5 \mu 1$ of Phusion Taq polymerase (New England Biolabs, Ipswich, MA, USA)

- $0.5 \mu 1$ deoxynucleotide triphosphate (dNTP).

Settings for PCR using the MJ Mini Personal Thermal Cycler (Bio-Rad Laboratories, Hercules, CA, USA) included an initial $95^{\circ} \mathrm{C}$ for $5 \mathrm{~min}, 30$ cycles of $95^{\circ} \mathrm{C}$ for $45 \mathrm{sec}, 51.4^{\circ} \mathrm{C}$ for $1 \mathrm{~min}$ and $72^{\circ} \mathrm{C}$ for $30 \mathrm{sec}$ and a final extension step of $72^{\circ} \mathrm{C}$ for $7 \mathrm{~min}$. PCR products were purified using the PCR cleanup protocol from a Gel/PCR DNA Fragment Extraction Kit (IBI Scientific, Peosta, IA, USA) (Appendix D). A 2\% agarose gel for electrophoresis was prepared using $100 \mathrm{ml}$ of EDTA, $2.0 \mathrm{~g}$ of $2 \%$ agarose and $5 \mu 1$ of ethidium bromide (EtBr). Wells were loaded with $5 \mu 1$ of DNA and $2 \mu 1$ of Thermo Scientific 6X DNA loading dye. After gels were complete, they were analyzed by using the Gel Doc XR (Bio-Rad Laboratories, Hercules, CA, USA). No DNA 
fragments appeared, which could have been caused by problems with the initial DNA extraction method, inaccurate PCR procedure, or just too low of DNA concentrations overall. Due to these results from the initial test extraction and amplification, Escherichia coli (E. coli) bacteria was cultured to test and optimize the DNA isolation kit and the PCR amplification steps. The E. coli bacteria is easily accessible and has a fast replication rate. This makes it a great positive control and guaranteeing that a high concentration of bacteria would be initially present for processing. If the DNA isolation kit was not able to extract the DNA from the E. coli samples then this would show that there were problems with kit's protocol. If a higher concentration in DNA was revealed, but bands did not appear in the gel, then this indicates a problem within the PCR mixture or amplification.

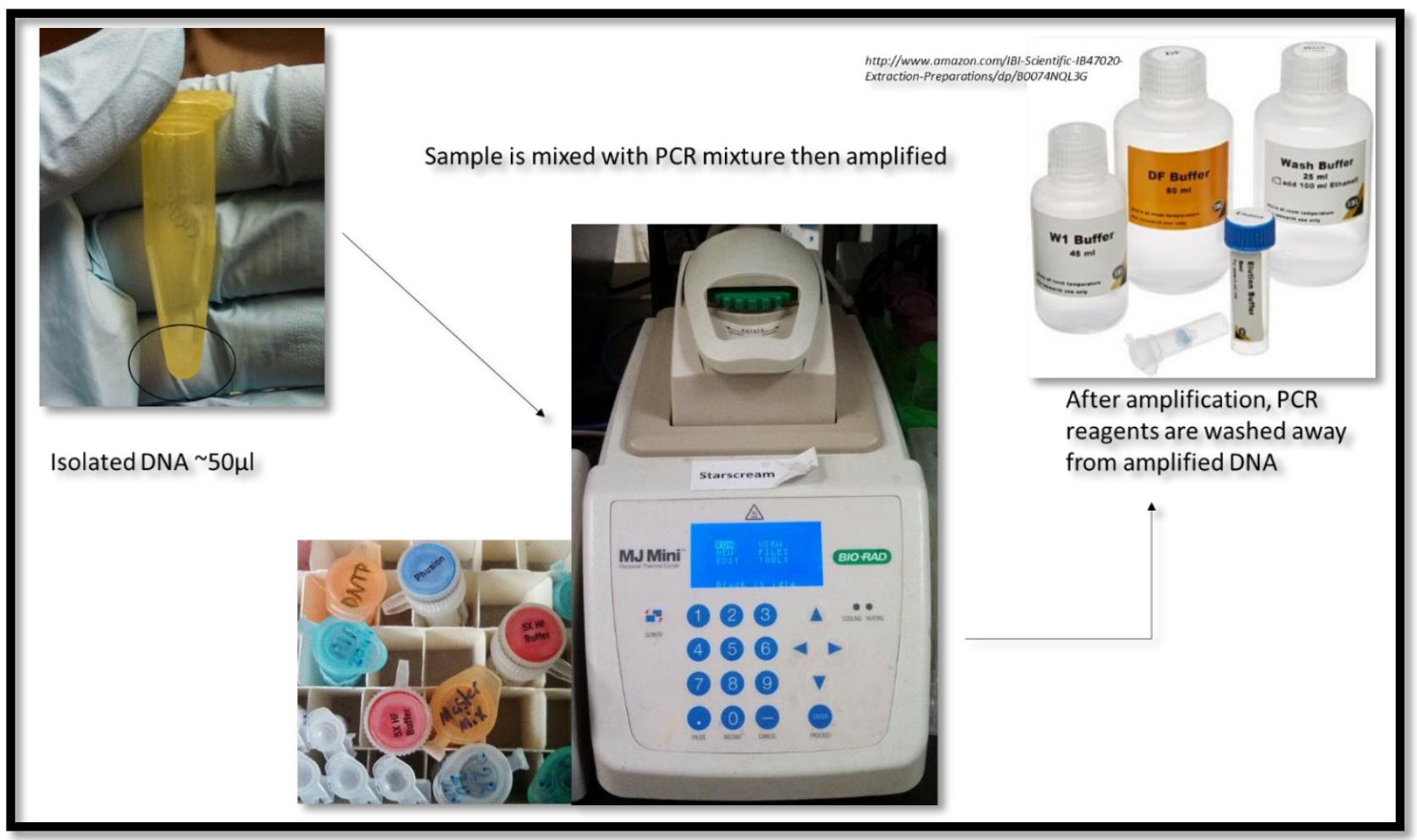

Figure 3.8: After isolation, the $16 \mathrm{~S}$ region of the sample was amplified and then cleaned. 


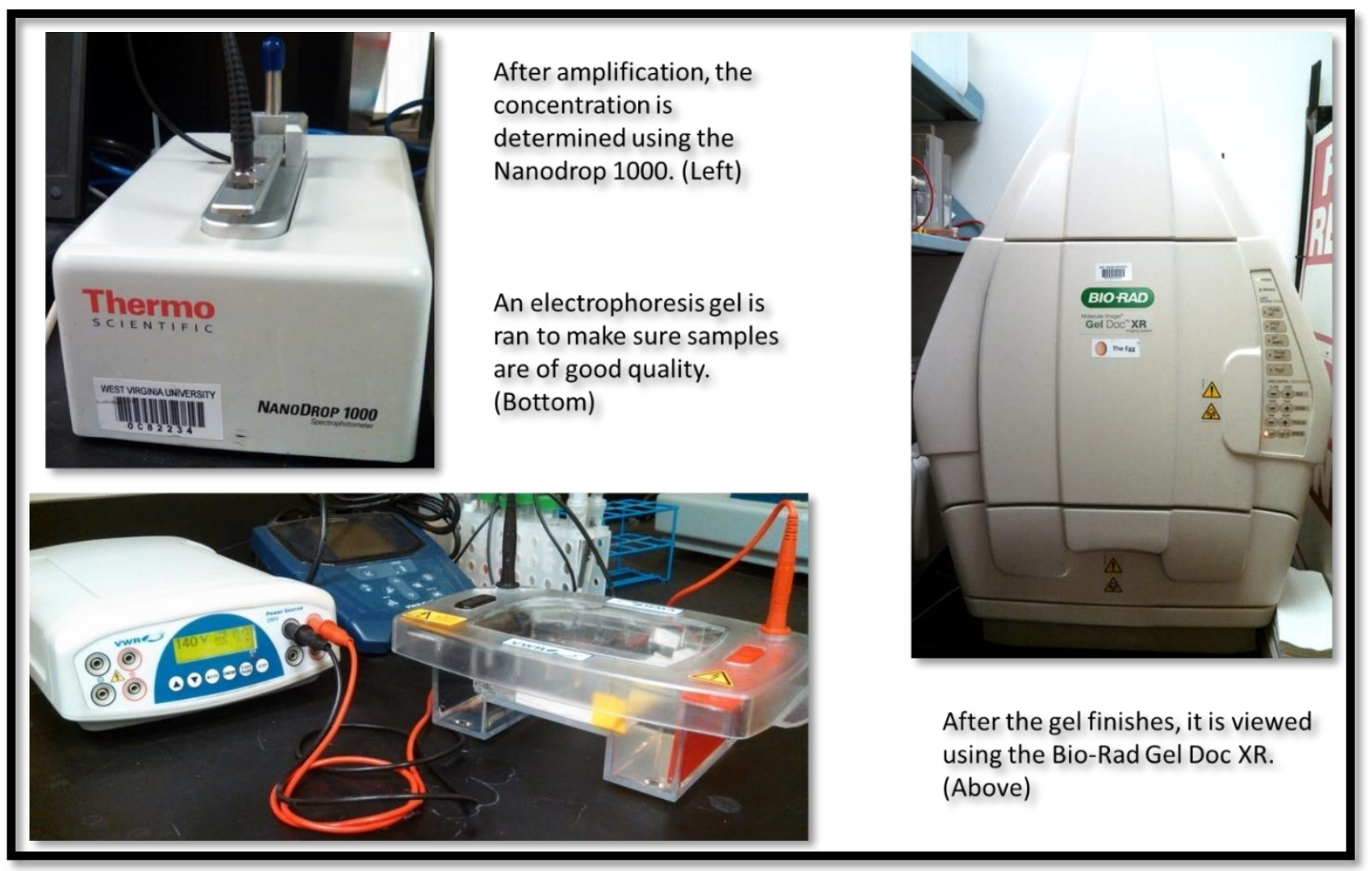

Figure 3.9: Samples are cleaned, and quality and concentration are determined

\subsection{Escherichia coli Control and Modification of Isolation Kit}

The E. coli was cultivated beginning with previous ligated E. coli samples that were

stored at $-20^{\circ} \mathrm{C}$. Transformation on the E. coli was performed using the following steps:

1) Briefly centrifuge the ligation and put it on ice

2) Allow a tube of competent cells to thaw completely on ice

3) Once thawed, add $2 \mu \mathrm{l}$ of ligation directly to competent cells and gently mix with pipette tip.

4) Incubate on ice for 30 minutes 
5) Heat shock the tube in a $42^{\circ} \mathrm{C}$ water bath for 30 seconds then put back on ice

6) Add $250 \mu \mathrm{l}$ of SOC Outgrowth Medium to the tube

7) Parafilm the tube and put it horizontally on the shaker for 1 hour at 255 RPM and set temperature for $37^{\circ} \mathrm{C}$

8) Spread XGal on an agar plate and allow it to soak in for 30 minutes at $37^{\circ} \mathrm{C}$

9) Spread transformation onto the plate and incubate the plate for $37^{\circ} \mathrm{C}$ for around 16 hours

After incubation, 5-6 colonies were picked and placed in a $15 \mathrm{ml}$ tube filled with SOC Outgrowth Medium. Next, the tube was vortexed for 1-2 seconds and then placed on a rotating rack inside the incubator. The tube was allowed to rotate overnight at $37^{\circ} \mathrm{C}$. For DNA extraction of the E. coli, approximately $1 \mathrm{ml}$ of liquid E. coli was added to the $2 \mathrm{ml}$ bead solution tube from an Ultraclean Plant DNA Isolation Kit Mo Bio bead tubes. Isolation of the E. coli DNA was carried out with no changes to protocol. After extraction, concentrations were much higher than the hand swabs with approximately $13-16 \mathrm{ng} / \mu 1$. An electrophoresis gel was ran on the unamplified E. coli samples to see if the DNA was correctly extracted and to make sure other unwanted fragments weren't present. Fig. 3.10 shows this gel with the distinct bands. The same PCR amplification as previously used was carried out but this time 3 different cycles were ran, 2 samples each for 10 , 15 and 30 cycles. Fig. 3.11 shows the gel results. From this gel results, it was decided that 15 cycles of amplification, not 30, led to the best results. 


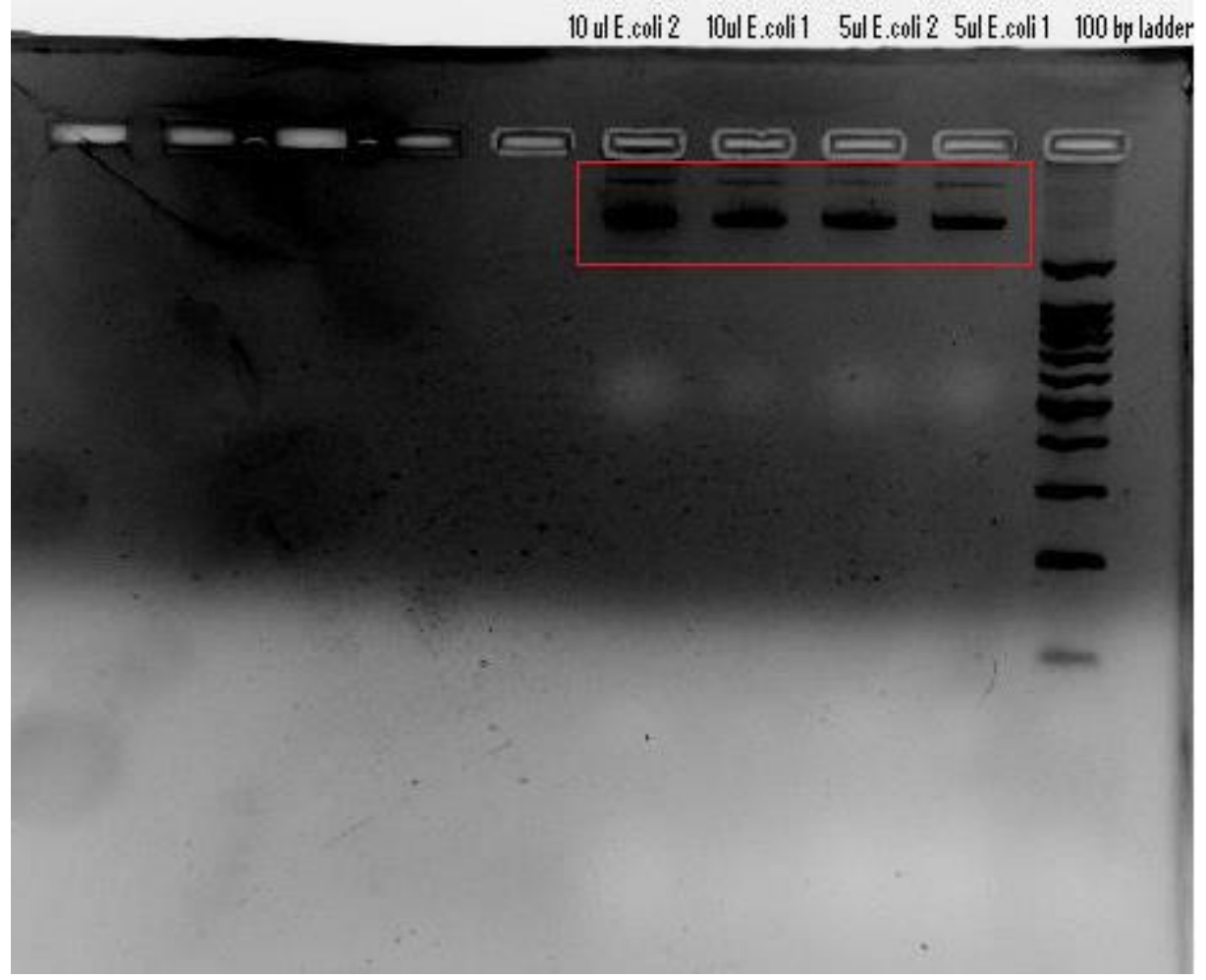

Figure 3.10: Gel from four unamplified E. coli samples. The first two wells contained $10 \mu \mathrm{l}$ of DNA and $2 \mu 1$ of dye and the last two only contained $5 \mu 1$ of DNA and $2 \mu 1$ of dye. All four lanes show the presence of DNA.

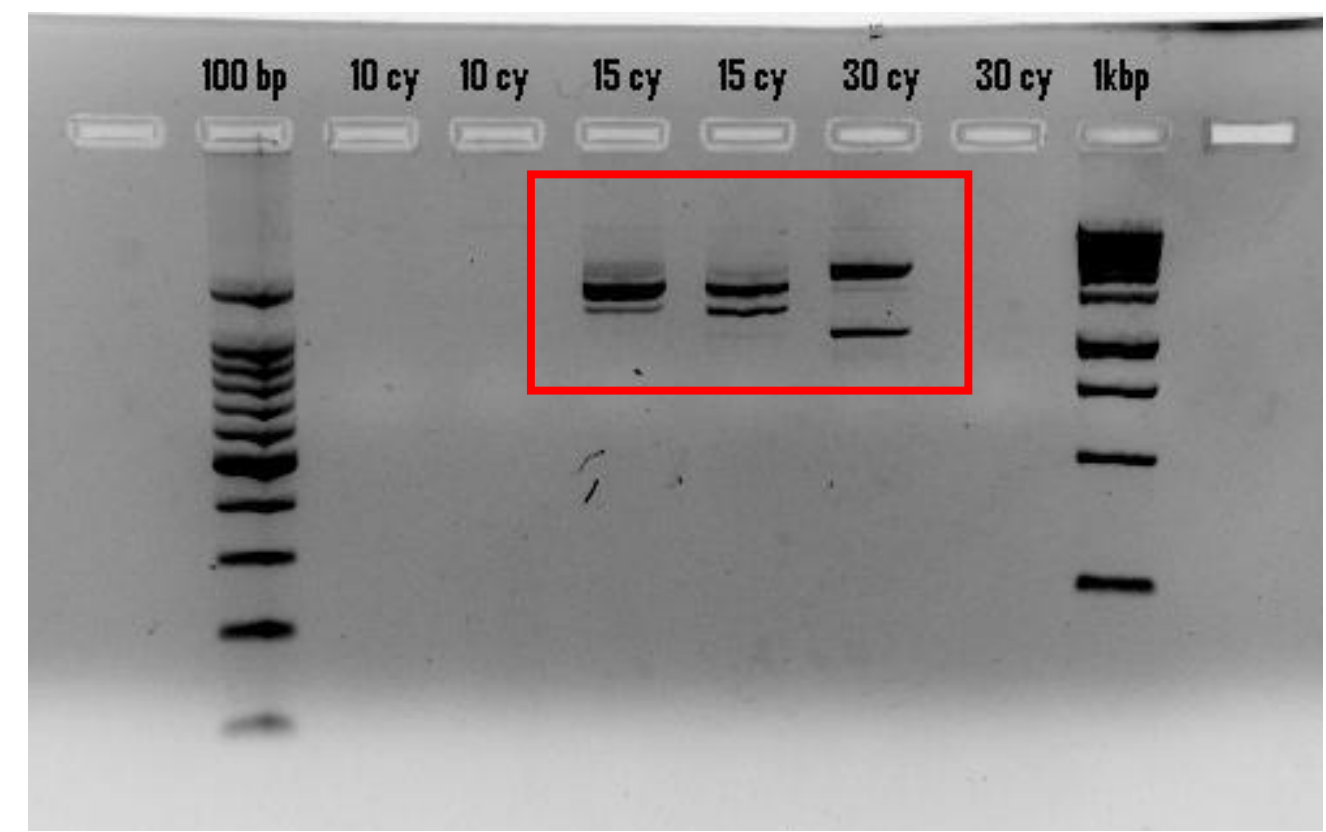

Figure 3.11: Gel from amplified E. coli samples. 15 cycles gave the best distinct bands (indicated in highlighted region). 
Previously isolated hand bacteria DNA was re-amplified using the optimized number of cycles, but again bands did not appear. A series of modified steps to the Ultraclean Plant DNA Isolation Kit was then executed to find the best methods to extract the most DNA. These modified steps included altering vortex times, wait times, and increasing amounts of supernatant transferred. The following changes to the protocol yielded in the maximum DNA concentration from swabbed test hand bacteria samples.

1) Prior to adding solution $\mathrm{P} 1$ samples were placed in the $65^{\circ} \mathrm{C}$ water bath for 5 minutes

2) Step $9,500 \mu 1$ of supernatant was transferred to a clean $2 \mathrm{ml}$ collection tube

3) Step 14, $600 \mu \mathrm{l}$ of supernatant was transferred to a clean $2 \mathrm{ml}$ collection tube

4) Step 23, Milli-Q $\mathrm{H}_{2} \mathrm{O}$ was used for elution buffer instead of solution P5 and was left to stand for 5 minutes before centrifuging.

\subsection{Amplification of the V3 Region and Library Generation}

After samples were isolated, amplified at the $16 \mathrm{~S}$ rRNA gene region and then purified using the PCR cleanup kit, the V3 region was amplified using forward primer 341F and modified reverse primer 518R (synthesized by Eurofins Genomics, see TABLE I). These primers are located just outside the V3 region [47] [48]. The modified reverse primer contained a unique six base pair index e.g. CGTGAT, ACATCG, GCCTAA, which would allow for identification of each sample during multiplexing [48]. 
Table I: Bacteria Specific 16S rRNA and V3 Region PCR Primer and Sequence

\begin{tabular}{c|l|l|} 
Region & Code & \\
\hline \multirow{2}{*}{ 16S rRNA } & E8F & AGAGTTGGATCCTGGCTCAG \\
\cline { 2 - 4 } & E1541R & AAGGAGGTGATCCANCCRCA \\
\hline \multirow{2}{*}{ V3 } & $341 \mathrm{~F}$ & AATGATACGGCGACCACCGAGATCTACACTCTITCCCTACACGACGCTCTTCCGATCTCCTACGGGAGGCAGCAG \\
\hline & $518 \mathrm{R}^{1}$ & CAAGCAGAAGACGGCATACGAGATNNNNNNGTGACTGGAGTCAGACGTGTGCTCTCCGATCTATACCGCGGCTGCTGG \\
\hline
\end{tabular}

${ }^{1}$ Insertion of six bases "NNNNNN" is for a unique index

The same PCR reaction mixture that was used for the 16S rRNA was used again with the exception for the exchange of the $16 \mathrm{~S}$ rRNA primers for the V3 primers. Again, using the MJ Mini Personal Thermal Cycler, PCR settings were an initial 5 min denaturation set at $95^{\circ} \mathrm{C}, 20$ cycles of $95^{\circ} \mathrm{C}$ for $1 \mathrm{~min}, 50^{\circ} \mathrm{C}$ for $1 \mathrm{~min}$, and $72^{\circ} \mathrm{C}$ for $1 \mathrm{~min}$ and then completed with an extension step set at $72^{\circ} \mathrm{C}$ for $7 \mathrm{~min}$. Each library consisted of samples that could be identified by the unique index present in the reverse primer. Samples were again purified using the IBI Scientific kit and their concentration was determined using the NanoDrop 1000 spectrophotometer. Another step that should have been carried out prior to the sample clean-up was to run an additional gel on each of the samples to make sure the quality of the sample was determined and not just concentration. Fig. 3.12 displays results that are good, marginal, and bad. The 'marginal' and 'bad' samples should have been redone before continuing on with the following steps but were not. This is because it was first thought if a sample concentration met requirements then the sample was fine for sequencing. It was later, after these samples were sequenced, that it noticed it was necessary to run the gels also on all the samples. The samples listed as 'bad' contain no band where the V3 target region should be shown meaning the target region was not properly amplified. Instead they show a small band farther down the gel which is indication of primer dimers. Primer dimers are by-products that can occur during the PCR cycles. Usually they occur when the primers bind to 
each other. The reagents instead amplify the primer dimers and inhibit the amplification of the DNA target region. The 'marginal' samples contain a band present in the right part of the gel showing that the target region was amplified but the gel also reveals the primer dimers which will interfere with the sequencing and produce marginal results.

After just the concentration was determined, the samples were then each diluted to $20 \mathrm{ng} / \mu \mathrm{l}$ accordingly. $5 \mu \mathrm{l}$ of each sample was pooled and sent to the Genomics Core Facility at West Virginia University for a 150 bp paired-end multiplexed sequencing using the Illumina Miseq (Fig. 3.13). Samples were loaded at a concentration of $[8 \mathrm{pM}]$ following the guidelines provided by Illumina for the MiSeq V2 reagent chemistry. After project runs were complete, the data was sent to BaseSpace [36], Illumina's next-generation sequencing cloud, for automatic analysis and storage. Index reads and base call quality scores for each sample were written to two FASTQ format files; one file for the forward run and the other for the reverse run. Due to some low and bad quality samples, only 82 samples from the set were used for further evaluation. Like previously stated, a gel ran on samples before being sent out could have prevented this. 


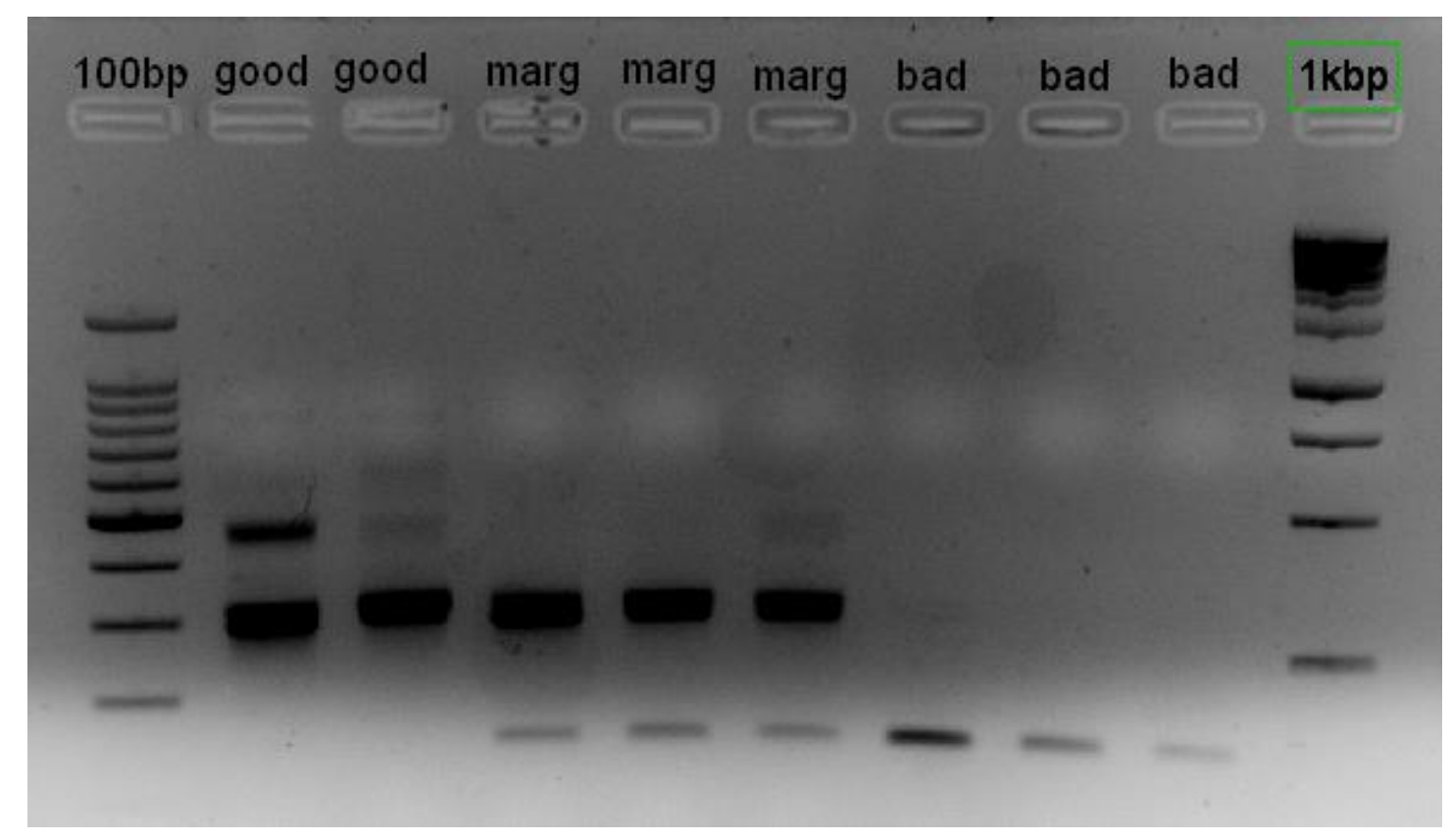

Figure 3.12: Examples of good, marginal, and bad quality samples

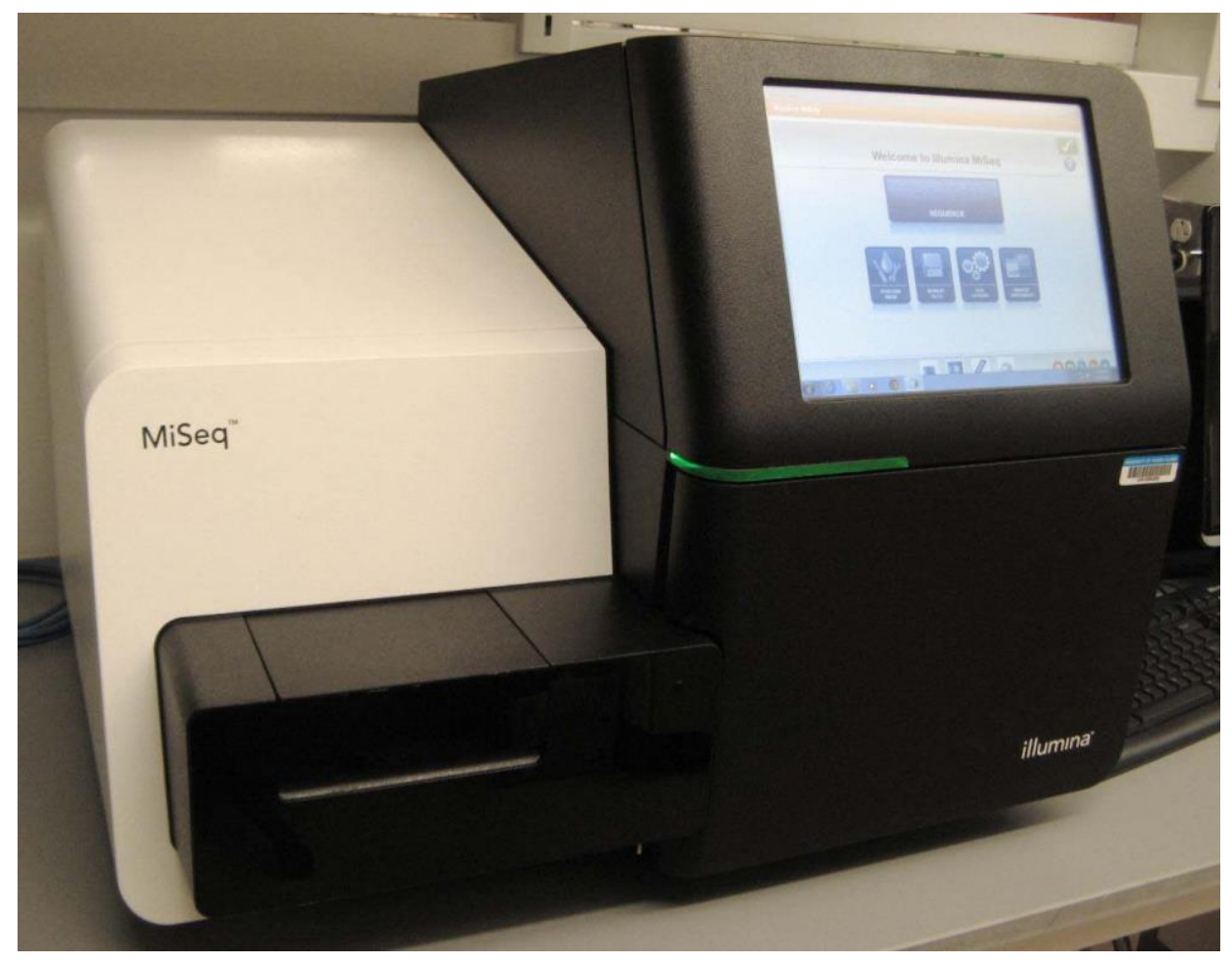

Figure 3.13: Illumina's Miseq Instrument ${ }^{3}$

\footnotetext{
${ }^{3}$ Image from http://www.web.uri.edu
} 
Chapter 4: Data

Extraction \& Analysis 
This chapter discusses what bioinformatics tools and methods were used to analyze the data set derived from BaseSpace and what initial results were discovered with the first sample set. It also describes what other methods and tools were used by the genome facility to create their own pipeline to analyze the data set.

\subsection{First Bioinformatics Method}

The first method involved tools from BaseSpace, Matlab R2012b, Mothur, and UniFrac.

Fig. 4.1 shows a flowchart of the pipeline. The process began by using the FASTQ files created from the data read by the Illumina Miseq. BaseSpace performed classification on the index reads using a Bayesian classifier. The classification process involved matching short subsequences of the reads to a set of $16 \mathrm{~S}$ reference sequences from the Greengenes database. The accumulated word matches for each read were used to assign reads to a particular taxonomic classification. Summary statistics provide the total number of classified clusters for each sample at taxonomic levels, kingdom to genus. Fig. 4.2 shows a pie chart generated by BaseSpace displaying the percentage of OTUs at each level. The chart displayed in this image is the genus level. After the FASTQ files, classification files, and confidence level files were downloaded, the first step was to merge the forward and reverse FASTQ files together for each sample to create complete reads. This was done by using the make.contigs command from Mothur's user interface. This command reads in the forward and reverse sequence files of a sample. The sequence fragments created from both the forward and reverse reads are combined to form contigs. Contigs simply refer to any contiguous stretch of fragment sequence data created by read overlap. From this case, the pairedend sequencing creates the read overlap. This area that overlaps between the two sequences is 
found in Mothur and then the reverse sequence run is reversed and complemented and joined to the forward read to make one complete forward read. These reads for each sample are then output to a new fasta file which contains the sequence name followed by the new complete sequence.

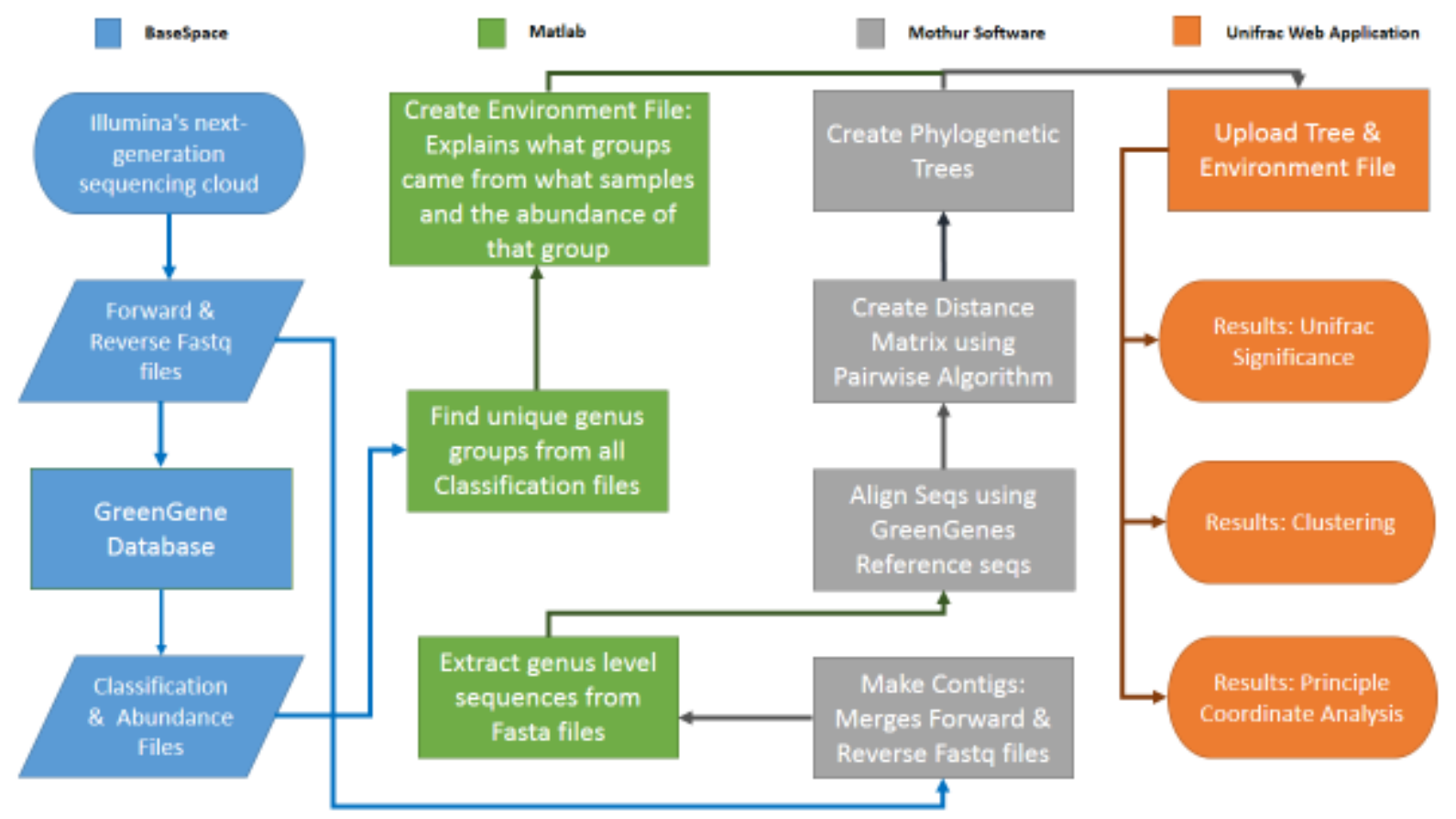

Figure 4.1: Diagram of bioinformatics tools and methods used to analyze bacteria data 


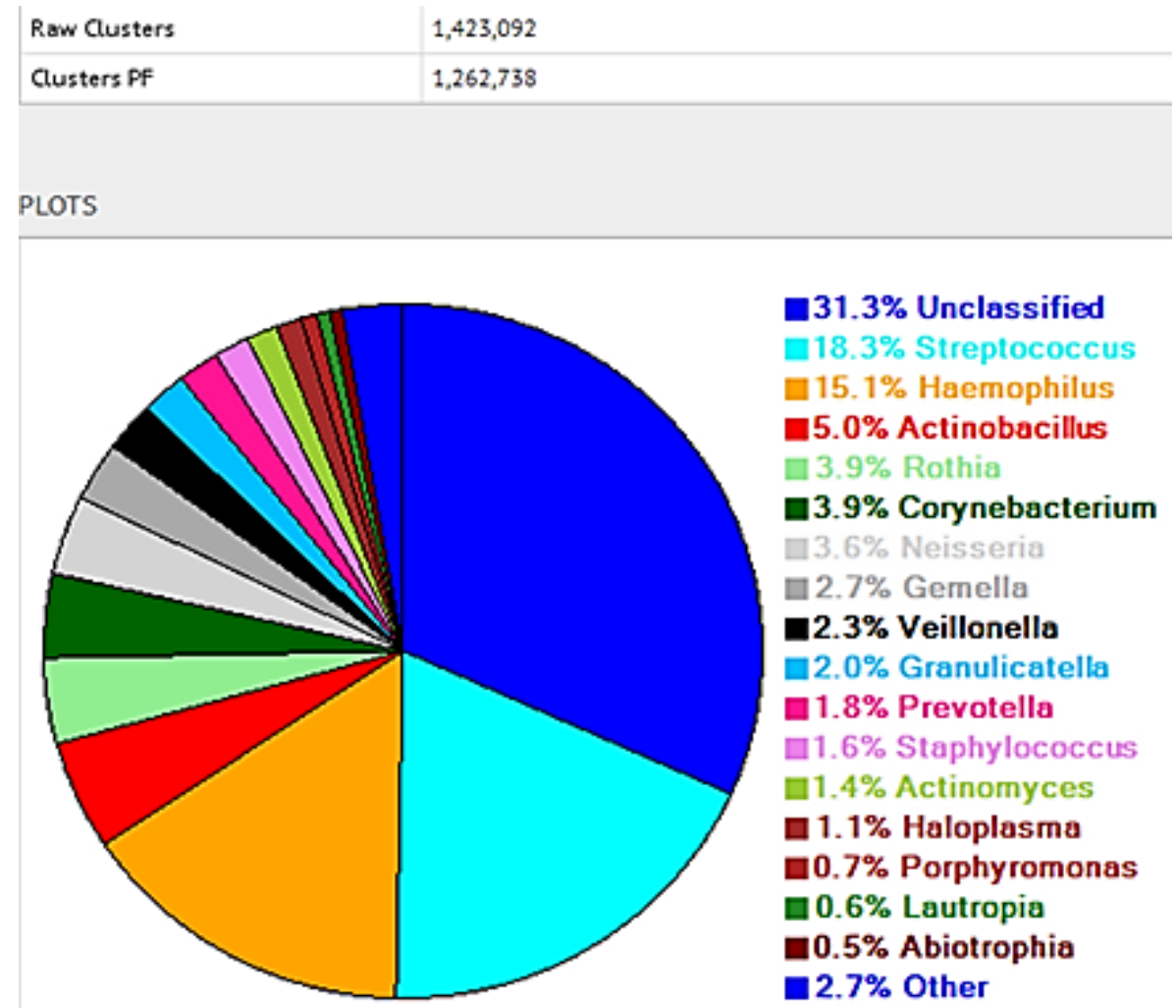

TAXONOMY
\begin{tabular}{|l|l|}
\hline Taxonomic Level & Clusters Classified \\
\hline Kingdom & $1,262,411$ \\
\hline Phytum & $1,149,137$ \\
\hline Class & $1,075,722$ \\
\hline Order & 980,753 \\
\hline Family & 924,350 \\
\hline Genus & 867,448 \\
\hline
\end{tabular}

Figure 4.2: (Top) Percentage of OTUs that made up the sample at the genus level. (Bottom) Total clusters (OTUs) that were classified at each taxonomy level.

Approximately $9.3^{*} 10^{5}$ sequence reads were created for each of the first 10 samples. Sequences that were classified down to the genus level were extracted from the fasta files using Matlab scripts. This cut the sequences down to approximately $2.8^{*} 10^{5}$ sequences per sample. After being sorted, sequences were then aligned using the 'align.seqs' command in Mothur that used the Needleman-Wunsch algorithm [49]. Sequence alignment is important in arranging the DNA so 
that regions of similarity can be identified. The reference file used was from the GreenGenes database. This reference alignment file contains complete sequences from 202,421 bacterial and archaeal sequences and was released in May 2013. After all samples were aligned they were outputted to a new file called '.aligned.fasta.' This file was then used to calculate the uncorrected pairwise distances between the aligned sequences in all 10 samples. This was done by using the Mothur command 'dist.seqs'. This command outputs the distance scores between all sequences into a phylip formatted lower triangle matrix 'phylip.dist' file. A phylip-formatted distance matrix typically has the number of sequences described by the distance matrix on the first row. The following lines after have the sequence name as well as the pairwise distance from that sequence to the other sequences [38]. A triangle matrix prevents repeats of the same distance number being repeated. Fig. 4.4 is an example of an upper triangle distance matrix. The next step was to use this distance file to create a single rooted phylogenetic tree containing all 10 samples. This was done by using the 'clearcut' command. This command uses the relaxed neighbor joining algorithm and outputs the tree in Newick format and output the tree to a 'phylip.tre' file. The relaxed neighbor joining (RNJ) algorithm is a fast variant of the original neighbor joining algorithm that is commonly used for distance-based tree construction. RNJ has improved speed and produces similar results to $\mathrm{NJ}$, making it beneficial for large data sets [50]. Fig. 4.3 provides a simple visualization of these commands from sequences to the phylogenetic tree. 
Sequences

Bacteria1=CACCGTCACG Bacteria2=CAGTGTCAGG Bacteria3=CCCTGGTCG

Bacteria4=CAGTGGAGG

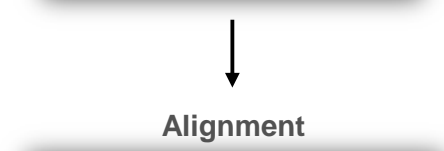

Bacteria1=CACCGTCACG

Bacteria2=CAGTGTCAGG

Bacteria3=CCCTG-GTCG

Bacteria4=CAGTG-GAGG
Distance Matrix

\begin{tabular}{|l|c|c|c|c|}
\hline & Bacteria1 & Bacteria2 & Bacteria3 & Bacteria4 \\
\hline Bacteria1 & 0 & 0.3 & 0.5 & 0.5 \\
\hline Bacteria2 & 0.3 & 0 & 0.6 & 0.2 \\
\hline Bacteria3 & 0.5 & 0.6 & 0 & 0.4 \\
\hline Bacteria4 & 0.5 & 0.2 & 0.4 & 0 \\
\hline \multicolumn{5}{|c|}{} \\
& $\downarrow$ &
\end{tabular}

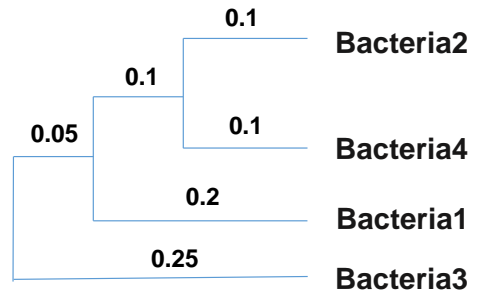

Figure 4.3: Diagram on how the samples went from sequence to a phylogenetic tree

\subsection{Analysis of First 10 Samples}

The first 10 samples sequenced included the right hands from four males and six females that listed their ethnicity as either Caucasian, African American, Asian, Asian Indian or Middle Eastern. Across these 10 samples 635 different OTUs at the genus level were identified with females having approximately $10 \%$ higher diversity than the males.

After the phylogenetic tree was completed from Mothur, it was uploaded to the UniFrac web application ${ }^{4}$ along with the identity files that were described in the UniFrac section in Chapter 2. The UniFrac interface provides several tools for microbial analysis. Tests that were performed were: environment distance matrix, cluster environments, PCoA (principle coordinate analysis), and UniFrac significance.

\footnotetext{
${ }^{4}$ http://unifrac.colorado.edu/
} 
Fig. 4.4 shows the UniFrac distance matrix created from the phylogenetic tree. From the results there was only on average $13 \%$ uniqueness between samples when the abundance was taken into consideration (weighted, Fig. 4.4 bottom image). When samples were compared just on the types of different OTUs (unweighted, Fig. 4.4 top image) there $40 \%$ uniqueness between samples. The unweighted comparison is much higher than the weighted comparison because with unweighted all OTUs are considered evenly, unlike with weighted where the common OTUs (more abundant) add more weight to the analysis.
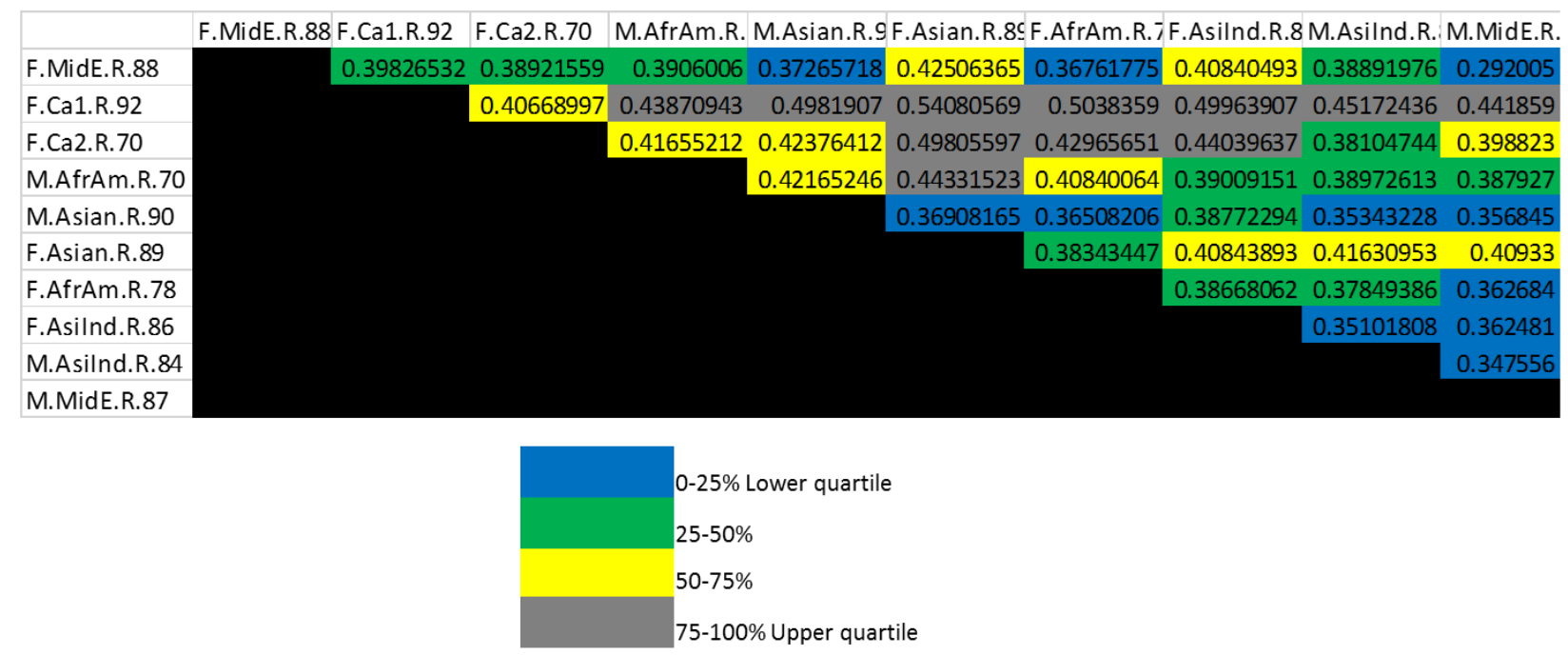

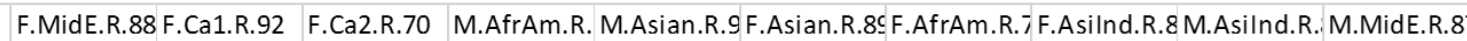

\begin{tabular}{|c|c|c|c|c|c|c|c|c|c|}
\hline F.MidE.R. 88 & 0.14336389 & 0.1099606 & 0.07363758 & 0.14272934 & 0.16527339 & 0.16737404 & 0.04748965 & 0.04560041 & 0.06567678 \\
\hline F.Ca1.R.92 & & 0.14590172 & 0.13975475 & 0.18294132 & 0.18399529 & 0.19465356 & 0.13056176 & 0.16997364 & 0.19540217 \\
\hline F.Ca2.R.70 & & & 0.13031849 & 0.14944607 & 0.16730631 & 0.17087183 & 0.12527142 & 0.11907601 & 0.14750165 \\
\hline M.AfrAm.R.70 & & & & 0.13170132 & 0.15288731 & 0.15170827 & 0.09060864 & 0.0697233 & 0.09431701 \\
\hline M.Asian.R.90 & & & & & 0.04185008 & 0.03363942 & 0.14589418 & 0.13276309 & 0.1307724 \\
\hline F.Asian.R.89 & & & & & & 0.02492241 & 0.16377731 & 0.15637404 & 0.15784289 \\
\hline F.AfrAm.R.78 & & & & & & & 0.16523548 & 0.15843788 & 0.15841089 \\
\hline F.Asilnd.R. 86 & & & & & & & & 0.05598176 & 0.08168486 \\
\hline M.Asilnd. R. 84 & & & & & & & & & 0.04986892 \\
\hline M.MidE.R. 87 & & & & & & & & & \\
\hline
\end{tabular}

Figure 4.4: Environment UniFrac distance matrices. (Top) Unweighted UniFrac, (Bottom) Weighted UniFrac.

Clustering and principle coordinate analysis both base their measurements on the UniFrac distance measurements. The more similar the samples are, the closer they will appear in the new output tree. With both methods, the weighted scores were used to generate the outputs. Figures 4.5 
and 4.6 show similarity within the samples based on ethnicity. As shown in Fig. 4.5, both the male and female Asian Indians and Asians, and both Caucasian females clustered together. Fig. 4.6 gives a better visual representation of the distance between the samples. The farther away from each other, the less the similarity they have.

Scale: 1 dash, slash, backslash $\sim 0.0008$ branch length units

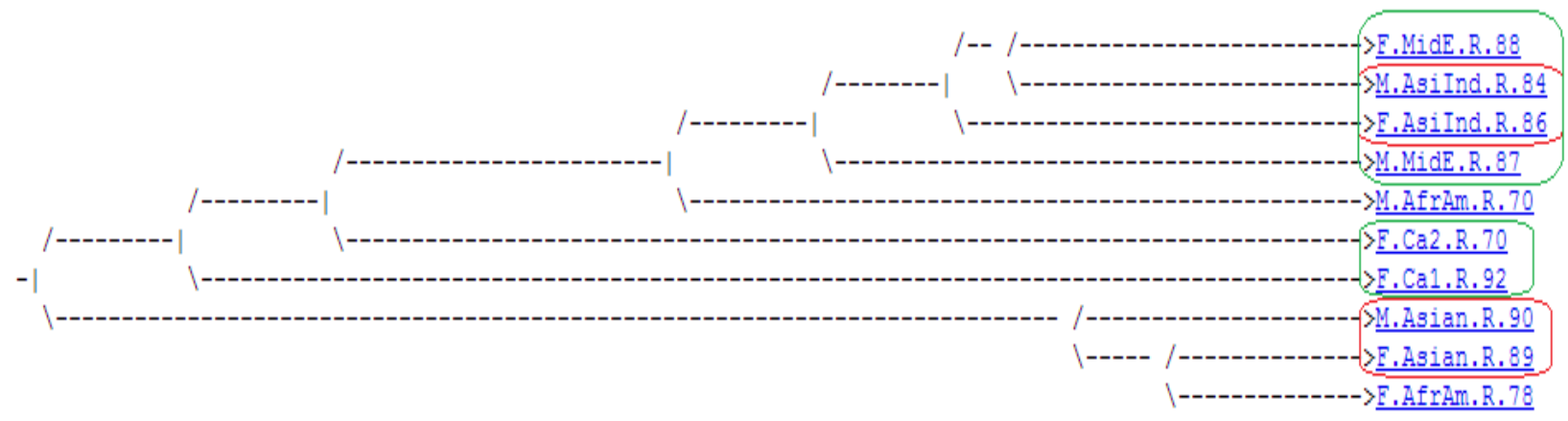

Figure 4.5: Sample clustering on first 10 samples using weighted UniFrac measurements

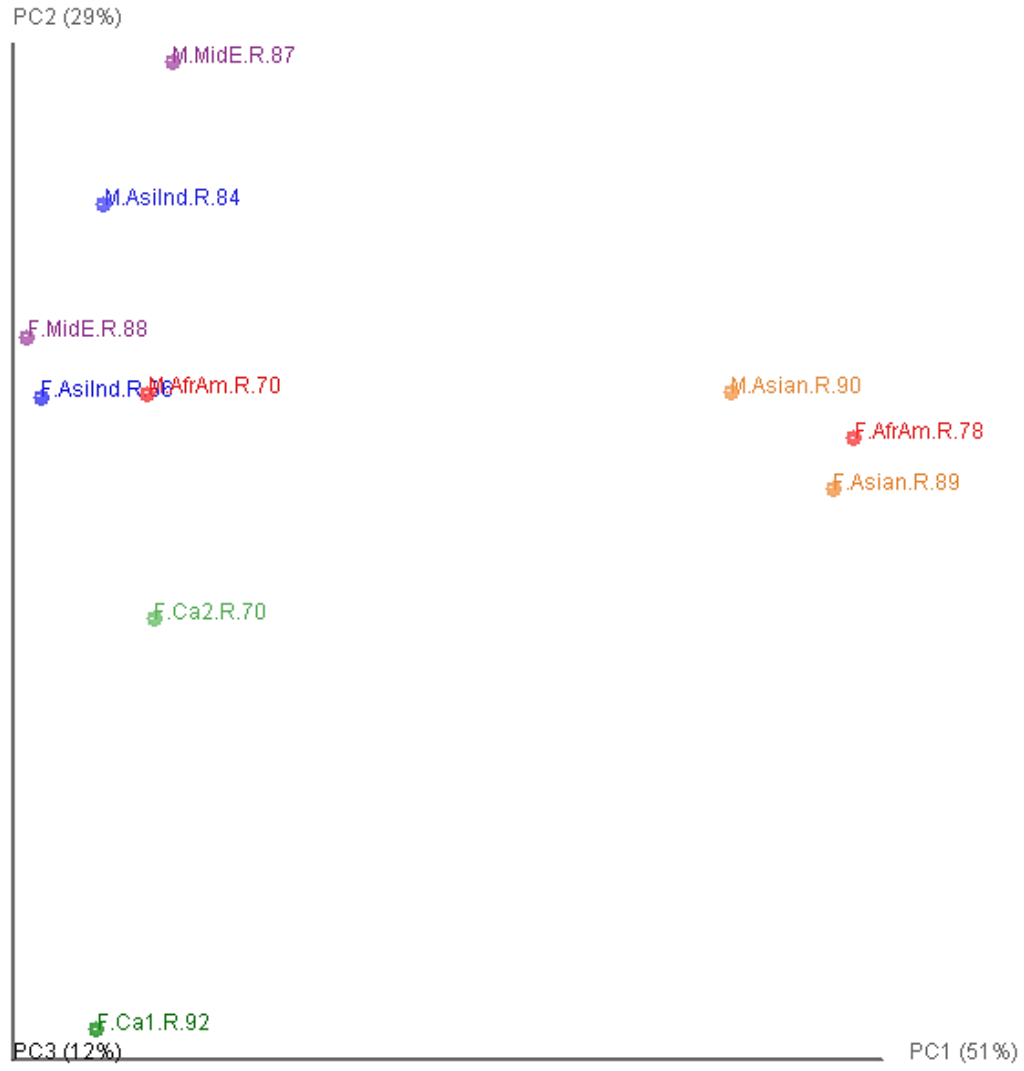

Figure 4.6: Weighted Principal Coordinate Analysis plot for first 10 samples 


\subsection{Additional Bioinformatics Method by WVU Genomics Facility}

The second bioinformatics method was provided by the Genomics Core Facility. This pipeline used the Extended Randomized Numerical alignE filter (ERNE-filter) for quality trimming and contamination filtering. The index reads were matched using the USEARCH algorithm which searches a database at exceptionally high speeds for high-identity hits to one or more database sequences [51]. The sequences were classified using an open source software package called QIIME, which stands for stands for Quantitative Insights Into Microbial Ecology [52]. The sequences were parsed and merged indexes using custom scripts. Data was then analyzed using open source software R package, vegan [53]. $\mathrm{R}$ is a software for statistical computing and graphics. The package vegan supports all basic ordination methods including non-metric multidimensional scaling. The results provided from the facility's pipeline were classification files that were similar to format as BaseSpace's. Since the files did not include the actual sequences and just the OTU summary a phylogenetic tree was not created using this method. Instead, this data was used for classification analysis. Results from this are presented in the next chapter. 


\section{Chapter 5: Results \& Conclusion}


This chapter will display the results of individual clustering achieved by performing bioinformatics methods on hand bacteria samples collected from a total of 82 samples. Additional samples will be added at the end of this chapter.

\subsection{Results}

With a total of 82 samples, an average of 646,518 bacteria clusters passed filter. Illumina uses a filter called a chastity filter to determine what raw data is not reliable. The chastity of a base call is calculated by the ratio of the intensity of the brightest intensity base for a cluster divided by the sum of the brightest and the second brightest intensity. Clusters pass filter (PF) if no more than one base call in the first 25 cycles has a chastity of $<0.6$.

Of this initial average, an average of 394,179 bacteria clusters were identified at genus level with an average of 231 identified operational taxonomic units (OTUs) per sample and a total of 777 different OTUs identified across the sample set. The diversity between woman and men changed slightly with the additional samples. Instead of a $10 \%$ higher diversity the difference dropped down to a $9 \%$ higher diversity than that of the men.

Using the first method described in Chapter 4, a UniFrac distance matrix was created. Results showed a slightly higher uniqueness score, from $40 \%$ to $43 \%$ on average. PCoA plots were created using the weighted UniFrac matrix. Figures 5.1- 5.3 shows PCoA plots with the 82 samples based off of ethnicity. Participants who identified themselves as Middle Eastern, Asian Indian, and Turkish descent were shown to have closer clustering (Fig. 5.1). Participants who identified 
themselves as just Asian descent also showed clustering and dissimilarity from Asian Indian, Middle Eastern and Turkish although Fig. 5.2 just shows the dissimilarity between Asian and Asian Indian. Fig. 5.3 shows no clustering or dissimilarity between Caucasians and African Americans. Slight clustering with Hispanics is observed but this group only contained four samples so observations are hard to determine.

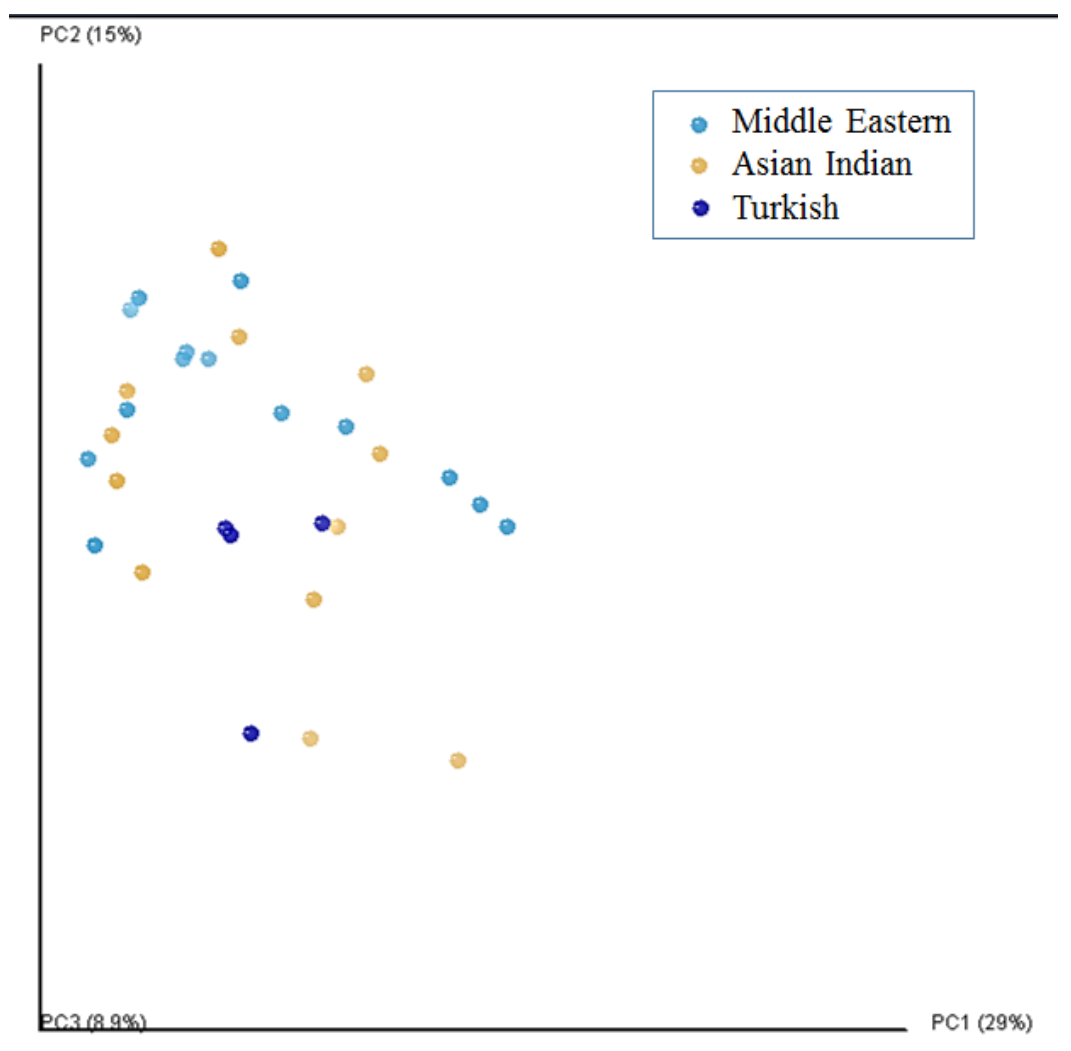

Figure 5.1: Clustering of Middle Eastern, Asian Indian and Turkish ethnicities 


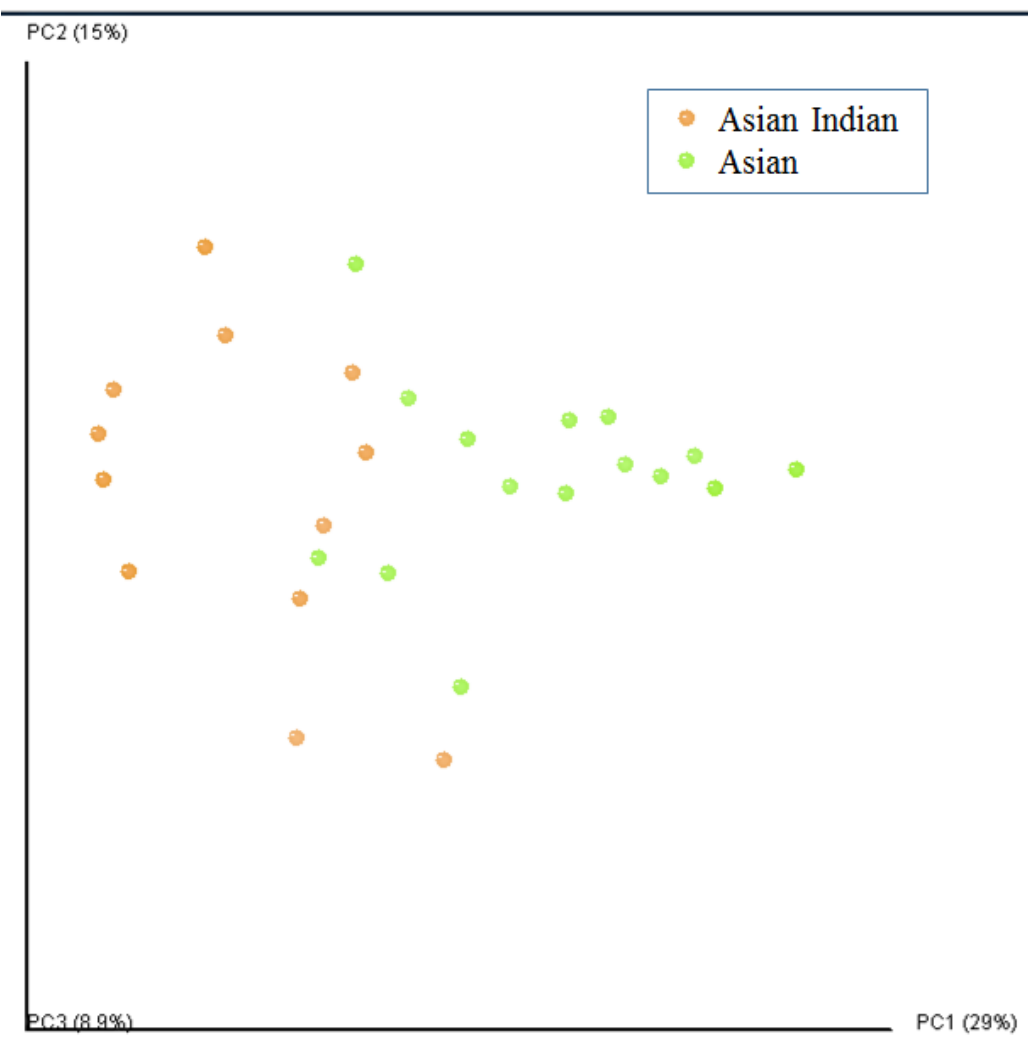

Figure 5.2: Dissimilarity between Asian Indian and Asian ethnicities

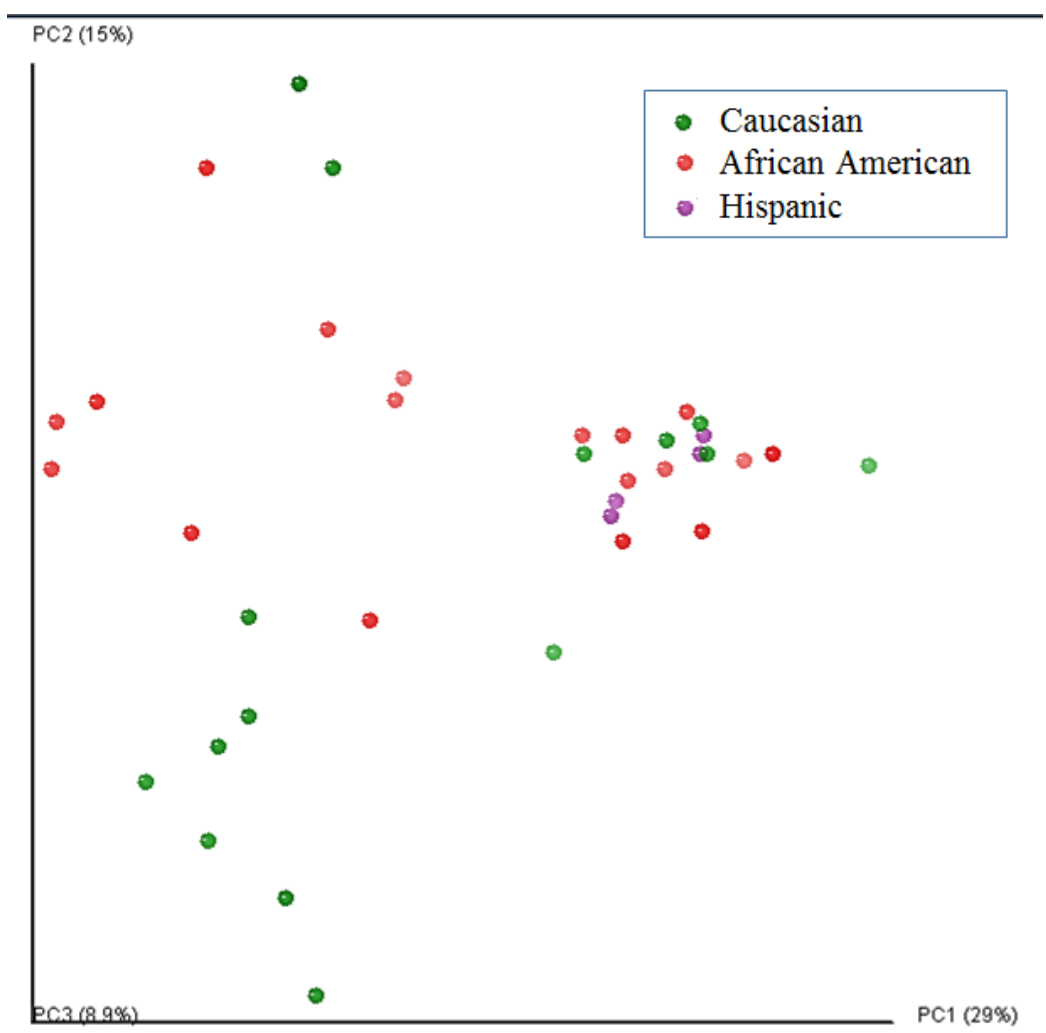

Figure 5.3: No Caucasian or African American clustering, slight Hispanic clustering 
Figures 5.4 and 5.5 show plots based off of participants' age and gender. Neither plot shows any apparent clustering but as previously mentioned women differ from men by having a higher diversity of OTUs.

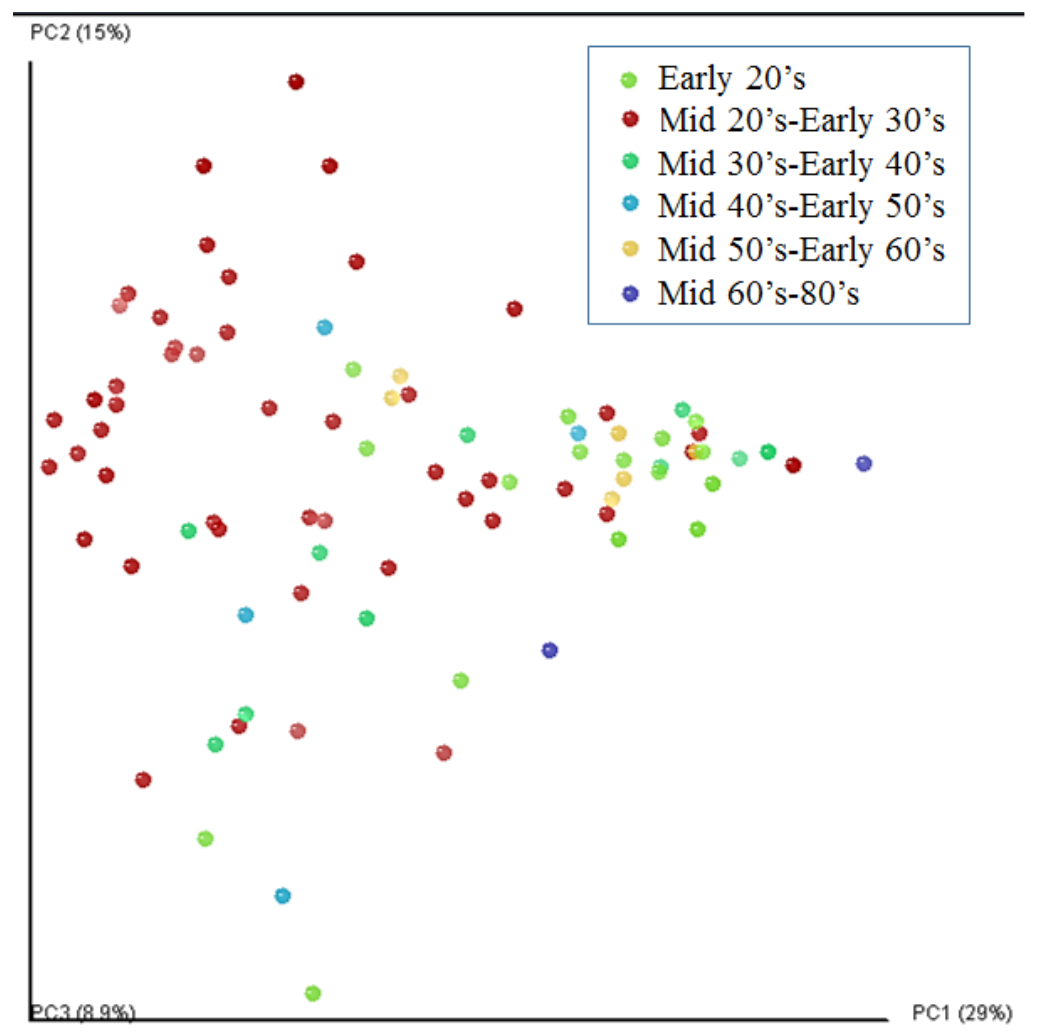

Figure 5.4: No apparent clustering between groups when based off of age 


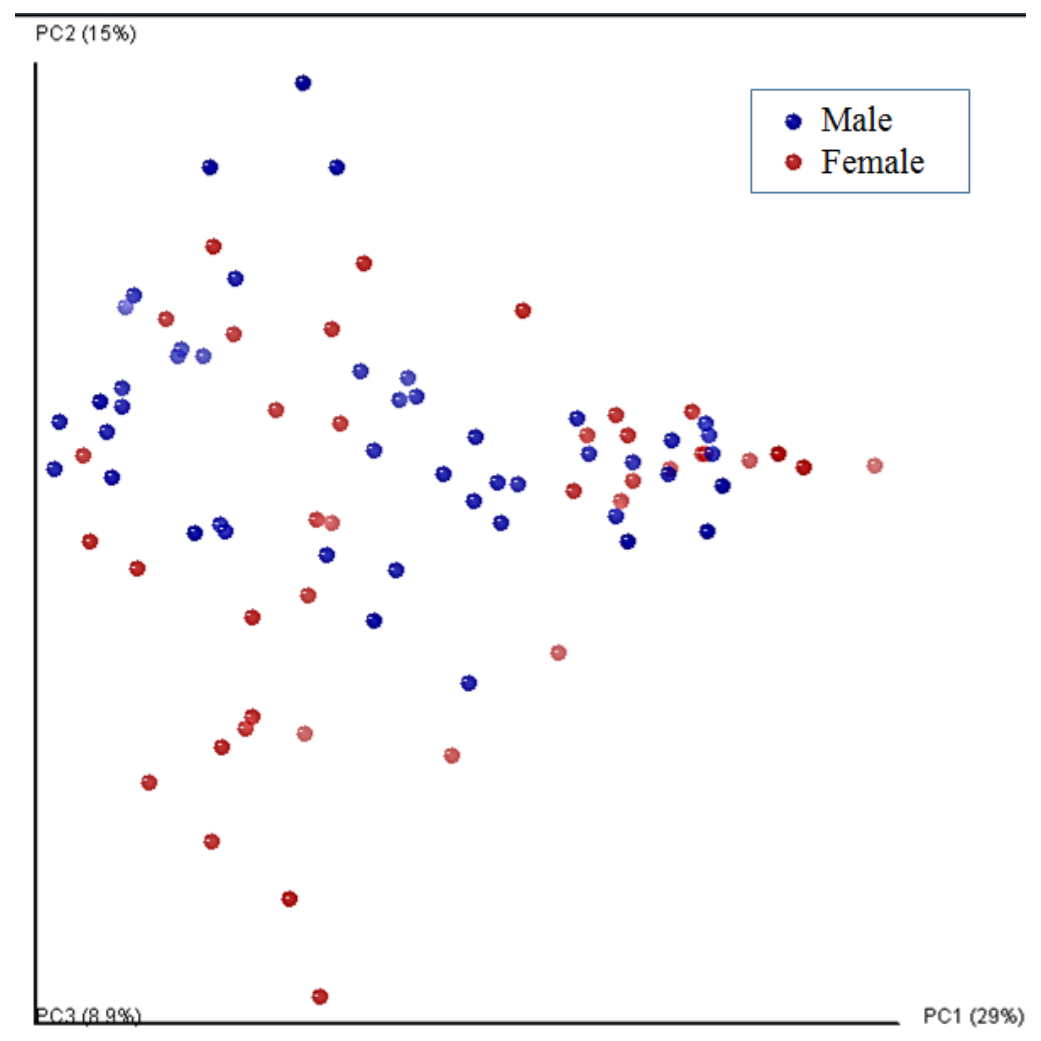

Figure 5.5: No apparent clustering when based off of gender.

For both bioinformatics methods, the five most common OTUs showed to be the best for ethnicity classification. A supervised support vector machine (SVM) was used for training and cross validation. The highest accuracy rates were best achieved when a third degree polynomial kernel function was used and if $60 \%$ of the data set was used for training and then the remaining $40 \%$ used for testing. The training set was randomly sampled for each ethnicity class. To get an average accuracy rate, 400 iterations were competed. Table II shows the accuracy rate that was reported for each method. Method I which involved bioinformatics from BaseSpace, Matlab R2012b, and Mothur used OTUs Sphingopyxis, Streptococcus, Corynebacterium, Straphylococcus, and Propionibacterium for the five features and Method II which was provided by WVU's genome facility used Kaistobacter, Acinetobacter, Corynebacterium, Straphylococcus and Propionibacterium. Both methods showed similar results. Asian and African American 
showed the lowest accuracy rate while Turkish and Hispanic showed the highest, but also had the least amount of samples with only four samples per group, causing less information about the groups to be gathered.

Table II: Accuracy Rate of Support Vector Machine Classification Method

\begin{tabular}{|l|c|c|c|}
\hline Ethnicity & $\begin{array}{c}\text { Number of } \\
\text { Samples }\end{array}$ & Method I (\%) \\
\hline Caucasian & 15 & 81 & 77 \\
\hline Hispanic & 4 & 85 & 88 \\
\hline African & 18 & 66 & 70 \\
\hline American & 4 & 92 & 93 \\
\hline Turkish & 14 & 76 & 79 \\
\hline Middle Eastern & 15 & 64 & 67 \\
\hline Asian & 12 & 76 & 77 \\
\hline Asian Indian & & & \\
\hline
\end{tabular}

Fig. 5.6 and 5.7 give a visualization of the average percentage of these five most common bacteria found on the hand for each ethnicity. Similar trends are again shown between both methods. Hispanic and Asian displayed a higher percentage of Sphingopyxis (from Method I) Kaistobacter (from Method II) compared to other ethnicities. Middle Eastern and Asian Indian showed similar ratios of the 5 most common chosen OTUs which supports the clustering results from the PCoA plots. 


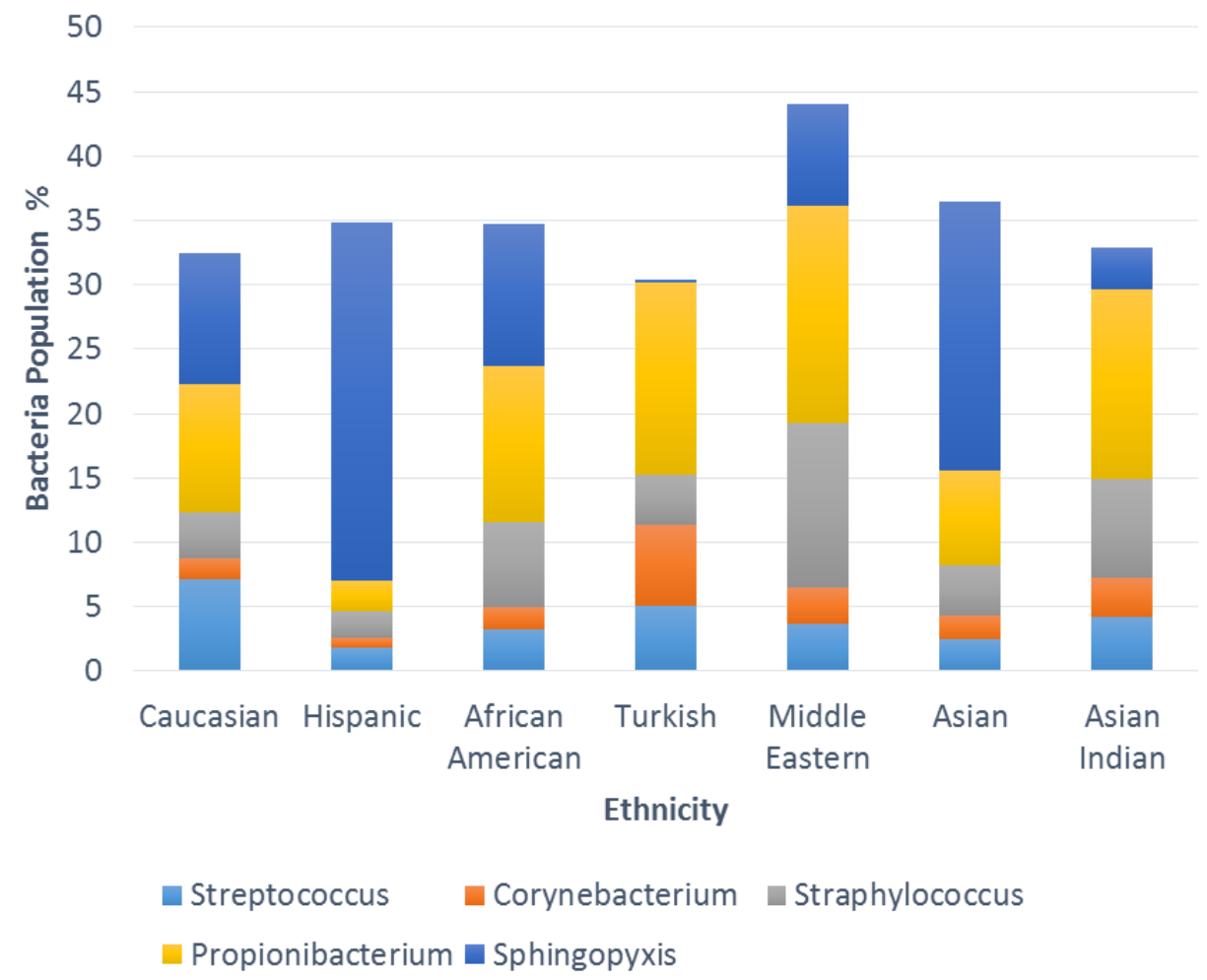

Figure 5.6: Percentage of the five most common OTUs found using the first method

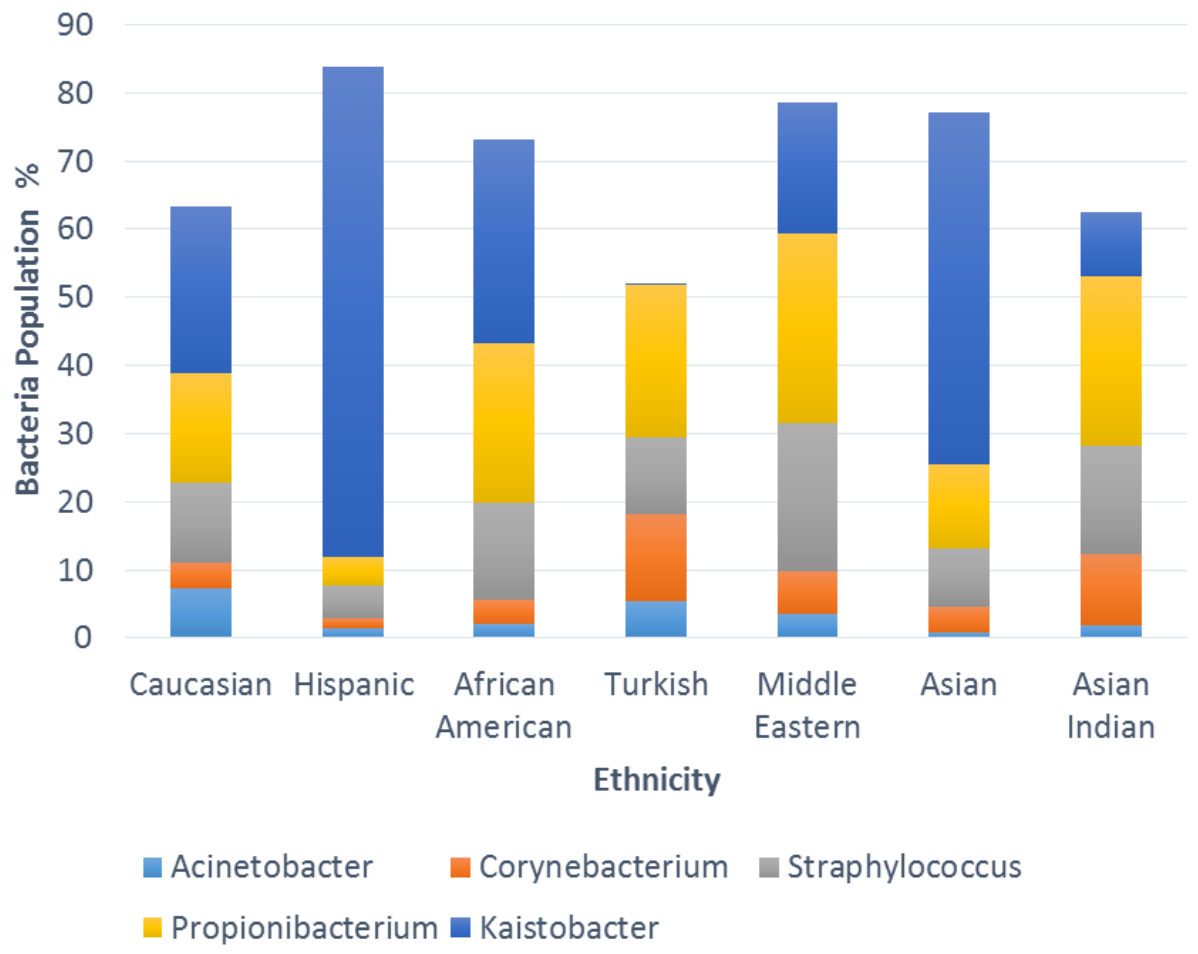

Figure 5.7: Percentage of the five most common OTUs found using the second method 


\subsection{Additional Samples}

After the initial 82 samples, 22 more samples were added to the sample set for a total of 104 (52 individuals) processed samples. 20 of these additional samples were previously considered 'marginal' or 'bad' from former project runs. PCR and gels were redone until good quality was obtained before sequencing. The other two additional samples were the additional of one more individual. The additional samples added 249 more OTUs to the previous 777 OTUs identified at the genus level across the sample set for a total of 1,026. The additional samples also brought the total sequences that passed filter at the genus level to $45.8 \mathrm{M}$ sequences.

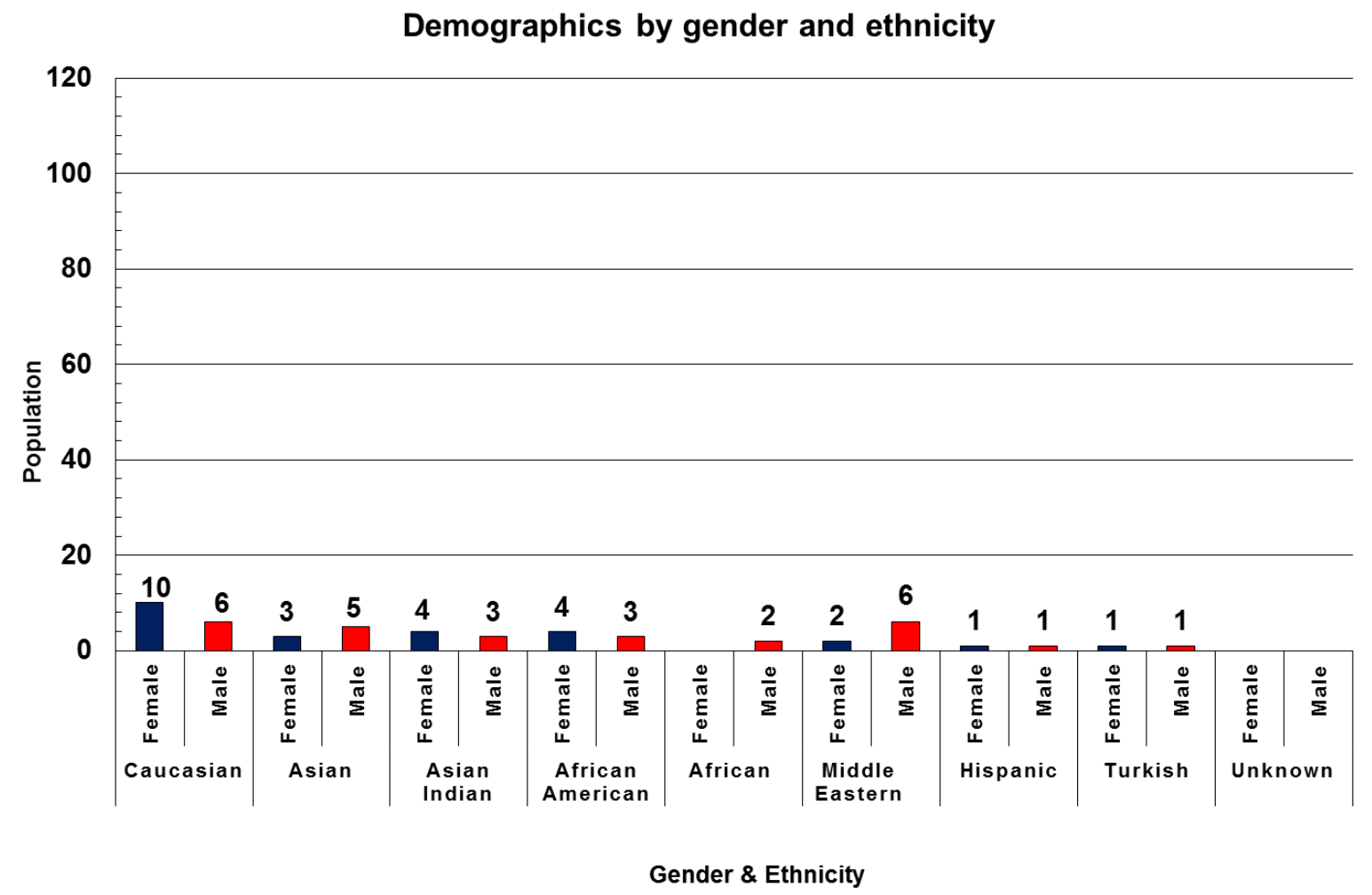

Figure 5.8: Distribution of gender and ethnicity for the collection sample set 
With the new data, a new phylogenetic tree was created. This tree was used to create a weighted UniFrac distance matrix which was used to generate new PCoA plots (Figures 5.95.12). Figures 5.9 and 5.10 PCoA plots display the distribution of the samples based off of ethnicity. The same clustering as before with Middle Eastern, Asian Indian, and Turkish still occurred along with this group being distinguished from the Asian clustering. Fig. 5.10 displays the same ethnicity plot but shows six of the points/samples circled. Three with green circles and three with red circles. The red circles represent samples that contain bad quality data, which was most likely caused from amplification errors. Part of the remaining stored DNA of these three samples was re-amplified and re-sequenced. These re-sequenced samples are the points circled in green.

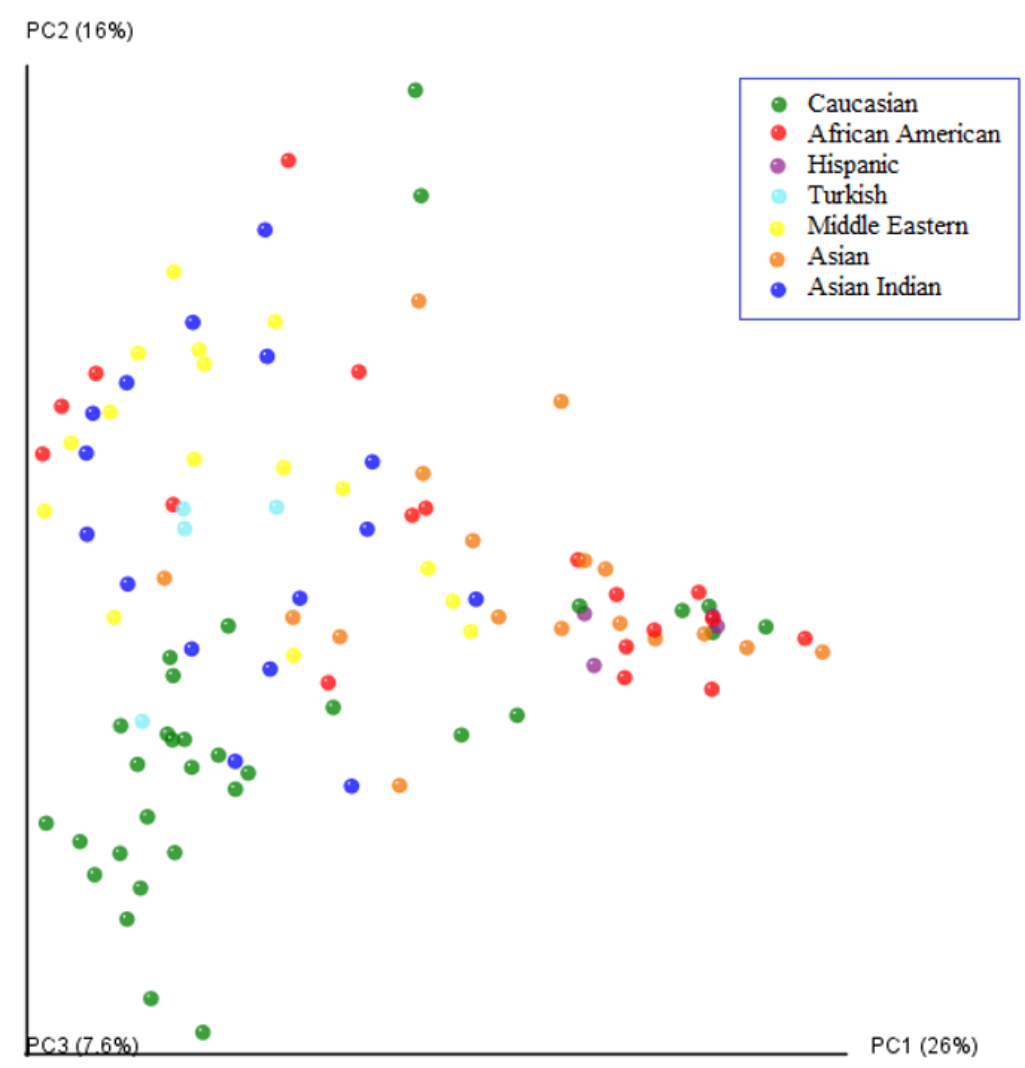

Figure 5.9: Additional samples, primarily Caucasian, were added to the sample set 


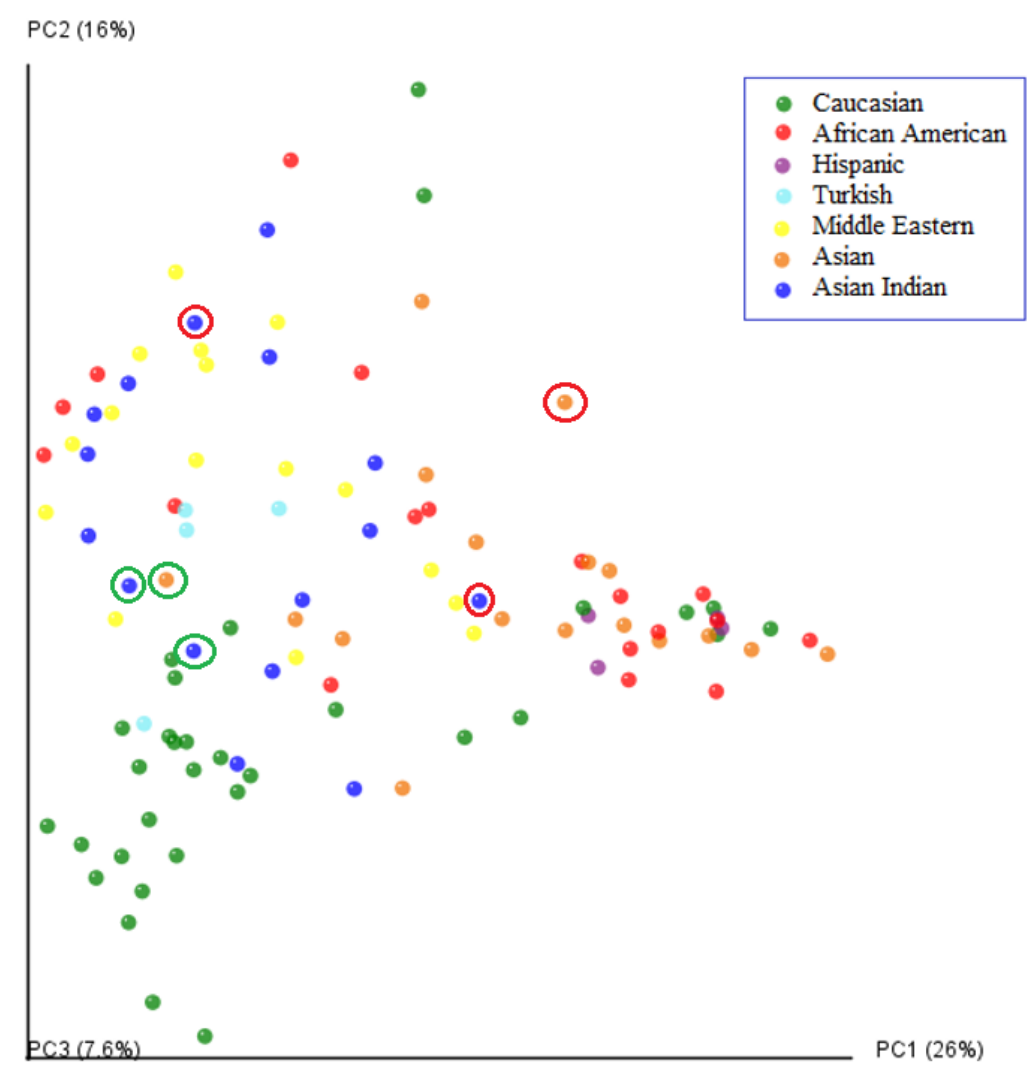

Figure 5.10: Ethnicity plot including three repeated samples. The three samples circled in green are re-sequenced and considered good quality. Samples in red are the same sample but marked as bad quality.

With the ethnicity plot, there also slows some clustering with Caucasians which are marked green in the lower left-hand panel. This clustered group contains a majority of the re-sequenced samples (17 of the 22 additional samples were Caucasian). To perhaps explain this clustering, the distance matrices were analyzed. Fig. 5.11 displays a color coded unweighted UniFrac distance matrix. The four colors represent the distribution of the UniFrac scores, where blue represents samples in the lower uniqueness quartile (20-40\%), green in the second quartile, yellow in the third quartile, and gray representing the fourth quartile samples with the highest uniqueness scores (70$80 \%$ ). The last 22 samples at the end of the top row and also at the bottom of the first column, are the additional samples to this data set. These samples stand out from the rest of the samples in this matrix. This matrix shows that the additional set is most unique to the other sample sets and most similar to samples within the same set. Although the plots were generated from the weighted 
UniFrac matrix (displayed in Fig. 5.12), which does not show separation between sample sets, this distinction in the unweighted matrix may be the cause for the Caucasian clustering in the PCoA plots.

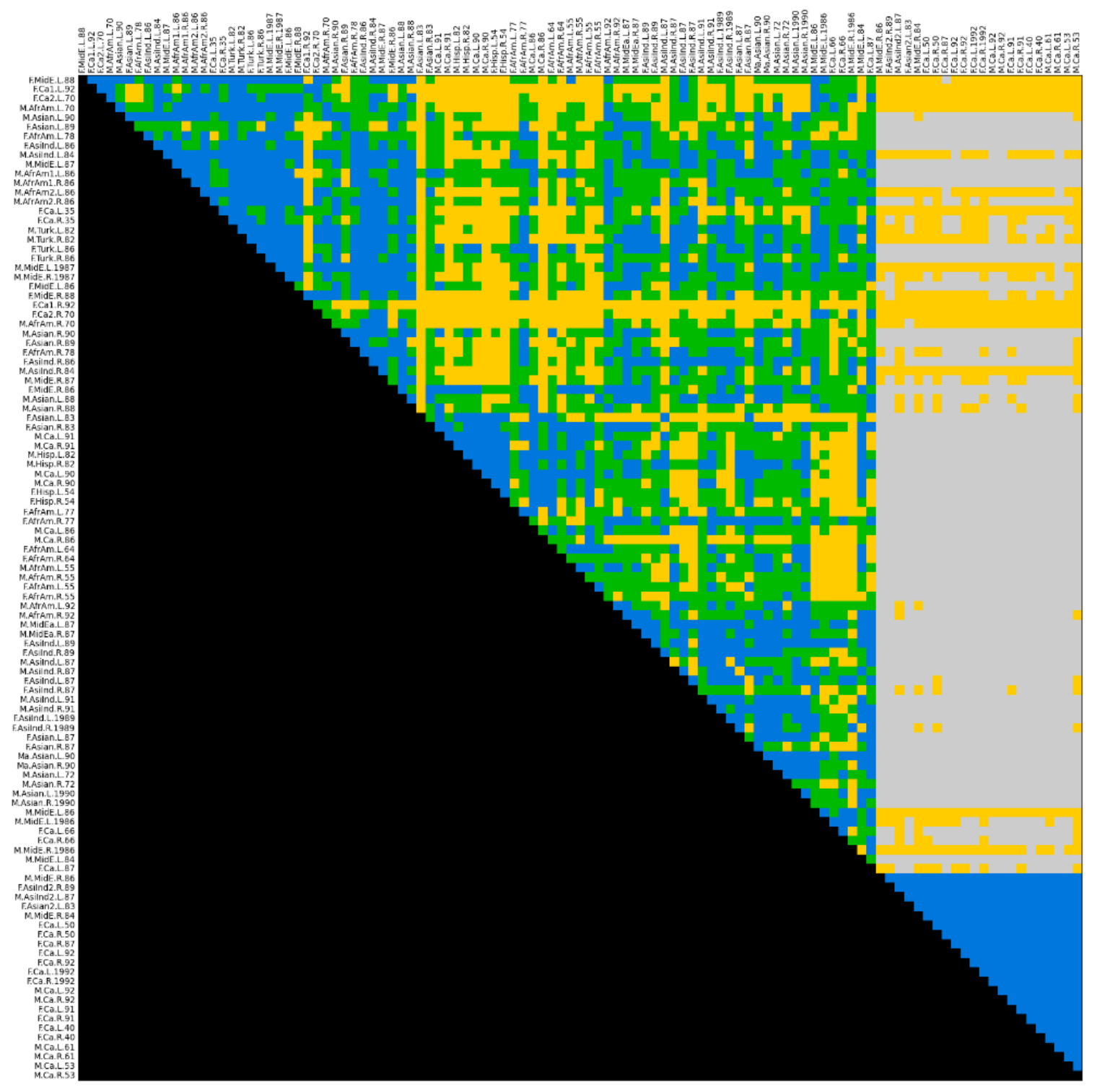

Figure 5.11: Unweighted UniFrac distance matrix from 107 samples (three samples are repeated) 


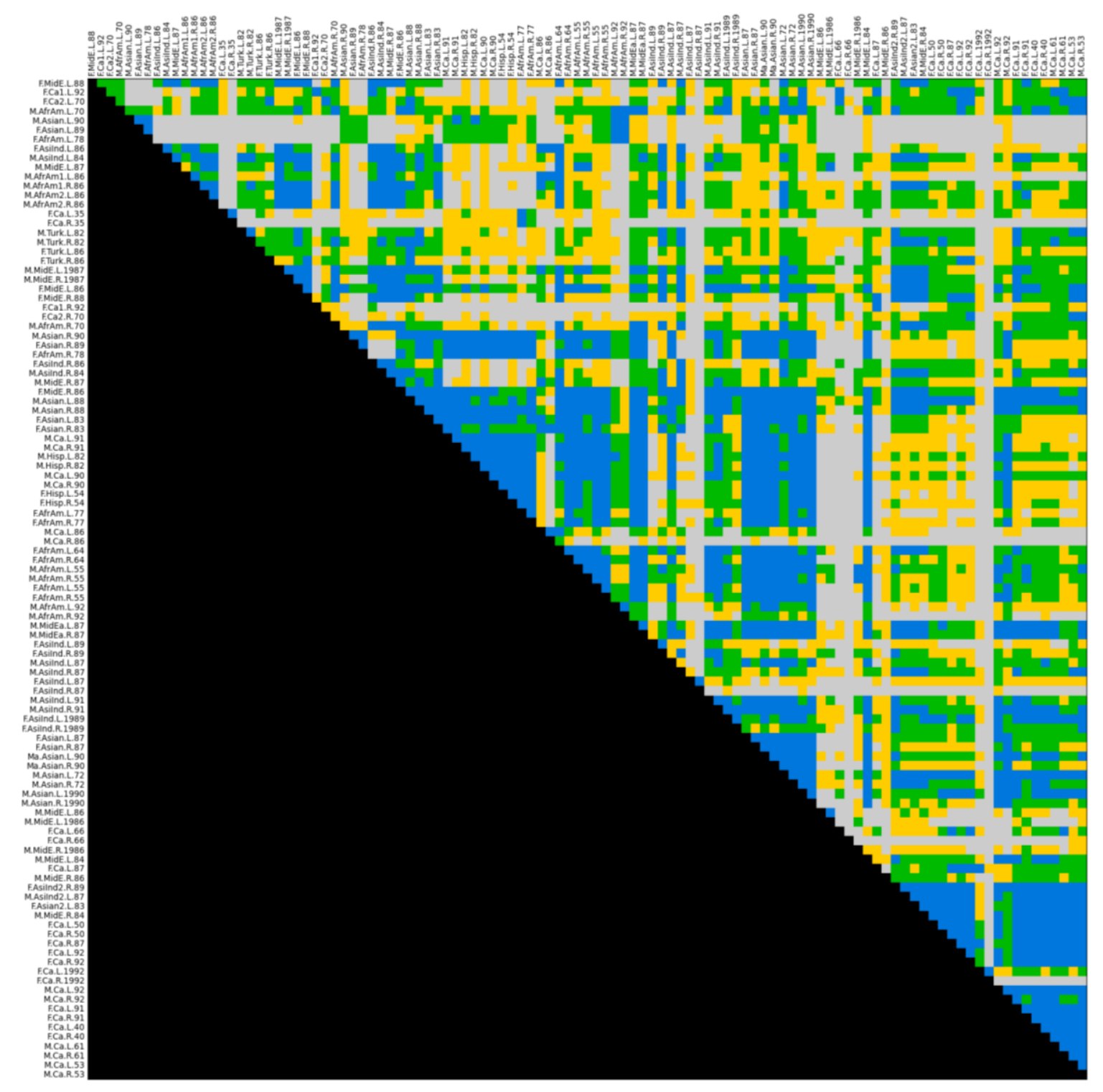

Figure 5.12: Weighted UniFrac matrix on 107 samples

The new plots based on gender and age, again, did not show any clustering. The diversity although between woman and men changed with the additional samples. Instead of a 9\% higher bacteria diversity in women than men, the difference increased to $15.7 \%$ higher diversity. 


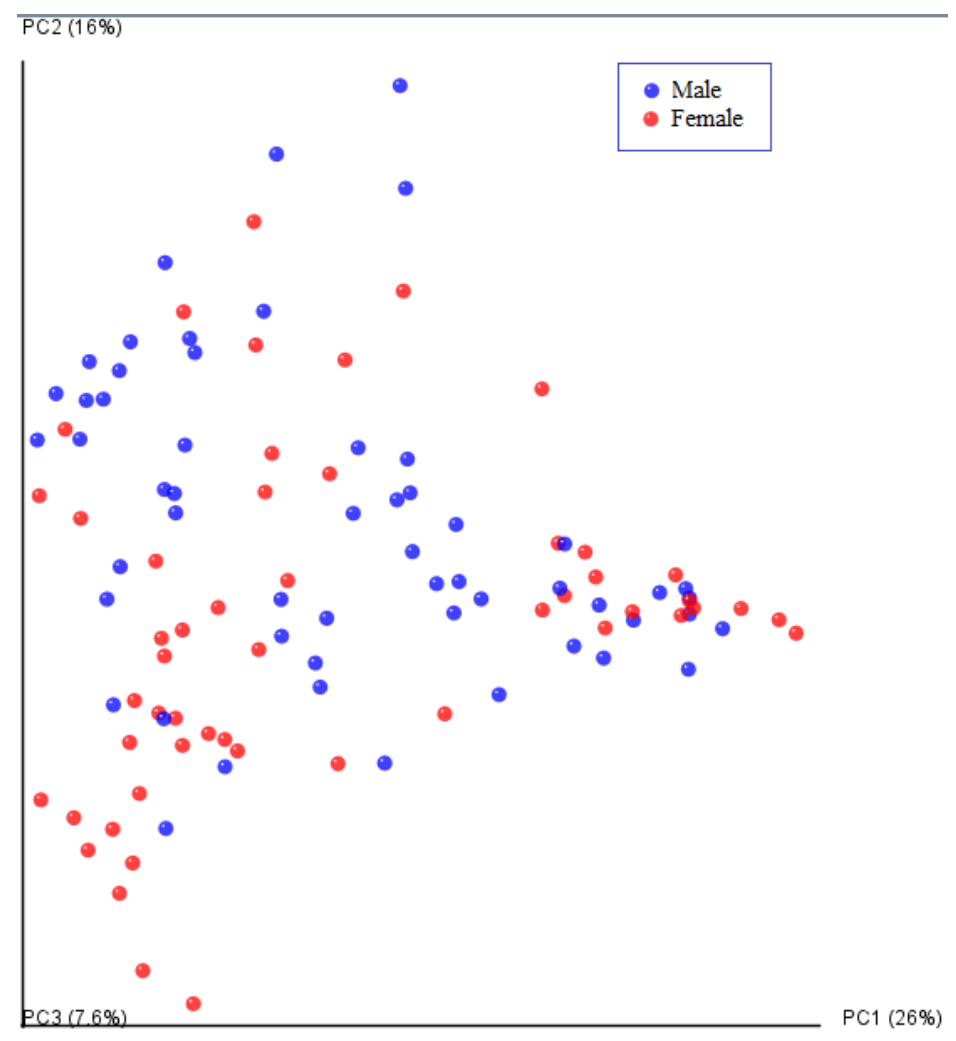

Figure 5.13: No apparent clustering based off of participant's gender

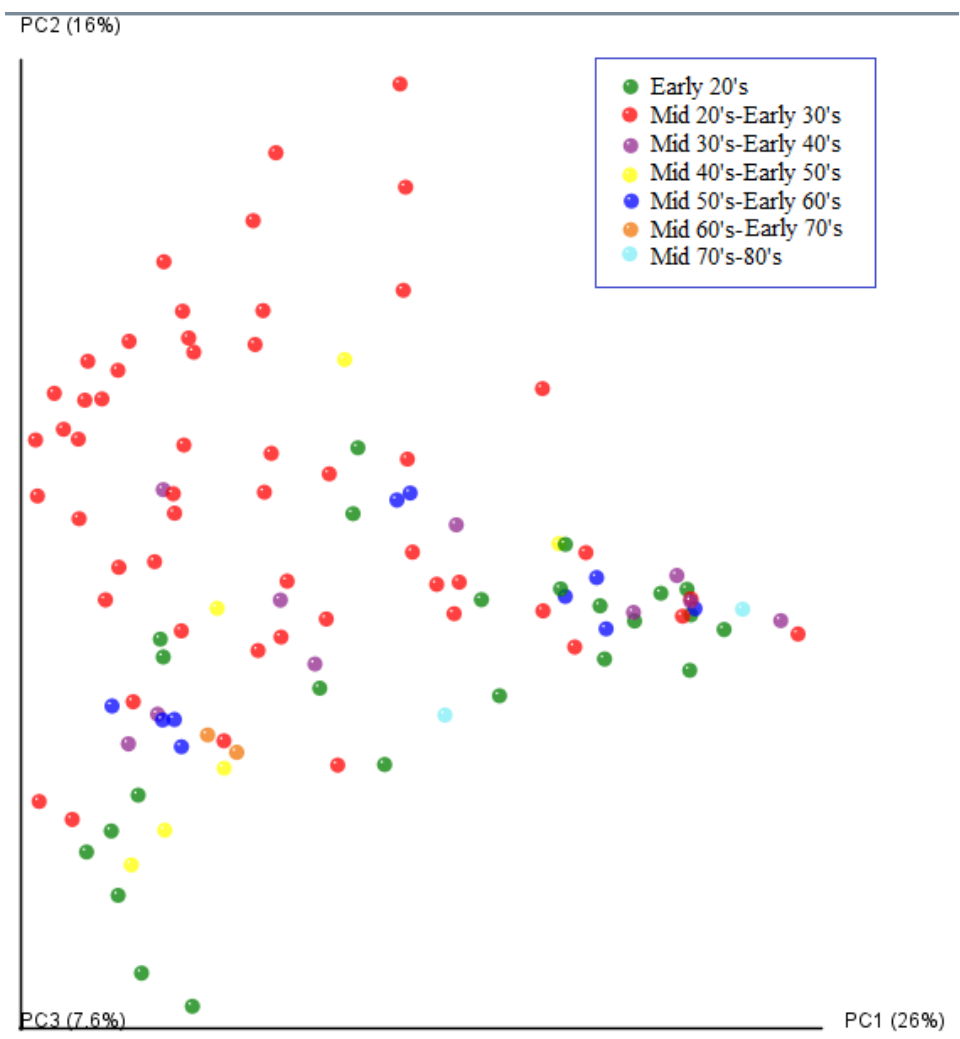

Figure 5.14: No apparent clustering based off of participant's age 
Performing the same SVM method as before, which consisted of taking the top five most common genus OTUs to classify each ethnicity, did not reveal much difference with the additional samples. To try and improve this, the top 11 most common OTUs were used to see how each ethnicity classification performed with each one. The same steps as before, with using the third degree polynomial kernel, $60 \%$ train, $40 \%$ test, and 200 iterations to calculate an average error rate, was used. Figure 5.15 and Table III display the results for each ethnicity compared to each OTU. As shown, each ethnicity group displayed a different error rate with each OTU, showing that using the most common OTU does not benefit for all groups.

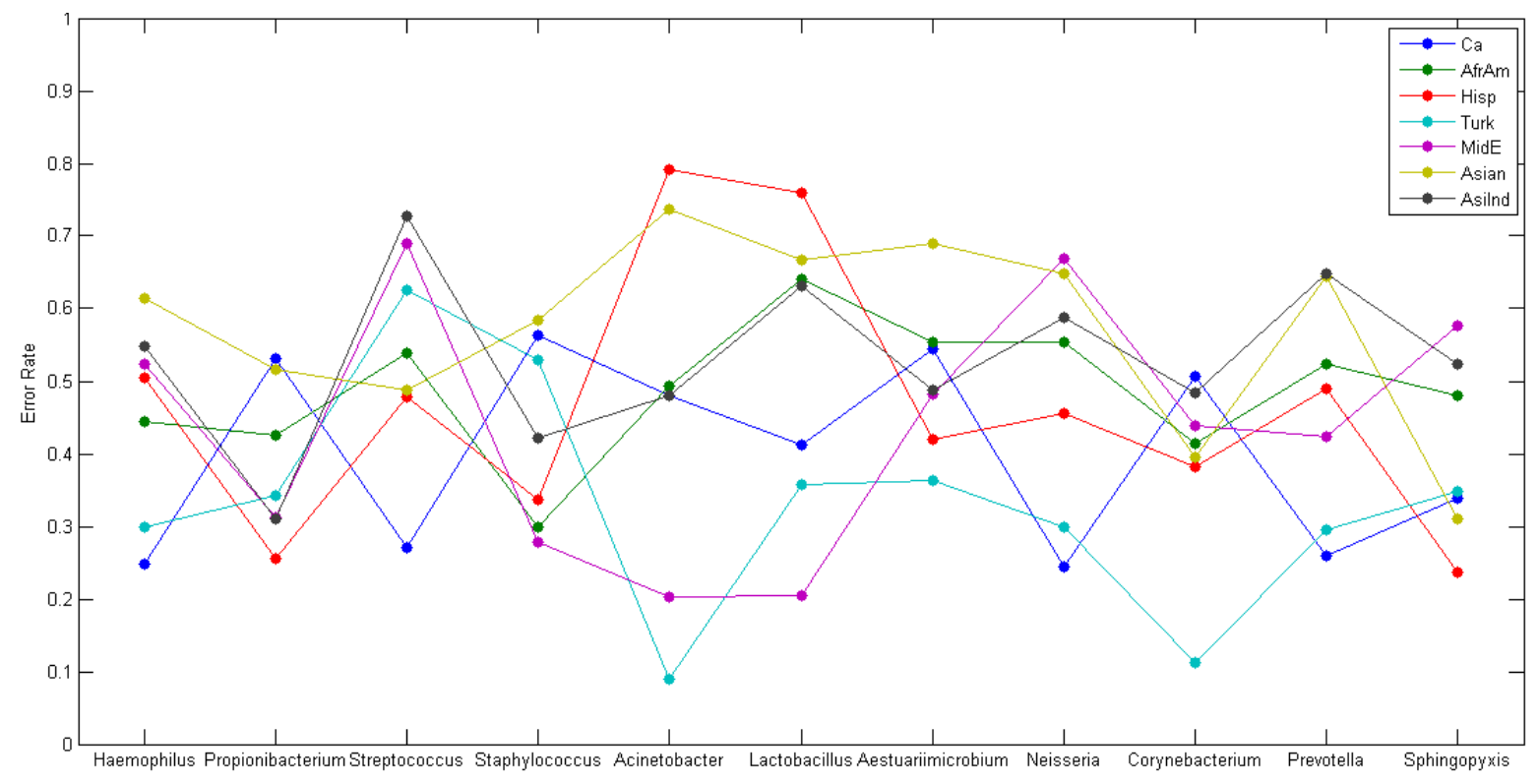

Figure 5.15: SVM error rates based off of the 11 most common OTUs found across the sample set 
Table III: SVM error rates from the visual in Figure 5.1

\begin{tabular}{|c|c|c|c|c|c|c|c|}
\hline 11 Most Common Genus OTU & Caucasian & $\begin{array}{l}\text { African } \\
\text { American }\end{array}$ & Hispanic & Turkish & $\begin{array}{l}\text { Middle } \\
\text { Eastern }\end{array}$ & Asian & $\begin{array}{l}\text { Asian } \\
\text { Indian }\end{array}$ \\
\hline Haemophilus & 0.238 & 0.452 & 0.507 & 0.295 & 0.54 & 0.629 & 0.55 \\
\hline Propionibacterium & 0.542 & 0.409 & 0.257 & 0.334 & 0.314 & 0.511 & 0.326 \\
\hline Streptococcus & 0.279 & 0.562 & 0.484 & 0.647 & 0.715 & 0.474 & 0.717 \\
\hline Staphylococcus & 0.563 & 0.305 & 0.333 & 0.542 & 0.278 & 0.585 & 0.43 \\
\hline Acinetobacter & 0.525 & 0.513 & 0.726 & 0.085 & 0.198 & 0.734 & 0.43 \\
\hline Lactobacillus & 0.406 & 0.65 & 0.781 & 0.386 & 0.208 & 0.686 & 0.686 \\
\hline Aestuariimicrobium & 0.577 & 0.565 & 0.421 & 0.361 & 0.487 & 0.692 & 0.496 \\
\hline Neisseria & 0.25 & 0.546 & 0.453 & 0.28 & 0.65 & 0.653 & 0.615 \\
\hline Corynebacterium & 0.489 & 0.43 & 0.378 & 0.118 & 0.435 & 0.398 & 0.474 \\
\hline Prevotella & 0.261 & 0.505 & 0.497 & 0.288 & 0.44 & 0.628 & 0.66 \\
\hline Sphingopyxis & 0.358 & 0.475 & 0.239 & 0.35 & 0.57 & 0.299 & 0.506 \\
\hline
\end{tabular}

Another test was to see how adding more or less features/OTUs to the SVM affected the classification rate. Table IV displays the top 5 best OTUs that resulted in the lowest rates from Table III for each ethnicity. Column 1 being the feature with the lowest/best rate, 2 being the second lowest and so on. Columns with scores equals the error rate with the previous features added in for classification. For instance column $1+2+3$ equals the top 3 lowest features used to classify that particular ethnicity. Scores in red text indicate the lowest/best rates.

Table IV: SVM error rates for top 5 best performances of each ethnicity

\begin{tabular}{|c|c|c|c|c|c|c|c|c|c|c|}
\hline & 1 & 1 & 2 & $1+2$ & 3 & $1+2+3$ & 4 & $1+2+3+4$ & 5 & $1+2+3+4+5$ \\
\hline Caucasian & Haemophilus & 0.249 & Neisseria & 0.236 & Prevotella & 0.22 & Streptococcus & 0.226 & Sphingopyxis & 0.259 \\
\hline Hispanic & Sphingopyxis & 0.243 & Propionibacterium & 0.136 & Staphylococcus & 0.111 & Corynebacterium & 0.115 & Aestuariimicrobium & 0.323 \\
\hline Turkish & Acinetobacter & 0.083 & Corynebacterium & 0.091 & Neisseria & 0.058 & Prevotella & 0.06 & Haemophilus & 0.068 \\
\hline $\begin{array}{l}\text { Middle } \\
\text { Eastern }\end{array}$ & Acinetobacter & 0.203 & Lactobacillus & 0.194 & Staphylococcus & 0.233 & Propionibacterium & 0.219 & Corynebacterium & 0.2 \\
\hline Asian & Sphingopyxis & 0.302 & Corynebacterium & 0.314 & Streptococcus & 0.346 & Propionibacterium & 0.321 & Staphylococcus & 0.281 \\
\hline $\begin{array}{l}\text { Asian } \\
\text { Indian }\end{array}$ & Propionibacterium & 0.325 & Staphylococcus & 0.296 & Acinetobacter & 0.296 & Corynebacterium & 0.245 & Aestuariimicrobium & 0.394 \\
\hline
\end{tabular}




\subsection{Conclusion}

New methods for molecular biometrics has become more desirable with the advancements in sequencing technology and bioinformatics tools. The goal of this research was to identify bacteria using the $\mathrm{V} 3$ region of the $16 \mathrm{~S}$ rRNA gene and then use these bacteria as features for identification of an individual. The results reveal that there is a difference in bacterial diversity between men and women which supports other researchers' previous finding. Although uniqueness scores were lower than what was to be expected, the results still showed that no two samples had the same bacteria profile. The results also indicated that there is some clustering between Asian, Asian Indian, Middle Eastern, Turkish and Hispanic ethnicities. This shows that these ethnicities have a higher similarity between one another than to other ethnicities that didn't show any clustering such as Caucasian and African American.

Although this research focused on a small sample set and did not include samples that were taken at different times which would allow for comparison, matching or validation. These results do provide a basis for performing identification based on bacteria found on the human hand. Again, since clustering was apparent with some of the ethnicities and there were particular bacteria that did show more prominent on certain ethnicities than others, this shows that there could be a potential relationship between the individual and their bacteria profile. With more samples from the collection that can be processed, the data set can be increased which has the potential to allow for recognizing more or better patterns. 


\section{Chapter 6: Summary \& Next Phase}


Molecular markers such as DNA, odor and human microbes are emerging as potential biometric measures that can be used in human identification. Bacteria from the human gut have shown to be more linked to a person's genetics but are not as easily obtainable for a biometric aspect. Similarly, the bacteria found in the oral cavity have shown to be more influenced by a person's genetics rather than their hygiene or diet, but swabbing bacteria from this area could be considered an invasive area. Bacteria collected from the skin have shown to be diverse and also have proven to be able to be used as a forensic tool by linking objects to the owners. With this background information, the goal was to instead use bacteria collected from the hand as an implementation for biometrics instead of forensics.

With a collection of 255 individuals equaling 510 hand bacteria swabs, a subset of this collection was used to evaluate the $\mathrm{V} 3$ region of the $16 \mathrm{~S}$ rRNA gene for skin bacteria classification. Modified procedures were used to process and prepare the bacteria samples for 150 bp paired-end multiplexed sequencing using Illumina's Miseq. With a bioinformatics pipeline including tools from BaseSpace, Mothur, Matlab R2012b, and UniFrac, founding work for evaluating hand bacteria as a biometric was established. These results showed that women had a $15.7 \%$ higher diversity of bacteria on their hands than men, that some of the most common bacteria are found to be more populated on certain ethnicities than others and that some ethnicities share a more similar hand bacteria environment to each other than compared to other ethnicities (Fig. 6.1). With further work, it is anticipated to find more markers and the right algorithms to best classify and analyze this data and make it successful as a new biometric identifier. 

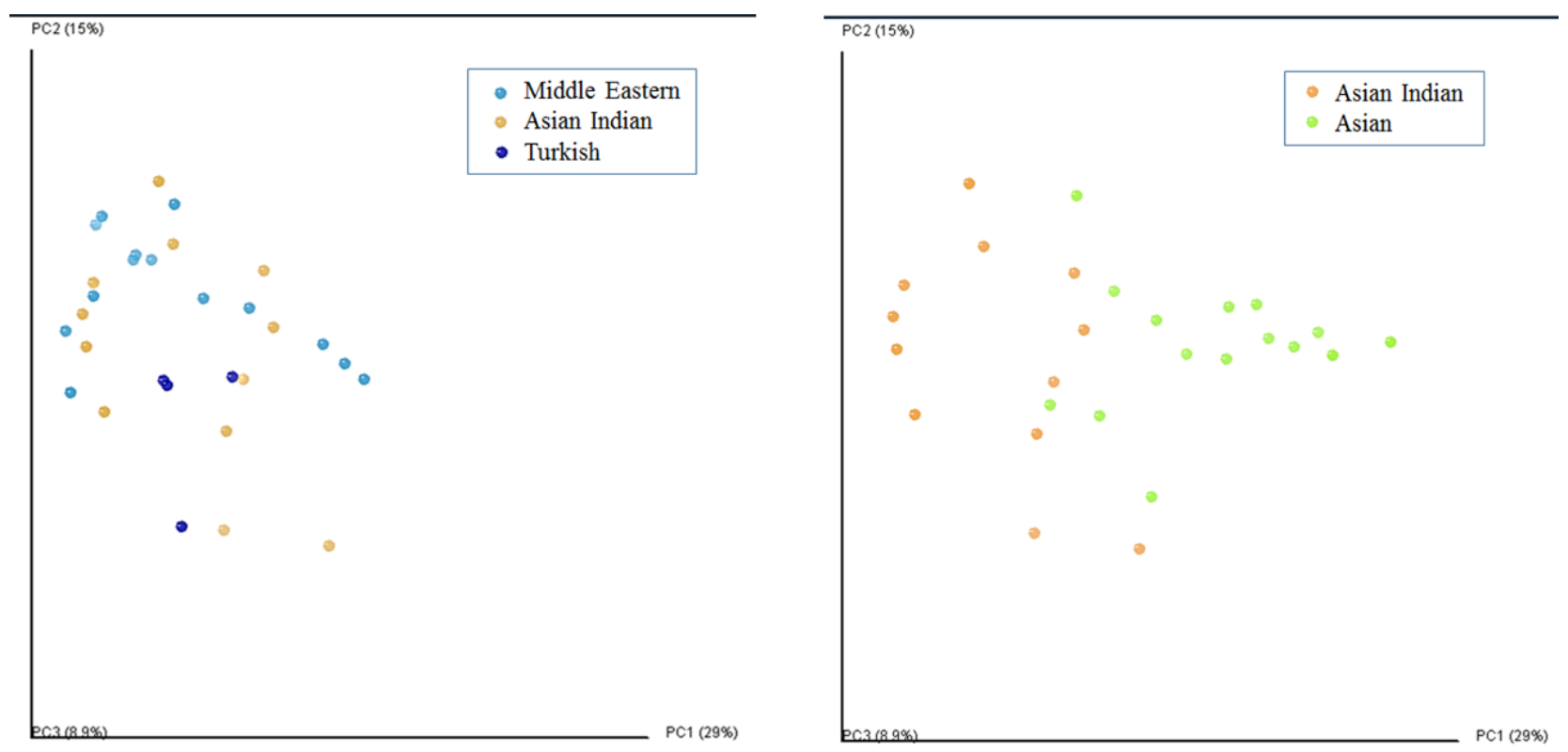

Figure 6.1: Review of clustering comparisons between some of the ethnicities.

The next step for this work it to continue processing the remaining 406 hand bacteria samples. As mentioned, the larger the database is, the better the accuracy during cross validation can be made equaling better observations and conclusions about the database and findings. This larger database would also allow for other methods of machine learning and pattern recognition to be used. An increase in size would also help make better assumptions about the medical information gathered from the participants is relevant to any of the individual's bacteria data.

Another approach is to analyze different regions of the bacteria DNA (Fig. 6.2). Since only a small part of the isolated DNA is needed for amplification, different methods and different amplification of target regions can be applied to the same sample. These target regions could be additional hypervariable regions from the 16S rRNA gene such as the V2 or V6. The V2 region ( nucleotides $137-242$ of the $16 \mathrm{~S}$ ) has been used in other studies such as the study presented in this thesis involving observations on skin bacteria between family members [22]. The V2 region, which is approximately 40 bps larger than the $\mathrm{V} 3$ region has shown to be similar in classifying bacteria 
down to the genus level like the V3 region [23]. Another region that has shown promising outcomes is the V6 region. The V6 region only consists of about 60 nucleotides $(\sim 986-1043$ of the $16 \mathrm{~S}$ ) but has shown considerable sequence variability and has been able to distinguish most bacteria species [23].
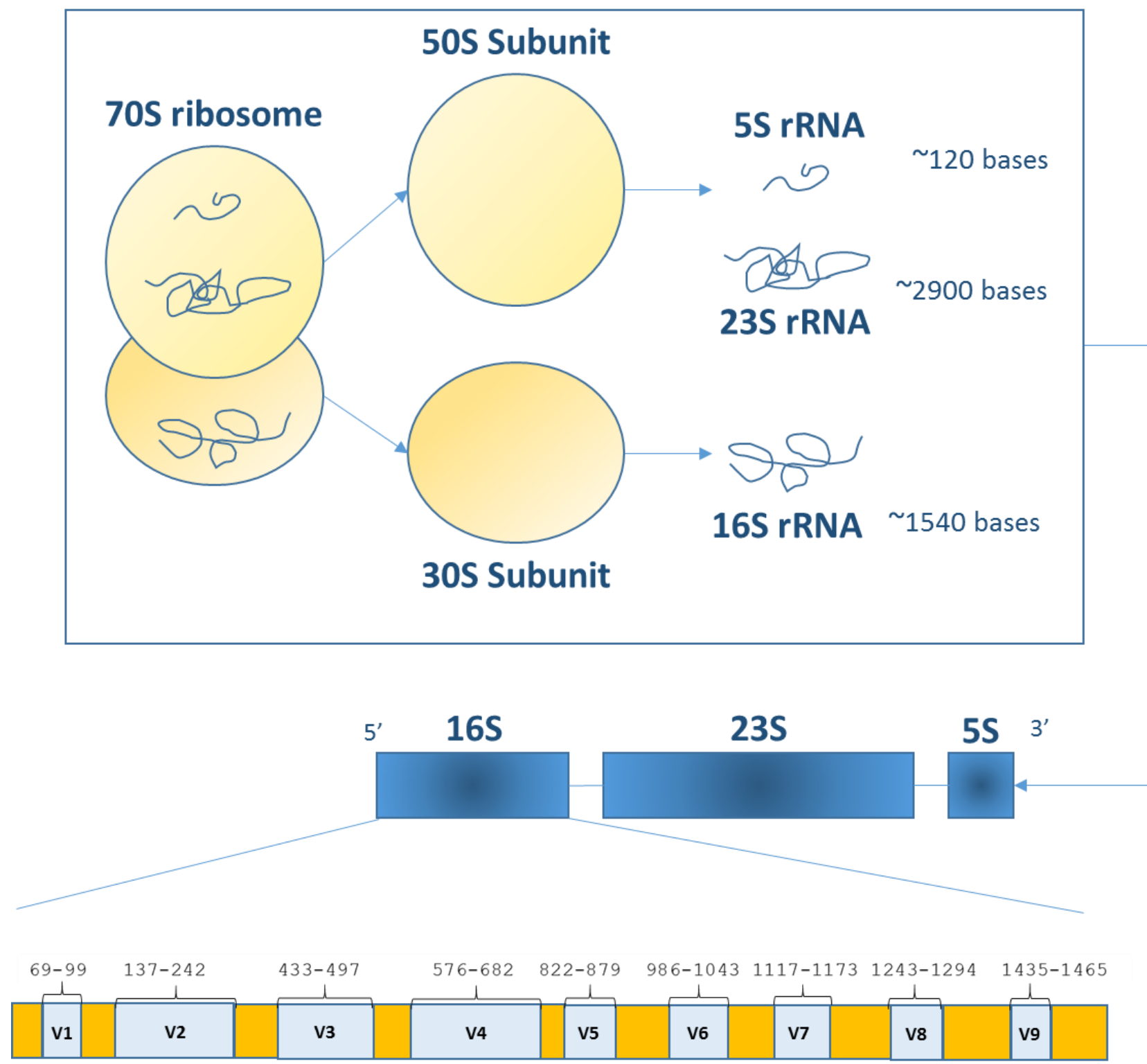

\section{Variable Regions: $\square$ Conserved Regions:}

Figure 6.2: $70 \mathrm{~S}$ broken into $16 \mathrm{~S}, 23 \mathrm{~S}$ and 5S. 16S broken down into regions. ${ }^{5}$

\footnotetext{
${ }^{5}$ Images modified from http://www.mcqbiology.com, www.alimetrics.net and www.nature.com
} 
Combining these regions or simply sequencing the whole $16 \mathrm{~S}$ rRNA would provide more DNA information. More DNA sequenced will allow for better classification of the bacteria to possibly the species and subspecies levels. This better classification would most likely increase the uniqueness scores between individuals. Although majority of current research has shown to get the best results by using the variation that is present in the $16 \mathrm{~S}$, other regions of the $70 \mathrm{~S}$ ribosome (Fig. 6.2) such as the $23 \mathrm{~S}$ and $5 \mathrm{~S}$ rRNA will also be considered for sequencing.

Additional steps will be to collect more hand bacteria swabs over time and to also recollect from the individuals who had already participated in this first collection. This recollection will hopefully help generate a gallery for examining and creating match scores between individuals. As well as collecting more samples, more information about the individuals themselves will need to be gathered such as their diet and traveling habits, along with family relationships from others who have participated in the study, and to also find any correlation between the individual's DNA that was collected from the prior blood drawing to the bacteria found on their hands. An even more detailed collection will need to be established, not only with just resampling, but to also resample at different time intervals. This could start just after hand washing, and possibly continue for 30 minute intervals after until the same baseline is discovered. Along with the time intervals, if a baseline or profile can be established for an individual than it will be necessary to find out what factors can alter or 'spoof' this profile. Potential factors could be the prior washing or an individual on antibiotics, which could greatly decrease or eliminate that bacteria profile. Other factors to analyze will be, if an individual had a substance or other compounds on their hand, would this inhibit their bacteria profile. As shown, the work presented in this thesis is very preliminary, but also provides the beginning for many more goals and paths for the future to be reached. 


\section{References}

[1] A. K. Jain, A. A. Ross and K. Nandakumar, Introduction to Biometrics, Springer, 2011, pp. $1-4$.

[2] National Science and Technology Council Subcommittee on Biometrics, "The National Biometrics Challenge," National Science and Technology Council Subcommittee, Washington D.C., 2011.

[3] K. Ricanek, "The Next Biometric Challenge: Medical Alterations," IEEE Computer Society, vol. 46, no. 9, pp. 94-96, 2013.

[4] I. S. o. A. P. Surgery, "The International Society of Aesthetic Plastic Surgery Releases," Leigh Hope Fountain, New York City, 2014.

[5] P. Griffin, Understanding the Face Image Format Standards, Gaithersburg, MD : ANSI/NIST Workshop, 2005.

[6] A. Dantcheva, C. Velardo, A. D'Angelo and J. L. Dugelay, "Bag of Soft Biometrics for Person Identification: new trends and challenges," Multimedia Tools and Applications, vol. 51, no. 2, pp. 739-777, 2010.

[7] J. Weber-Lehmann, E. Schilling, G. Gradl, D. C. Richter, J. Jens Wiehler and B. Rolf, "Finding the needle in the haystack: Differentiating "identical" twins in paternity testing and forensics by ultra-deep next generation sequencing," Forensic Science International: Genetics, vol. 9, pp. 42-46, 2014.

[8] I. Rodriguez-Lujan, G. Bailador, C. Sanchez-Avila, A. Herrero and G. Vidal-de-Miguel, "Analysis of pattern recognition and dimensionality reduction techniques for odor biometrics," Knowledge-Based Systems, vol. 52, pp. 279-289, 2013.

[9] D. N. Fredricks, "Microbial Ecology of Human Skin in Health and Disease," Journal of Investigative Dermatology Symposium Proceedings, vol. 6, pp. 167-169, 2001.

[10] N. Fierer, M. Hamady, C. L. Lauber and K. Rob, "The influence of sex, handedness, and washing on the diversity of hand surface bacteria," Proc Natl Acad Sci USA, vol. 105, no. 46, pp. 17994-17999, 2008.

[11] Consortium, The Human Microbiome Project, "Structure, function and diversity of the healthy human microbiome," Nature, vol. 486, no. 7402, pp. 207-214, 2012.

[12] N. Fierer, C. L. Lauber, N. Zhou, D. McDonald, E. K. Costello and R. Knight, "Forensic identification using skin bacterial communities," Proc Natl Acad Sci USA, vol. 107, no. 14, pp. 6477-6481, 2010. 
[13] A. M. O'Hara and F. Shanahan, "The gut flora as a forgotten organ," EMBO reports, vol. 7, no. 7, pp. 688-693, 2006.

[14] T. Yatsunenko, F. E. Rey, M. J. Manary, I. Trehan, M. G. Dominguez-Bello, M. Contreras and M. Magris, "Human gut microbiome viewed across age and geography," Nature, vol. 486, no. 7402, pp. 222-227, 2012.

[15] N. Marathe, S. Shetty, V. Lanjekar, D. Ranade and Y. Shouche, "Changes in human gut flora with age: an Indian familial study," BMC Microbiology, vol. 12, no. 1, p. 222, 2012.

[16] M. R. Mason, H. N. Nagaraja, T. Camerlengo, V. Joshi and P. S. Kumar, "Deep Sequencing Identifies Ethnicity-Specific Bacterial Signatures in the Oral Microbiome," Plos One , vol. 8, no. e77287, 2013.

[17] A. L. Cogen, V. Nizet and R. L. Gallo, "Skin microbiota: a source of disease or defence?," British Journal of Dermatology, vol. 158, no. 3, pp. 442-455, 2008.

[18] S. M. Smith, R. H. Eng and F. T. J. Padberg, "Survival of nosocomial pathogenic bacteria at ambient temperature," Journal of Medicine, vol. 27, no. 5-6, pp. 293-302, 1996.

[19] R. R. Roth and W. D. James, "Microbial Ecology of the Skin," Annu Rev Microbiol, vol. 42, pp. 441-464, 1988.

[20] C. Lozupone, M. E. Lladser, D. Knights, J. Stombaugh and R. Knight, "UniFrac: an effective distance metric for microbial community comparison," The ISME Journal, vol. 5, no. 2, pp. 169-172, 2011.

[21] C. Lozupone and R. Knight, "UniFrac: a New Phylogenetic Method for Comparing Microbial Communities," Appl Environ Microbiol, vol. 71, no. 12, p. 8228-8235, 2005.

[22] S. J. Song, C. Lauber, E. K. Costello, C. A. Lozupone, G. Humphrey, D. Berg-Lyons, J. G. Caporaso, D. Knights, J. C. Clemente, S. Nakielny, J. I. Gordon, N. Fierer and R. Knight, "Cohabiting family members share microbiota with one another and with their dogs," eLife, vol. 2, no. e00458, 2013.

[23] S. Chakravorty, D. Helb, M. Burday, N. Connell and D. Alland, "A detailed analysis of $16 \mathrm{~S}$ ribosomal RNA gene segments for the diagnosis of pathogenic bacteria," J Microbiol Methods, vol. 69, no. 2, pp. 330-339, 2007.

[24] J. Slonczewski and J. W. Forester, Microbiology: An Evolving Science, New York: W.W. Norton, 2009.

[25] J. Pevsner, "Classification of Bacteria and Archaea," in Bioinformatics and Functional Genomics 2nd Edition, Hoboken, Wiley-Blackwell, 2009, pp. 611-612. 
[26] J. M. Janda and S. L. Abbott, "16S rRNA Gene Sequencing for Bacterial Identification in the Diagnostic Laboratory: Pluses, Perils, and Pitballs," J Clin Microbiol, vol. 45, no. 9, pp. 2761-2764, 2007.

[27] R. Padmanabhan and R. Wu, "Use of oligonucleotides of defined sequences as primers in DNA sequence analysis," Biochemical and Biophysical Research, vol. 48, pp. 1295-1302, 1972.

[28] L. Liu, Y. Li, S. Li, N. Hu, Y. He, R. Pong, D. Lin, L. Lu, M. Law and Maggie, "Comparison of Next-Generation Sequencing Systems," Journal of Biomedicine and Biotechnology, vol. 2012, pp. 1-11, 2012.

[29] J. P. McCutcheon and C. D. von Dohlen, "An interdependent metabolic patchwork in the nested symbiosis of mealybugs," Curr. Biol, vol. 21, no. 16, pp. 1366-1372, 2011.

[30] Y.-j. Chang, M. Land and A. Lapidus, "Non-contiguous finished genome sequence and contextual data of the filamentous soil bacterium Ktedonobacter racemifer type strain (SOSP1-21T)," Stand Genomic Sci, vol. 5, no. 1, pp. 97-111, 2011.

[31] P. A. Carr and G. M. Church, "Genome engineering," Nature Biotechnology, vol. 27, pp. 1151-1162, 2009.

[32] E. R. Mardis, "Next-Generation DNA Sequencing Methods," Annual Review of Genomics and Human Genetics, vol. 9, pp. 387-402, 2008.

[33] M. J. Claesson, Q. Wang, O. O'Sullivan, R. Greene-Diniz, J. R. Cole, R. P. Ross and P. W. O'Toole, "Comparison of two next-generation sequencing technologies for resolving highly complex microbiota composition using tandem variable 16S rRNA gene regions," Nucleic Acids Research, vol. 38, no. 22, p. e200, 2010.

[34] "Illumina's Systems MiSeq Desktop Sequencer," Illumina Inc, 2014. [Online]. Available: http://www.illumina.com/systems/miseq.ilmn.

[35] Q. Wang, G. M. Garrity, J. M. Tiedje and J. R. Cole, "Naive Bayesian Classifier for Rapid Assignment of rRNA Sequences into the New Bacterial Taxonomy," Applied and Environmental Microbiology, vol. 73, no. 16, pp. 5261-5267, 2007.

[36] "BaseSpace ${ }^{\mathrm{TM}}$ : Getting Started," Illumina BaseSpace ${ }^{\mathrm{TM}}$ Developers, [Online]. Available: http://developer.basespace.illumina.com/docs/content/documentation/gettingstarted/overview.

[37] Rhode Island Genomics and Sequencing Center, "Next Generation Sequencing University of Rhode Island," College of the Environment and Life Sciences, 2014. [Online]. Available: http://web.uri.edu/gsc/next-generation-sequencing/. 
[38] P. D. Schloss, S. L. Westcott, T. Ryabin, J. R. Hall, R. Hartmann, E. B. Hollister, R. A. Lesniewski, B. B. Oakley and D. H. Parks, "Introducing mothur: Open-source, platformindependent, community-supported software for describing and comparing microbial communities," Appl Environ Microbiol, vol. 75, no. 23, pp. 7537-7541, 2009.

[39] R. Whittaker, "Vegetation of the Siskiyou Mountains, Oregon and California," Ecological Monographs, vol. 30, pp. 279-338, 1960.

[40] C. Lozupone, M. Hamady and R. Knight, "Unifrac - An online tool for comparing microbial community diversity in a phylogenetic context," BMC Bioinformatics, vol. 7, no. 371, 2006.

[41] M. Hamady, C. Lozupone and R. Knight, "Fast Unifrac: faciliating high-throughput phylogenetic analyses of microbial communities including analysis of pyrosequencing and PhyloChip data," The ISME Journal, vol. 4, no. 1, pp. 17-27, 2009.

[42] V. Kecman, Learning and Soft Computing, Cambridge, MA: MIT Press, 2001.

[43] L. C. Paulino, C.-H. Tseng, B. E. Strober and M. J. Blaser, "Molecular Analysis of Fungal Microbiota in Samples from Healthy Human Skin and Psoriatic Lesions," J Clin Micobiol, vol. 44, no. 8, pp. 2933-2941, 2006.

[44] MO BIO Laboratories Inc, "UltraClean® Plant DNA Isolation Kit, Instruction Manual," MO BIO Laboratories, Inc, [Online]. Available: http://www.mobio.com/images/custom/file/protocol/13000.pdf.

[45] D. F. Swinehart, "The Beer-Lambert Law," Journal of Chemical Education, vol. 39, no. 7 , p. 333, 1962.

[46] G. C. Baker, J. J. Smith and D. A. Cowan, "Review and re-analysis of domain-specific 16S primers," Journal of Microbial Methods, vol. 55, no. 3, pp. 541-555, 2003.

[47] G. Muyzer, E. C. De Waal and A. G. Uitterlinden, "Profiling of Complex Microbial Populations by Denaturing Gradient Gel Electrophoresis Analysis of Polymerase Chain Reaction-Amplified Genes Coding for 16S rRNA," Applied and Environmental Microbiology, vol. 59, no. 3, pp. 695-700, 1993.

[48] A. K. Bartram, M. D. Lynch, J. C. Stearns, G. Moreno-Hagelsieb and J. D. Neufeld, "Generation of Multimillion-Sequence 16S rRNA Gene Libraries from Complex Microbial Communities by Assembling Paired-End Illumina Reads," Appl Environ Microbial, vol. 77, no. 15, p. 5569, 2011.

[49] S. B. Needleman and C. D. Wunsch, "A general method applicable to the search for similarities in the amino acid sequence of two proteins," Journal of Molecular Biology, vol. 48, no. 3, pp. 443-453, 1970. 
[50] J. Evans, S. L. Foster and J. A. Foster, "Relaxed Neighbor-Joining: A Fast Distance-Based Phylogenetic Tree Construction Method," J Mol Evol, vol. 62, no. 6, pp. 785-792, 2006.

[51] R. C. Edge, "Search and clustering orders of magnitude faster than BLAST," Bioinformatics, vol. 26, no. 19, pp. 2460-2461, 2010.

[52] J. G. Caporaso, J. Kuczynski, J. Stombaugh and K. Bittinger, "QIIME allows analysis of high-throughput community sequencing data," Nat Methods, vol. 7, no. 5, p. 335-336, 2010.

[53] J. Oksanen, F. G. Blanchet, R. Kindt, P. Legendre, R. B. O'Hara and G. L. Simpson, "Package 'vegan'," 2011. [Online]. Available: http://CRAN.R-project.org/package=vegan.

[54] Illumina, "16S Metagenomic Sequencing Library Preparation," 27 November 2013. [Online]. Available:

http://support.illumina.com/downloads/16s_metagenomic_sequencing_library_preparation .ilmn.

[55] V. Ki and C. Rotstein, "Bacterial skin and soft tissue infections in adults: A review of their epidemiology, pathogenesis, diagnosis, treatment and site of care," Can J Infect Dis Med Microbial, vol. 19, no. 2, pp. 173-184, 2008.

[56] J. N. Lundstrom and M. J. Olsson, "Functional Neuronal Processing of Human Body Odors," Vitam Horm, vol. 83, pp. 1-23, 2010.

[57] IBI Scientific, "Gel/PCR DNA Fragments Extraction Kit," IBI Scientific, 2014. [Online]. Available: https://www.ibisci.com/images/IB47010IB47020IB47030Protocol.pdf.

[58] M. Wenner, "Humans Carry More Bacterial Cells than Human Ones," Scientific American, 2007.

[59] Homeland Security, "New biometric identifier: hand bacteria," 16 March 2010. [Online]. Available: http://www.homelandsecuritynewswire.com/new-biometric-identifier-handbacteria.

[60] R. L. Gallo and T. Nakatsuji, "Microbial Symbiosis with the Innate Immune Defense System of the Skin," J Invest Dermatol, vol. 131, no. 10, pp. 1974-1980, 2011. 
Appendix A: Consent Form 


\title{
WestVirginiaUniversity. \\ Office of Research Compliance \\ CONSENT AND INFORMATION FORM
}

\author{
DNA_FaceFeatures ICF \\ Principal Investigator: Dawson, Jeremy \\ Department: ENGINEERING - Lane Dept. of Comp. Sci. \& Elec. Sign. \\ Tracking Number: $\quad \mathrm{H}-23693$
}

\section{Study Title:}

Human DNA and Facial Features

\section{Co-Investigator(s):}

Dawson, Jeremy; Ross, Arun; Adjeroh, Donald; Sooter, Letha; Duncan, Adam; Rice, Kelly.

\section{Sponsor}

US Department of Justice/Office of Justice Programs/National Institute of Justice

\section{Contact Persons}

In the event you experience any side effects or injury related to this research, you should contact Dr.Jeremy Dawson at 304/293-4028.

If you have any questions, concerns, or complaints about this research, you can contact Dr. Arun Ross at 304/293-9135 or Dr. Donald Adjeroh at 304/293-9681.

For information regarding your rights as a research subject, you may contact the Office of Research Compliance at 304/293-7073.

\section{Introduction}

In addition if you would like to discuss problems, concerns, have suggestions related to research, or would like to offer input about the research, contact the Office of Research Integrity and Compliance at 304293-7073.

\begin{tabular}{lll}
\hline Tracking \#. & $\mathrm{H}-23693$ & Page 1 of 7 \\
Approved On: & $03 / 27 / 2013$ & \\
Valid Through: & $03 / 26 / 2014$ & \\
Last Amended: & N/A &
\end{tabular}

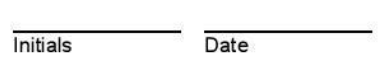


Tracking \#. $\quad$ H-23693

You, have been asked to participate in this research study, which has been explained to you by This study is being conducted by

Jeremy Dawson, PhD, Arun Ross, PhD, Donald Adjeroh, PhD, in the Department of Computer Science and Electrical Engineering at West Virginia University and Letha Sooter, PhD in the Basic Pharmaceutical Sciences at West Virginia University with funding provided by US Department of Justice/Office of Justice Programs/National Institute of Justice.

\section{Purposes of the Study}

There are two goals for our research: 1 ) to determine if we can get information from your blood sample that will allow us to develop a picture of your face based on your unique DNA signature, and 2) to see if we can relate your uniqueness and health to bacteria that live on your hands. WVU expects to collect data from approximately 200 subjects. Your personal health and DNA information will not be shared with anyone other than our research group.

\section{Description of Procedures}

After you arrive at the laboratory for your scheduled appointment, you will be asked to read carefully and sign the consent and information form. If you understand the study and agree to participate, our staff will accompany you to a computer for registration. Here, you will be given a random identification number associated with your biometric data. We will also ask simple questions about your age, physical appearance, and health issues (for examples, illness) that you may have.You may choose not to provide this information. The only link between your name and the other information you provide is the random identification number you are given at the registration area. We will collect a bacterial sample from your hand using a moistened cotton swab. The cotton tip of the swab will be cut off and processed later. You will be then be asked to stand in front of a commercial digital camera that will take your picture from up to five different angles: front, 45, $-45,90$, and -90 degrees profiles. A staff member will assist you in positioning for the various pose angles. Next, a staff member trained in collecting blood will obtain blood sample from your

\begin{tabular}{lll}
\hline Tracking \#. & $\mathrm{H}-23693$ & Page 2 of 7 \\
Approved On: & $03 / 27 / 2013$ & \\
Valid Through: & $03 / 26 / 2014$ & \\
Last Amended: & $\mathrm{N} / \mathrm{A}$ &
\end{tabular}

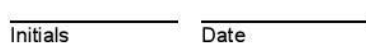


Tracking \#: $\quad$ H-23693

arm using a needle.. We will collect approximately 2 teaspoons of blood. The sample will be labeled with your randomly generated number.

\section{Risks and Discomforts}

You will face risks that are commonly associated with drawing blood for blood test analysis a hospital or clinic. Risks include slight discomfort where needle was inserted, bruising, swelling around the puncture site, fainting or feeling light-headed, and hematoma (blood accumulating under skin). If you faint, a cot and juice will be provided. Juice is used to provide you with sugar quickly. If this happens, you will be asked to lie down for at least 1520 minutes. In very rare cases, you may experience excessive bleeding. If this happens, the staff member who drew the blood will apply pressure to the needle stick site. You will not be released until the bleeding has stopped. If you are injured as a result of this research, treatment will be available. Responsibility for this treatment will be borne by you.

Compensation for your injuries will not be provided voluntarily by the investigator, sponsor, West Virginia University or other associated affiliates. We will explain to you that images of your face can potentially be used to identify you. You may decide not to participate in any process related to this data collection any time prior or during the data collection session.

\section{Alternatives}

You do not have to participate in this study.

The alternative is not to participate.

\section{Benefits}

If successful, this project will allow the development of methods through which human DNA and bacteria colonies can be used as a unique way to identify a person. You will gain an understanding of current research being conducted to investigate the relationship between hand bacteria and your health. You will have the personal satisfaction of having contributed to the betterment of society's health.

\section{Financial Considerations}

\begin{tabular}{lllll}
\hline Tracking \#. & $\mathrm{H}-23693$ & Page 3 of 7 & \\
Approved On: & $03 / 27 / 2013$ & & & Date \\
Valid Through: & $03 / 26 / 2014$ & & \\
Last Amended: & N/A & &
\end{tabular}


Tracking \#: H-23693

You will be paid with $\$ 40$ for participating in this study at the end of the data collection session.

\section{Confidentiality}

All information about you obtained as a result of your participation in the study will be kept as confidential as legally possible. Your biometric data is labeled with the generated random identification number. The face images, the sequenced bacterial DNA and your answers to the questionnaire are stored on external drives locked in a file cabinet in a safe place (ESB, room 175). Computers used to collect the data, including your personal health information, are password protected, and always in site of the data collection staff, and only key personnel have access to login.

We are collaborating with Marshall University and Knome Inc. to extract useful information from the DNA and bacteria samples you provide. The part of your DNA contain information about your facial features will only be available to our research group via a secure online connection. Your consent form will be locked in a filing cabinet. The blood and bacteria samples you provide will be kept in a locked freezer until transported (in a tamper evident shipping container) for analysis by our collaborators. Your data will not be shared with any other person, research group, organization or institution.

Your research records and test results, just like hospital records, may be subpoenaed by court order or may be inspected by the study sponsor or federal regulatory authorities (including the FDA if applicable) without your additional consent. In addition, there are certain instances where the researcher is legally required to give information to the appropriate authorities. These would include mandatory reporting of infectious diseases, mandatory reporting of information about behavior that is imminently dangerous to you or to others, such as suicide, child abuse, etc. In any publications that result from this research, neither your name nor any information from which you might be identified will be published without your consent. We know that information about you and your health is private. We are dedicated to protecting the privacy of that information. Because of this promise, we must get your written authorization (permission) before we may use or disclose your protected health information or share it with others for research purposes.

You can decide to sign or not to sign this authorization section. However, if you choose not to sign this authorization, you will not be able to take part

\begin{tabular}{lllll}
\hline Tracking \#: & $\mathrm{H}-23693$ & Page 4 of 7 & \\
Approved On: & $03 / 27 / 2013$ & & & \\
Valid Through: & $03 / 26 / 2014$ & & \\
Last Amended: & $\mathrm{N} / \mathrm{A}$ & &
\end{tabular}


Tracking \#: $\quad \mathrm{H}-23693$

in the research study. Whatever choice you make about this research study, it will not have an effect on your access to medical care.

Persons/Organizations providing the information: Patient/West Virginia

University Hospitals

Persons/Organizations receiving the information:

The research site(s) carrying out this study. This includes:

UHA or UHA Affiliated, WVU, WVU Hospitals.

Each site's research staff and medical staff and laboratories and other

people and groups that look into your health information as part of this study in agreement with the study protocol.

The United States Department of Health and Human Services (which includes the National Institutes of Health, Food and Drug Administration (FDA)) and other groups that have the right to use the information as required by law.

Department of Justice and the people and companies that they use to oversee, manage, or conduct the research.

The members and staff of any Institutional Review Board (IRB) that oversees this research study

West Virginia University Office of Research Compliance and Office of Sponsored Programs.

The following information will be used:

Information about you that is created or collected during the study such as: health history and demographic data

The information is being disclosed for the following reasons:

Review of your data for quality assurance purposes

Publication of study results (without identifying you)

Other research purposes such as developing a better understanding of

disease indicators

You may cancel this authorization at any time by writing to the Principal Investigator:

Jeremy M. Dawson, PhD. PO Box 6109 Morgantown, WV 26506-6109

If you cancel this authorization, any information that was collected already for this study cannot be withdrawn. Once information is disclosed, according to this authorization the recipient may redisclose it and then the information may no longer be protected by federal privacy regulations. This authorization will not expire unless you cancel it.

\section{Voluntary Participation}

\begin{tabular}{lllll}
\hline Tracking \#. & $\mathrm{H}-23693$ & Page 5 of 7 & & \\
Approved On: & $03 / 27 / 2013$ & & & Date \\
Valid Through: & $03 / 26 / 2014$ & & & \\
Last Amended: & $\mathrm{N} / \mathrm{A}$ & & &
\end{tabular}


Tracking \#. $\quad \mathrm{H}-23693$

Participation in this study is voluntary. You are free to withdraw your consent to participate in this study any time prior or during the data collection session. Refusal to participate or withdrawal will involve no penalty to you. In the event new information becomes available that may affect your willingness to participate in this study, this information will be given to you so that you can make an informed decision about whether or not to continue your participation. You have been given the opportunity to ask questions about the research, and you have received answers concerning areas you did not understand.

We will have other biometric data collections in the future. Please let us know if you want to be contacted for future studies.

Yes No If you agree, please provide the method of contact that is convenient for you.

Email

Telephone

Participant's signature

The results of the research may be published and biometric data, including the picture of your face, may be included in the publications. By signing below you agree, that your biometric data may be used in future publications that may include but are not limited to, research papers, journal articles, presentations, educational material or other related documents.

Yes__ No

Participant's signature

I received a _ and Participant's signature credit card for participating in this project.

\begin{tabular}{lll}
\hline Tracking \#. & $\mathrm{H}-23693$ & Page 6 of 7 \\
Approved On: & $03 / 27 / 2013$ & \\
Valid Through: & $03 / 26 / 2014$ & \\
Last Amended: & $\mathrm{N} / \mathrm{A}$ &
\end{tabular}


Upon signing this form, you will receive a copy.

I willingly consent to participate in this research.

Signature of Subject or

Printed Name

Date

Time

Subjects Legal Representative

The participant has had the opportunity to have questions addressed. The participant willingly agrees to be in the study.

Signature of Investigator or

Co-Investigator
Printed Name

Date
Time
Tracking \#. $\quad \mathrm{H}-23693$

Approved On: $\quad$ 03/27/2013

Valid Through: $\quad$ 03/26/2014

Last Amended:
Page 7 of 7

$\overline{\text { Initials }} \overline{\text { Date }}$ 


\section{Appendix B: Medical History Form}




\section{Overview}

\section{General Health History}

Medication History

Hand Information

Personal Disease History

Personal\&Family Medical History

\section{Sheet 1: General Health History}

Are you presently sick or ill?

Yes/No

If yes, with what illness?

If yes, who made the diagnosis?

Medical professional/self/other

Were you sick or ill within the past week?

Yes/No

If yes, with what illness?

If yes, who made the diagnosis?

Medical professional/self/other

Were you sick or ill within the past two weeks? 
Yes/No

If yes, with what illness?

If yes, who made the diagnosis?

Medical professional/self/other

Were you sick or ill within the past month?

Yes/No

If yes, with what illness?

If yes, who made the diagnosis?

Medical professional/self/other

List Allergies (food, medication, environmental, any) 


\section{Sheet 2: Medication History}

Medications taken today (prescription and non-prescription)

Medications taken within the past week (prescription and non-prescription, not listed above)

Medications taken within the past month (prescription and non-prescription, not listed above)

Medications taken within the past year (prescription and non-prescription, not listed above)

\section{Sheet 3: Hand Information}

$\begin{array}{llll}\text { Hand Information } & \begin{array}{l}\text { Self } \\ \text { (Today) }\end{array} & \begin{array}{l}\text { Self (Within the } \\ \text { Past Week) }\end{array} & \begin{array}{l}\text { Self (Within the Past Self (Within the } \\ \text { Month) }\end{array}\end{array}$


Dry Skin

Oily Skin

Soap (regular)

Soap (anti-bacterial)

Hand Sanitizer (any)

Cream (regular)

Cream (anti-bacterial, such as Polysporin or Neosporin)

Topical Medication (prescription)

Topical Medication (non-prescription, not listed above)

\section{Sheet 4: Personal Disease History}

\section{Medical Condition}

$\begin{array}{llll}\text { Self } & \text { Self } & \text { Self } \\ \text { (Today } & \text { (Within } & \text { (Within } & \text { Self } \\ \text { ) } & \text { the Past } & \text { the Past } & \text { (Past) } \\ & \text { Week) } & \text { Month) } & \end{array}$

AIDS

Chicken Pox

Cholera

Cold Sores

Dermatitis 
Eye Stye

Fleas

Gonorrhea

Hepatitis

Herpes (Simplex)

Herpes Zoster Ophthalmicus (HZO)

HIV

Leishmaniasis

Leprosy

Lice (genital)

Lice (head)

Lyme Disease

Lymphangitis

Malaria

Measles

Mycobacterium Infection

Poison Ivy

Pseudomonas Aeruginosa Infection

Rocky Mountain Spotted Fever

Rubella

Shingles

Skin Boil 
Skin Infection

Skin Ulcer

Small Pox

Staphylococcus infection

Streptococcus infection

Sunburn

Syphilis

Tuberculosis

Warts (Human Papillomavirus, genital)

Warts (Human Papillomavirus, non-genital)

Yeast Infection (Candidiasis, genital)

Yeast Infection (Candidiasis, non-genital)

\section{Sheet 5: Personal\&Family Medical History}

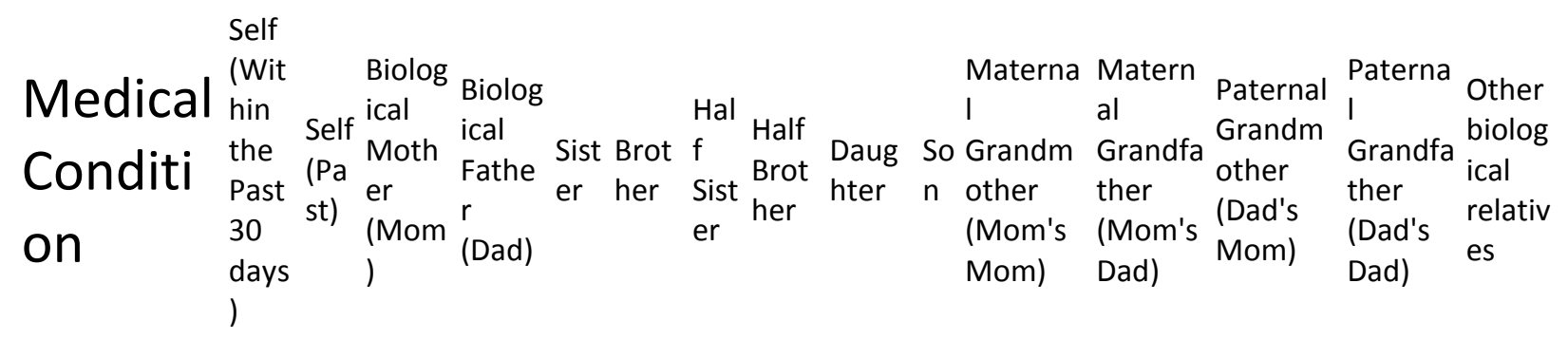

Acid Reflux

Disease

(GERD)

Acne 
Albinism

Alcohol Use

(once a week

or less)

Alcoholism

Allergies

(Food)

Allergies,

Medicine

Alzheimer's

Disease

Anemia

Anesthesia

Problem

Anorexia

Anxiety

Arthritis (any)

Arthritis

(Osteoarthritis

)

Arthritis

(Rheumatoid)

Asthma

Attention

Deficit

Disorder

(ADD)

Attention

Deficit

Hyperactivity

Disorder 
(ADHD)

Autism

Autoimmune

Disorder

Behcet's

Syndrome

Bipolar

Disorder

(Manic

Depressive

Illness)

Birth Defects

(any)

Bleeding

Disorder

(hemophilia)

Blood Clot

(brain, stroke)

Blood Clot

(leg)

Blood Clot

(lung)

Bulimia

Caffeine

Addiction

Caffeine Use (once a week or less)

Cancer (any)

Cancer, Breast 
Cancer, Colon

Cancer, Lung

Cancer,

Melanoma

Cancer, Ovary

Cancer,

Prostate

Cancer, Skin

(except

melanoma)

Cataracts

Cerebral Palsy

Chemical

Dependency

(any)

Cigarette

Addiction

Cigarette Use (once a week or less)

Cleft lip

Cleft palate

Clotting

Disorder

Colon Polyp

Congenital

Heart Disease

Convulsions 
Coronary

Artery Disease

(narrowing/ha

rdening of

heart blood

vessels)

Cystic Fibrosis

Dementia

Depression

Diabetes (any)

Diabetes,

Type 1

(typically

childhood

onset)

Diabetes,

Type 2

(typically adult

onset)

Dissociative

Identity

Disorder

(MPD, DID)

Down's

syndrome

Dwarfism

Eczema

Emphysema

Eyes, Far

Sighted

Eyes, Near

Sighted 
Gallbladder

Disease

Glaucoma

Gout

Handedness,

Left

Handedness,

Right

Hay fever

(Allergic

Rhinitis)

Hearing

Problems

Heart Attack

(Myocardial

Infarction)

Heart Failure

Hernia

High Blood

Pressure

(Hypertension

)

High

Cholesterol

(Hyperlipidem

ia)

Hormone

disorder

Huntington

Disease

Illegal Drug

Addiction 


\author{
Illegal Drug \\ Use (once a \\ week or less) \\ Infertility \\ Insomnia \\ Intestinal \\ Ulcer \\ Irritable Bowel \\ Syndrome \\ Kidney \\ Disease \\ Learning \\ Disability \\ Liver Disease \\ Lou Gehrig's \\ disease (ALS) \\ Lupus \\ (Systemic \\ Lupus \\ Erythematosis \\ ) \\ Mental \\ retardation \\ Migraine \\ headaches \\ Mitral Valve \\ Prolapse \\ Multiple \\ Sclerosis \\ Muscular \\ Dystrophy
}


Myasthenia

gravis

Obesity

Osteoporosis

Parkinson's

Disease

Phenylketonur

ia (PKU)

Psoriasis

Retinopathy

Schizophrenia

Scleroderma

Scoliosis

Seizure

Disorder

Sickle Cell

Anemia

Skin Disorder

Skin moles, abnormal

Sleep Apnea

Stomach Ulcer

Tay-Sach

disease

Teeth (Extra)

Teeth 
(Missing)

Thyroid

disorders

Tobacco (non-

cigarette)

Addiction

Tobacco (non-

cigarette) Use

(once a week

or less)

Vitiligo 


\section{Appendix C: UltraClean ${ }^{\circledR}$ Plant DNA Isolation Kit, Instruction Manual}




\section{UltraClean $^{\circledR}$ Plant DNA Isolation Kit}

\begin{tabular}{|l|l|}
\hline Catalog No. & Quantity \\
\hline $13000-50$ & 50 Preps \\
$13000-250$ & 250 Preps \\
\hline
\end{tabular}

Instruction Manual

New protocol instructions: Shake Solution P3 to mix before using to ensure consistent results.

Please recycle

Version: 10272009

Technical information: Toll free 1-800-606-6246, or 1-760-929-9911 Email: technical@mobio.com Website: www.mobio.com 


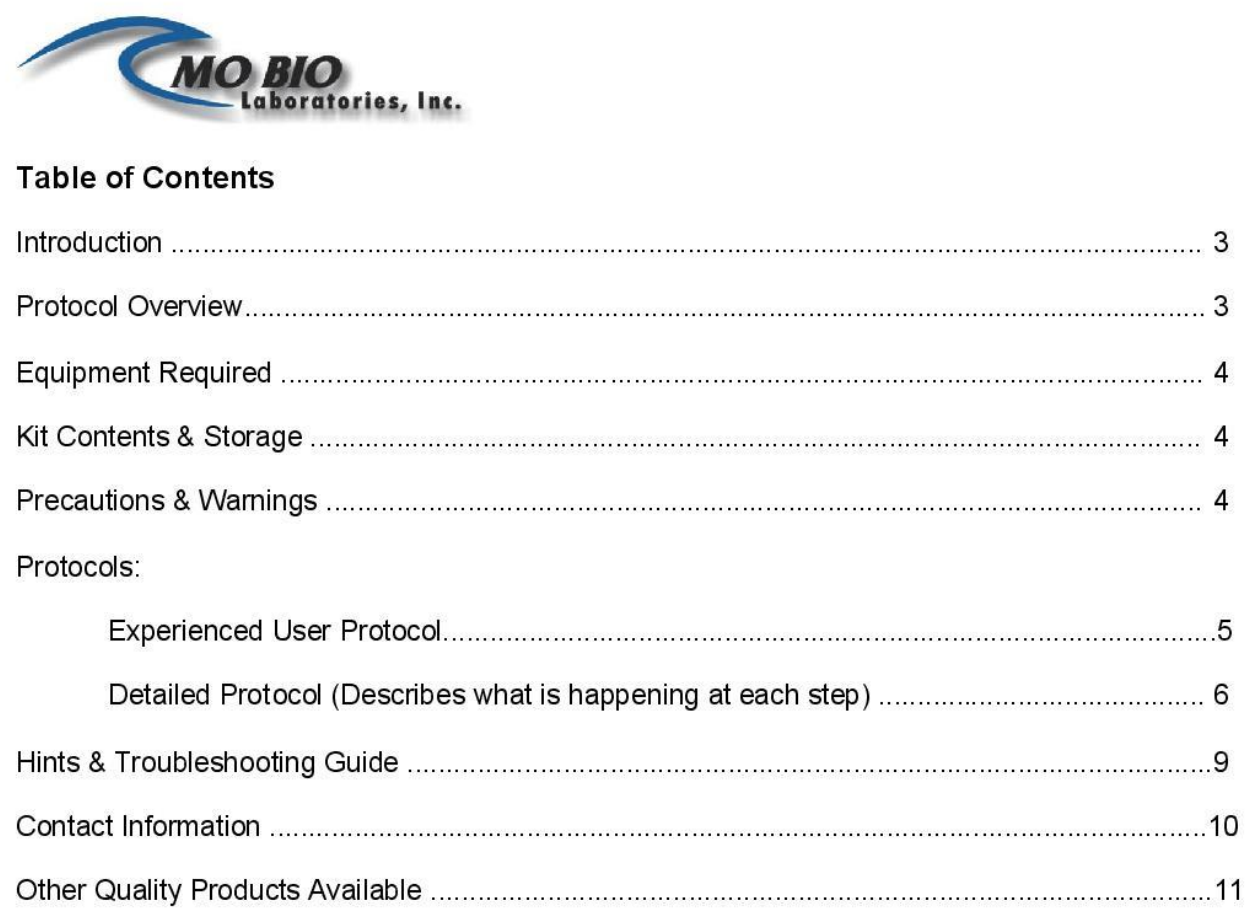




\section{Introduction}

The UltraClean ${ }^{\circledR}$ Plant DNA Isolation Kit is designed for fast and easy purification of total cellular DNA from plant cells and tissues. The bead beating technology used in this kit replaces cumbersome DNA isolation procedures such as CTAB, phenol, or chloroform extraction. Using the kit procedure, alcohol precipitation is not necessary and purified DNA is ready for immediate use. The kit is ideal for isolating enough DNA for PCR using just a vortex.

\section{Protocol Overview}

Plant samples from 5 - $50 \mathrm{mg}$ are added to a bead tube along with a kit supplied buffer for rapid homogenization. Cell lysis and DNA release occurs by mechanical and chemical methods. Released genomic DNA is captured on a silica membrane in a spin column format. DNA is washed and eluted from the membrane and ready for PCR and other downstream applications.

This kit is for research purposes only. Not for diagnostic use.

\begin{tabular}{|l|l|l|}
\hline Other Related Products & Catalog No. & Quantity \\
\hline UltraClean $^{\circledR}$-htp 96 Well Plant DNA Isolation Kit & $13096-4$ & $4 \times 96$ preps \\
& $13096-12$ & $12 \times 96$ preps \\
\hline UltraClean $^{(}$Plant RNA Isolation Kit & $13300-20$ & 20 preps \\
& $13300-50$ & 50 preps \\
\hline Vortex Adapter, holds 24 (1.5-2.0 ml) tubes & $13000-V 1-24$ & 1 unit \\
\hline
\end{tabular}




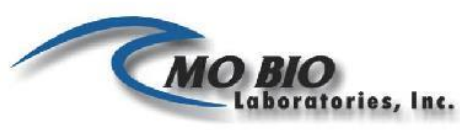

Equipment Required

Micro centrifuge $(10,000 \times g)$

Pipettor (volumes required $50-500 \mu \mathrm{l}$ ),

Vortex-Genie ${ }^{\circledR} 2$ Vortex (MO BIO Catalog\# 13111-V or 13111-V-220)

\section{Kit Contents}

\begin{tabular}{|c|c|c|c|c|}
\hline & \multicolumn{2}{|c|}{ Kit Catalog\# 13000-50 } & \multicolumn{2}{|c|}{ Kit Catalog\# 13000-250 } \\
\hline Component & Catalog\# & Amount & Catalog\# & Amount \\
\hline Solution P1 & $13000-50-1$ & $3 \mathrm{ml}$ & $13000-250-1$ & $16.5 \mathrm{ml}$ \\
\hline Solution P2 & $13000-50-2$ & $12.5 \mathrm{ml}$ & $13000-250-2$ & $70 \mathrm{ml}$ \\
\hline Solution P3 & $13000-50-3$ & $45 \mathrm{ml}$ & $13000-250-3$ & $250 \mathrm{ml}$ \\
\hline Solution P4 & $13000-50-4$ & $15 \mathrm{ml}$ & $13000-250-4$ & $3 \times 30 \mathrm{ml}$ \\
\hline Solution P5 & $13000-50-5$ & $2.5 \mathrm{ml}$ & $13000-250-5$ & $14 \mathrm{ml}$ \\
\hline $\begin{array}{l}\text { Bead Solution Tubes } \\
\text { (contain } 550 \mu \text { solution) }\end{array}$ & $13000-50-B S T$ & 50 & $13000-250-B S T$ & 250 \\
\hline Spin Filters & $13000-50-S F$ & 50 & $13000-250-S F$ & 250 \\
\hline $2 \mathrm{ml}$ Collection Tubes & $13000-50-T$ & 150 & $13000-250-T$ & 750 \\
\hline
\end{tabular}

\section{Kit Storage}

Kit reagents and components should be stored at room temperature $\left(15-30^{\circ} \mathrm{C}\right)$.

\section{Precautions}

Please wear gloves when using this product. Avoid all skin contact with kit reagents. In case of contact, wash thoroughly with water. Do not ingest. See Material Safety Data Sheets for emergency procedures in case of accidental ingestion or contact. All MSDS information is available upon request (760-9299911) or at www.mobio.com. Reagents labeled flammable should be kept away from open flames and sparks.

WARNING: Solution P4 contains ethanol. It is flammable.

IMPORTANT NOTE FOR USE: Make sure the $2 \mathrm{ml}$ Bead Solution Tubes rotate freely in your centrifuge without rubbing. Shake to mix Solution P3 before use. 


\section{Experienced User Protocol}

Please wear gloves at all times

1. To the $2 \mathrm{ml}$ Bead Solution tubes provided, add $5-50 \mathrm{mg}$ of plant tissue. (Approximately one to ten samples of a hole punch).

2. (Check Solution P1. If precipitated, heat to dissolve.)

3. Add $60 \mu \mathrm{l}$ of Solution P1 and vortex once to mix. Upon adding, white precipitate may form initially, but will dissolve upon heating.

4. Place the Bead Solution Tubes in a water bath at $65^{\circ} \mathrm{C}$ for 10 minutes.

5. Secure Bead Solution Tubes horizontally using the MO BIO Vortex Adapter tube holder for the vortex (MO BIO Catalog\# 13000-V1) or onto a flat-bed pad with tape.

6. Vortex at maximum speed for 10 minutes.

7. Make sure the Bead Solution Tubes rotate freely in your centrifuge without rubbing.

8. Centrifuge tubes at $10,000 \times g$ for 30 seconds. CAUTION: Be sure not to exceed $10,000 \times g$ or tubes may break.

9. Transfer the supernatant to a clean $\mathbf{2} \mathrm{ml}$ Collection Tube (provided).

Note: With $50 \mathrm{mg}$ of plant tissue and depending upon plant type, expect $400-450 \mu \mathrm{l}$ of supernatant, which may contain some particles.

10. Add $250 \mu$ of Solution P2.

11. Vortex 5 seconds.

12. Incubate at $4^{\circ} \mathrm{C}$ for 5 minutes.

13. Centrifuge sample tubes for 1 minute at $10,000 \times \mathrm{g}$.

14. Avoiding the pellet, transfer $500 \mu \mathrm{l}$ of supernatant to a clean $2 \mathrm{ml}$ Collection Tube (provided)

15. Shake to mix Solution P3. Add $1 \mathrm{ml}$ of Solution P3 to the supernatant.

16. Vortex 5 seconds.

17. Note: $A$ total of three loads for each sample processed are required Load approximately $650 \mu$ onto Spin Filter and centrifuge at $10,000 \times g$ for 30 seconds. Discard the flow through and add the remaining supernatant to the Spin Filter and centrifuge at $10,000 \times g$ for 30 seconds.

18. Add $300 \mu$ of Solution P4.

19. Centrifuge for 30 seconds at $10,000 \times g$.

20. Discard the flow through.

21. Centrifuge again for 1 minute to remove residual Solution P4.

22. Carefully place Spin Filter in a new clean $\mathbf{2} \mathbf{~ m l ~ C o l l e c t i o n ~ T u b e ~ ( p r o v i d e d ) . ~ A v o i d ~ s p l a s h i n g ~ a n y ~}$ Solution P4 onto the Spin Filter.

23. Add $50 \mu$ of Solution P5 to the center of the white filter membrane.

24. Centrifuge 30 seconds.

25. Discard the Spin Filter. DNA in the tube is now application ready. No further steps are required.

We recommend storing DNA frozen $\left(-20^{\circ} \mathrm{C}\right)$. Solution P5 contains no EDTA.

Thank you for choosing the UltraClean ${ }^{\circledR}$ Plant DNA Isolation Kit. 


\section{Detailed Protocol (Describes what is happening at each step)}

Please wear gloves at all times

1. Add $5-50 \mathrm{mg}$ of plant tissue to the $2 \mathrm{ml}$ Bead Solution Tube provided. (Approximately one to ten samples of a hole punch).

What's happening: Plant material is added to the Bead Solution Tube to prepare it for a bead beating homogenization step.

2. (Check Solution P1. If precipitated, heat to $65^{\circ} \mathrm{C}$ for several minutes to dissolve.)

What's happening: Solution P1 contains SDS. It will form a precipitate if it gets cold. Heating and dissolving the solids will restore it to full efficiency.

3. Add $60 \mu \mathrm{l}$ of Solution P1 and vortex once to mix. Upon adding, white precipitate may form initially, but will dissolve upon heating.

What's happening: If your plant samples are cold, Solution P1 may precipitate. This will not affect the DNA isolation procedure.

4. Place the Bead Solution Tubes in a water bath at $65^{\circ} \mathrm{C}$ for 10 minutes.

What's happening: This heating step helps soften plant material prior to bead beating

5. Secure Bead Solution Tubes horizontally using the MO BIO Vortex Adapter tube holder for the vortex (MO BIO Catalog\# 13000-V1) or onto a flat-bed pad with tape.

6. Vortex at maximum speed for 10 minutes. Be sure to check tubes periodically if you have taped them to a flat vortex pad. It is very common for tubes to shake loose. We recommend the use of the MO BIO Vortex Adapter for this step.

What's happening: This bead beating step is a very good method to homogenize plant material without the need of grinding manually. In some cases the plant material will not be completely disintegrated after the 10 minute step. However, there should be sufficient disruption for a good to moderate yield of DNA.

7. Make sure the Bead Solution Tubes rotate freely in your centrifuge without rubbing.

8. Centrifuge tubes at $10,000 \times g$ for 30 seconds. CAUTION: Be sure not to exceed $10,000 \times g$ or tubes may break

What's happening: This step will pellet unwanted cell and tissue debris.

9. Transfer the supernatant to a clean $2 \mathrm{ml}$ Collection Tube (provided).

What's happening: The supernatant contains DNA and other cell components. Avoid transferring any solid plant tissue at this point.

10. Note: With $50 \mathrm{mg}$ of plant tissue and depending upon plant type, expect $400-450 \mu$ of supernatant, which may contain some particles.

11. Add $250 \mu$ of Solution P2.

Technical information: Toll free 1-800-606-6246, or 1-760-929-9911 Email: technical@mobio.com Website: www.mobio.com 
12. Vortex 5 seconds.

13. Incubate at $4^{\circ} \mathrm{C}$ for 5 minutes.

What's happening: Solution $P 2$ is a prote in precipitation reagent. It helps remove unwanted proteins

14. Centrifuge sample tubes for 1 minute at $10,000 \times \mathrm{g}$.

What's happening: This step pellets the precipitated proteins.

15. Avoiding the pellet, transfer $500 \mu \mathrm{l}$ of supernatant to a clean $2 \mathrm{ml}$ Collection Tube (provided)

16. Shake to mix Solution P3. Add $1 \mathrm{ml}$ of Solution P3 to the supernatant.

17. Vortex 5 seconds.

What's happening: Solution P3 is a binding salt. It is used to make the DNA bind to the silica spin filter membrane.

18. Note: $A$ total of three loads for each sample processed are required. Load approximately $650 \mu$ onto Spin Filter and centrifuge at 10,000 $\times g$ for 30 seconds. Discard the flow through and add the remaining supernatant to the Spin Filter and centrifuge at $10,000 \times g$ for 30 seconds.

What's happening: In the presence of Solution P3 the binding salt, DNA will bind to the spin filter. Spinning the SALT-DNA mixture through the spin filter leaves DNA bound to the filter membrane while allowing unwanted salt to pass through the membrane.

19. Add $300 \mu$ of Solution P4 to the Spin Filter.

20. Centrifuge for 30 seconds at $10,000 \times g$.

21. Discard the flow through.

What's happening: Solution P4 is a wash buffer. It removes residual salt and cleans the DNA. Solution P4 contains ethanol. It is flammable and should be discarded appropriately.

22. Centrifuge again for 1 minute to remove residual Solution P4.

What's happening: This is a critical step. It is very important to remove all traces of Solution P4 before continuing.

23. Carefully place Spin Filter in a new clean $2 \mathrm{ml}$ Collection Tube (provided). Avoid splashing any Solution P4 onto the Spin Filter.

24. Add $50 \mu$ of Solution P5 to the center of the white filter membrane.

25. Centrifuge 30 seconds.

What's happening: Solution P5 allows the bound DNA to be released from the spin filter membrane. It is a Tris buffer and contains no salt. DNA can not remain bound to the spin fitter so it is released into the Solution P5 as it passes through the spin filter membrane.

Technical information: Toll free 1-800-606-6246, or 1-760-929-9911 Email: technical@mobio.com Website: www.mobio.com 
26. Discard S pin Filter. DNA in the tube is now application ready. No further steps are required. We recommend storing DNA frozen $\left(-20^{\circ} \mathrm{C}\right)$. Solution P5 contains no EDTA.

Thank you for choosing the UltraClean ${ }^{\circledR}$ Plant DNA Isolation Kit. 


\section{Hints and Troubleshooting Guide}

\section{Concentrating the DNA}

Your final volume will be $50 \mu \mathrm{l}$. If this is too dilute for your purposes, add $2 \mu \mathrm{l}$ of $5 \mathrm{M} \mathrm{NaCl}$ or $5 \mu \mathrm{l}$ of $3 \mathrm{M}$ Sodium Acetate ( $\mathrm{pH}: 5.2)$ and mix. Then add $100 \mu \mathrm{l}$ of $100 \%$ cold ethanol. Mix. Centrifuge at $10,000 \times \mathrm{g}$ for 5 minutes. Decant all liquid. Dry residual ethanol in a speed vac or dessicator or ambient air.

Resuspend precipitated DNA in desired volume.

Amount of Plant Tissue to Process

Depends on plant type. Usually 5-50 mg works well. ( 1 to 6 hole punches of leaf tissue or equivalent).

DNA Floats Out of Well When Loaded on a Gel

You may have inadvertently transferred some residual Solution P4 into the final sample. Prevent this by being careful in step 15 not to transfer liquid onto the bottom of the spin filter basket. Ethanol precipitation is the best way to remove residues of Solution P4. (See Concentrating the DNA above.)

\section{Storing DNA}

DNA eluted in Solution P5 ( $10 \mathrm{mM}$ Tris) must be stored at $-20^{\circ} \mathrm{C}$ or it may degrade. DNA can be eluted in TE but the EDTA may inhibit reactions such as PCR and automated sequencing. 


\section{Contact Information}

Technical Support:

Phone MO BIO Laboratories, Inc. Toll Free 800-606-6246, or 760-929-9911

Email: technical@mobio.com

Fax: 760-929-0109

Mail: MO BIO Laboratories, Inc, 2746 Loker Ave West, Carlsbad, CA 92010

Ordering Information:

Direct: Phone MO BIO Laboratories, Inc. Toll Free 800-606-6246, or 760-929-9911

Email: orders@mobio.com

Fax: 760-929-0109

Mail: MO BIO Laboratories, Inc, 2746 Loker Ave West, Carlsbad, CA 92010

For the distributor nearest you, visit our web site at www.mobio.com/distributors 
MOBIO

Laboratories, Inc.

Other Quality Products Available from MO BIO Laboratories, Inc.

For more product and detailed information go to www.mobio.com/catalog-request to request a catalog.

\begin{tabular}{|c|c|c|}
\hline DNA Purification and Gel Extraction & Catalog No. & Quantity \\
\hline PowerClean $($ DNA Clean-Up Kit & $12877-50$ & 50 preps \\
\hline UltraClean $(15$ DNA Purification Kit & $12100-300$ & 300 preps \\
\hline UltraClean $(8)$ PCR Clean-Up Kit & $\begin{array}{l}12500-50 \\
12500-100 \\
12500-250\end{array}$ & $\begin{array}{l}50 \text { preps } \\
100 \text { preps } \\
250 \text { preps }\end{array}$ \\
\hline $\begin{array}{l}\text { UltraClean }(\mathbb{B} \text {-htp } 96 \text { Well PCR Clean- } \\
\text { Up Kit }\end{array}$ & $\begin{array}{l}12596-4 \\
12596-12 \\
\end{array}$ & $\begin{array}{l}4 \times 96 \text { preps } \\
12 \times 96 \text { preps }\end{array}$ \\
\hline $\begin{array}{l}\text { UltraClean® GelSpin® DNA } \\
\text { Extraction Kit }\end{array}$ & $\begin{array}{l}12400-50 \\
12400-100 \\
12400-250 \\
\end{array}$ & $\begin{array}{l}50 \text { preps } \\
100 \text { preps } \\
250 \text { preps } \\
\end{array}$ \\
\hline Plasmid DNA Isolation & Catalog No. & Quantity \\
\hline $\begin{array}{l}\text { UltraClean® } 6 \text { Minute Mini Plasmid } \\
\text { Prep Kit }\end{array}$ & $\begin{array}{l}12300-50 \\
12300-100 \\
12300-250\end{array}$ & $\begin{array}{l}50 \text { preps } \\
100 \text { preps } \\
250 \text { preps }\end{array}$ \\
\hline $\begin{array}{l}\text { UltraClean(8) Standard Mini Plasmid } \\
\text { Prep Kit }\end{array}$ & $\begin{array}{l}12301-50 \\
12301-100 \\
12301-250 \\
\end{array}$ & $\begin{array}{l}50 \text { preps } \\
100 \text { preps } \\
250 \text { preps } \\
\end{array}$ \\
\hline $\begin{array}{l}\text { UltraClean(8-htp } 96 \text { Well Plasmid Prep } \\
\text { Kit }\end{array}$ & $\begin{array}{l}12396-4 \\
12396-12 \\
\end{array}$ & $\begin{array}{l}4 \times 96 \text { preps } \\
12 \times 96 \text { preps }\end{array}$ \\
\hline UltraClean $\otimes$ Midi Plasmid Prep Kit & $\begin{array}{l}12700-20 \\
12700-50 \\
\end{array}$ & $\begin{array}{l}20 \text { preps } \\
50 \text { preps }\end{array}$ \\
\hline UltraClean $(8)$ Maxi Plasmid Prep Kit & $\begin{array}{l}12600-10 \\
12600-20 \\
\end{array}$ & $\begin{array}{l}10 \text { preps } \\
20 \text { preps } \\
\end{array}$ \\
\hline $\begin{array}{l}\text { UltraClean }(8) \text { Endotoxin-Free Mini } \\
\text { Plasmid Prep Kit }\end{array}$ & $\begin{array}{l}12311-100 \\
12311-250 \\
\end{array}$ & $\begin{array}{l}100 \text { preps } \\
250 \text { preps }\end{array}$ \\
\hline $\begin{array}{l}\text { UltraClean }(8) \text { Endotoxin-Free Midi } \\
\text { Plasmid Prep Kit }\end{array}$ & $12711-10$ & 10 preps \\
\hline $\begin{array}{l}\text { UltraClean }(8) \text { Endotoxin-Free Maxi } \\
\text { Plasmid Prep Kit }\end{array}$ & $12611-10$ & 10 preps \\
\hline UltraClean $(B)$ Endotoxin Removal Kit & 12615 & 1 kit \\
\hline $\begin{array}{l}\text { UltraClean (8) Endotoxin-Free Ethanol } \\
\text { Precipitation Kit }\end{array}$ & 12616 & 1 kit \\
\hline $\begin{array}{l}\text { UltraClean }(2) \text { Endotoxin Removal } \\
\text { Reagent }\end{array}$ & $12625-25$ & $25 \mathrm{ml}$ \\
\hline Endotoxin-Free Sodium Chloride & $12626-15$ & $15 \mathrm{ml}$ \\
\hline Endotoxin-Free Centrifuge Tubes & $\begin{array}{l}12617-100 \\
12618-50 \\
12619-25\end{array}$ & $\begin{array}{l}100 \text { each } / 2 \mathrm{ml} \\
\text { tubes } \\
50 \text { each/ } 15 \mathrm{ml} \\
\text { tubes } \\
25 \text { each } / 50 \mathrm{ml} \\
\text { tubes }\end{array}$ \\
\hline RNA Isolation & Catalog No. & Quantity \\
\hline 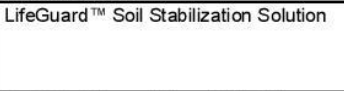 & $\begin{array}{l}12868-10 \\
12868-100 \\
12868-1000 \\
12868-7500\end{array}$ & $\begin{array}{l}10 \mathrm{ml} \\
100 \mathrm{ml} \\
1 \mathrm{~L} \\
7.5 \mathrm{~L}\end{array}$ \\
\hline $\begin{array}{l}\text { On-Spin Column DNase I Kit (RNase- } \\
\text { Free) }\end{array}$ & $15100-50$ & 50 preps \\
\hline $\begin{array}{l}\text { Bi Ostic }(\text { Stabilized Blood RNA } \\
\text { Isolation Kit }\end{array}$ & $\begin{array}{l}12231-20 \\
12231-50 \\
12231-100 \\
\end{array}$ & $\begin{array}{l}20 \text { preps } \\
50 \text { preps } \\
100 \text { preps }\end{array}$ \\
\hline $\begin{array}{l}\text { Bi Ostic } \circledast \text { Blood Total RNA Isolation } \\
\text { Kit }\end{array}$ & $\begin{array}{l}12230-20 \\
12230-50 \\
\end{array}$ & $\begin{array}{l}20 \text { preps } \\
50 \text { preps }\end{array}$ \\
\hline $\begin{array}{l}\text { RNA PowerSoil(囚 DNA Elution } \\
\text { Accessory Kit }\end{array}$ & $12867-25$ & 25 preps \\
\hline $\begin{array}{l}\text { RNA PowerSoil } \otimes \text { Total RNA Isolation } \\
\text { Kit }\end{array}$ & $12866-25$ & 25 preps \\
\hline $\begin{array}{l}\text { UltraClean }(8) \text { Microbial RNA Isolation } \\
\text { Kit }\end{array}$ & $\begin{array}{l}15800-50 \\
15800-250 \\
\end{array}$ & $\begin{array}{l}50 \text { preps } \\
250 \text { preps } \\
\end{array}$ \\
\hline $\begin{array}{l}\text { UltraClean }(8) \text { Tissue \& Cells RNA } \\
\text { Isolation Kit }\end{array}$ & $\begin{array}{l}15000-50 \\
15000-250\end{array}$ & $\begin{array}{l}50 \text { preps } \\
250 \text { preps }\end{array}$ \\
\hline
\end{tabular}

\begin{tabular}{|c|c|c|}
\hline RNA Isolation ...Continued & Catalog No. & Quantity \\
\hline UltraClean (8) Plant RNA Isolation Kit & $\begin{array}{l}13300-20 \\
13300-50\end{array}$ & $\begin{array}{l}20 \text { preps } \\
50 \text { preps }\end{array}$ \\
\hline Genomic DNA Isolation & Catalog No. & Quantity \\
\hline $\begin{array}{l}\text { PowerFood }{ }^{\mathrm{TM}} \text { Microbial DNA Isolation } \\
\text { Kit }\end{array}$ & $\begin{array}{l}21000-50 \\
21000-100\end{array}$ & $\begin{array}{l}50 \text { preps } \\
100 \text { preps }\end{array}$ \\
\hline $\begin{array}{l}\text { Bi Ostic Bacteremia DNA Isolation } \\
\text { Kit }\end{array}$ & $12240-50$ & 50 preps \\
\hline $\begin{array}{l}\text { Bi Osticß FFPE Tissue DNA Isolation } \\
\text { Kit }\end{array}$ & $12250-50$ & 50 preps \\
\hline Bi Ostic $($ Paraffin Removal Reagent & $12251-50$ & $2 \times 25 \mathrm{ml}$ \\
\hline PowerMax $\otimes$ Soil DNA Isolation Kit & $12988-10$ & 10 preps \\
\hline PowerSoil(®) DNA Isolation Kit & $\begin{array}{l}12888-50 \\
12888-100\end{array}$ & $\begin{array}{l}50 \text { preps } \\
100 \text { preps }\end{array}$ \\
\hline $\begin{array}{l}\text { PowerSoil[-htp } 96 \text { Well Soil DNA } \\
\text { Isolation Kit }\end{array}$ & $\begin{array}{l}12955-4 \\
12955-12\end{array}$ & $\begin{array}{l}4 \times 96 \text { preps } \\
12 \times 96 \text { preps }\end{array}$ \\
\hline UltraClean $(8)$ Soil DNA Isolation Kit & $\begin{array}{l}12800-50 \\
12800-100\end{array}$ & $\begin{array}{l}50 \text { preps } \\
100 \text { preps } \\
\end{array}$ \\
\hline $\begin{array}{l}\text { UltraClean }(\AA \text {-htp } 96 \text { Well Soil DNA } \\
\text { Isolation Kit }\end{array}$ & $\begin{array}{l}12896-4 \\
12896-12 \\
\end{array}$ & $\begin{array}{l}4 \times 96 \text { preps } \\
12 \times 96 \text { preps }\end{array}$ \\
\hline $\begin{array}{l}\text { UltraClean (8) Mega Soil DNA Isolation } \\
\text { Kit }\end{array}$ & $12900-10$ & 10 preps \\
\hline PowerClean $\otimes$ DNA Clean-Up Kit & $12877-50$ & 50 preps \\
\hline UltraClean $\otimes^{\circledR}$ Fecal DNA Isolation Kit & $\begin{array}{l}12811-50 \\
12811-100 \\
\end{array}$ & $\begin{array}{l}50 \text { preps } \\
100 \text { preps } \\
\end{array}$ \\
\hline $\begin{array}{l}\text { PowerMicrobial } \otimes \text { Midi DNA Isolation } \\
\text { Kit }\end{array}$ & $12225-25$ & 25 preps \\
\hline $\begin{array}{l}\text { PowerMicrobial }(\mathbb{2} \text { Maxi DNA Isolation } \\
\text { Kit }\end{array}$ & $12226-25$ & 25 preps \\
\hline $\begin{array}{l}\text { UltraClean }(8) \text { Microbial DNA Isolation } \\
\text { Kit }\end{array}$ & $\begin{array}{l}12224-50 \\
12224-250\end{array}$ & $\begin{array}{l}50 \text { preps } \\
250 \text { preps }\end{array}$ \\
\hline $\begin{array}{l}\text { UltraClean }(2-h t p 96 \text { Well Microbial } \\
\text { DNA Isolation Kit }\end{array}$ & $\begin{array}{l}10196-4 \\
10196-12 \\
\end{array}$ & $\begin{array}{l}4 \times 96 \text { preps } \\
12 \times 96 \text { preps }\end{array}$ \\
\hline PowerPlant $($ DNA Isolation Kit & $\begin{array}{l}13200-50 \\
13200-100\end{array}$ & $\begin{array}{l}50 \text { preps } \\
100 \text { preps }\end{array}$ \\
\hline UltraClean (8) Plant DNA Isolation Kit & $\begin{array}{l}13000-50 \\
13000-250\end{array}$ & $\begin{array}{l}50 \text { preps } \\
250 \text { preps } \\
\end{array}$ \\
\hline $\begin{array}{l}\text { UltraClean (8)-htp } 96 \text { Well Plant DNA } \\
\text { Isolation Kit }\end{array}$ & $\begin{array}{l}13096-4 \\
13096-12\end{array}$ & $\begin{array}{l}4 \times 96 \text { preps } \\
12 \times 96 \text { preps }\end{array}$ \\
\hline $\begin{array}{l}\text { UltraClean }(2) \text { Tissue \& Cells DNA } \\
\text { Isolation Kit }\end{array}$ & $\begin{array}{l}12334-50 \\
12334-250\end{array}$ & $\begin{array}{l}50 \text { preps } \\
250 \text { preps }\end{array}$ \\
\hline $\begin{array}{l}\text { UltraClean (2)-htp } 96 \text { Well Tissue DNA } \\
\text { Isolation Kit }\end{array}$ & $\begin{array}{l}12996-4 \\
12996-12\end{array}$ & $\begin{array}{l}4 \times 96 \text { preps } \\
12 \times 96 \text { preps }\end{array}$ \\
\hline $\begin{array}{l}\text { UltraClean }\left({ }^{2} \text { Blood DNA Isolation Kit }\right. \\
\text { (Non-Spin) }\end{array}$ & $12000-100$ & 100 preps \\
\hline $\begin{array}{l}\text { UltraClean }(8) \text { Blood DNA Isolation Kit } \\
\text { (Processes } 1,000 \mathrm{ml} \text { of Blood) }\end{array}$ & $12000-1000$ & 1 kit \\
\hline $\begin{array}{l}\text { UltraClean } \otimes \text { Blood DNA Isolation Kit } \\
\text { Plus RNase } \\
\text { (Processes } 1,000 \mathrm{ml} \text { of Blood) }\end{array}$ & $12002-1000$ & 1 kit \\
\hline $\begin{array}{l}\text { UltraClean }(8) \text { BloodSpin }(8) \text { DNA } \\
\text { Isolation Kit }\end{array}$ & $\begin{array}{l}12200-50 \\
12200-250\end{array}$ & $\begin{array}{l}50 \text { preps } \\
250 \text { preps }\end{array}$ \\
\hline $\begin{array}{l}\text { UltraClean }(8 \text {-htp } 96 \text { Well BloodSpin }(8) \\
\text { DNA Isolation Kit }\end{array}$ & $\begin{array}{l}12296-4 \\
12296-12\end{array}$ & $\begin{array}{l}4 \times 96 \text { preps } \\
12 \times 96 \text { preps }\end{array}$ \\
\hline
\end{tabular}

Technical information: Toll free 1-800-606-6246, or 1-760-929-9911 
MO BIO

Laboratories, Inc.

Other Quality Products Available from MO BIO Laboratories, Inc.

For more product and detailed information go to www.mobio.com/catalog-request to request a catalog.

\begin{tabular}{|c|c|c|}
\hline $\begin{array}{l}\text { Genomic DNA Isolation } \\
\text { Continued }\end{array}$ & Catalog No. & Quantity \\
\hline $\begin{array}{l}\text { UltraClean }(\mathbb{B} \text { Forensic DNA Isolation } \\
\text { Kit }\end{array}$ & $\begin{array}{l}14000-10 \\
14000-20\end{array}$ & $\begin{array}{l}10 \text { isolations } \\
20 \text { isolations }\end{array}$ \\
\hline PowerWater DNA Isolation Kit & $\begin{array}{l}14900-50-N F \\
14900-50-22 \\
14900-50-45 \\
14900-100-N F \\
14900-100-22 \\
14900-100-45\end{array}$ & $\begin{array}{l}50 \text { preps } \\
\text { (No filters) } \\
(0.22 \mu \mathrm{m}) \\
(0.45 \mu \mathrm{m}) \\
100 \text { preps } \\
(\text { No filters) } \\
(0.22 \mu \mathrm{m}) \\
(0.45 \mu \mathrm{m})\end{array}$ \\
\hline RapidWater $^{\text {TM }}$ DNA Isolation Kit & $\begin{array}{l}14810-50-\mathrm{NF} \\
14810-50-22 \\
14810-50-45 \\
14810-100-\mathrm{NF} \\
14810-100-22 \\
14810-100-45\end{array}$ & $\begin{array}{l}50 \text { preps } \\
\text { (No filters) } \\
(0.22 \mu \mathrm{m}) \\
(0.45 \mu \mathrm{m}) \\
100 \text { preps } \\
\text { (No filters) } \\
(0.22 \mu \mathrm{m}) \\
(0.45 \mu \mathrm{m})\end{array}$ \\
\hline $\begin{array}{l}\text { UltraClean }(2) \text { Water DNA Isolation Kit } \\
(0.45 \mu \mathrm{m} \text { filters })\end{array}$ & $14800-10$ & $\begin{array}{l}10 \text { preps } \\
25 \text { preps }\end{array}$ \\
\hline $\begin{array}{l}\text { UltraClean }(1) \text { Water DNA Isolation Kit } \\
(0.22 \mu \mathrm{m} \text { filters })\end{array}$ & $\begin{array}{l}14880-10 \\
14880-25\end{array}$ & $\begin{array}{l}10 \text { preps } \\
25 \text { preps }\end{array}$ \\
\hline $\begin{array}{l}\text { UltraClean(8) Water DNA Isolation Kit } \\
\text { (No filters) }\end{array}$ & $\begin{array}{l}14800-10-\mathrm{NF} \\
14800-25-\mathrm{NF}\end{array}$ & $\begin{array}{l}10 \text { preps } \\
25 \text { preps }\end{array}$ \\
\hline Microbiological Culture Media & Catalog No. & Quantity \\
\hline TB DRY®Powder Growth Media & $\begin{array}{l}12105-05 \\
12105-1 \\
12105-5\end{array}$ & $\begin{array}{l}500 \mathrm{~g} \\
1 \mathrm{~kg} \\
5 \mathrm{~kg}\end{array}$ \\
\hline $\begin{array}{l}\text { LB Broth Powder Growth Media, pH } \\
7\end{array}$ & $\begin{array}{l}12106-05 \\
12106-1 \\
12106-5\end{array}$ & $\begin{array}{l}500 \mathrm{~g} \\
1 \mathrm{~kg} \\
5 \mathrm{~kg}\end{array}$ \\
\hline LB Agar Powder Growth Media, pH 7 & $\begin{array}{l}12107-05 \\
12107-1 \\
12107-5 \\
\end{array}$ & $\begin{array}{l}500 \mathrm{~g} \\
1 \mathrm{~kg} \\
5 \mathrm{~kg} \\
\end{array}$ \\
\hline $\begin{array}{l}\text { LB Broth (Lennox) Powder Growth } \\
\text { Media, pH } 7\end{array}$ & $\begin{array}{l}12108-05 \\
12108-1 \\
12108-5\end{array}$ & $\begin{array}{l}500 \mathrm{~g} \\
1 \mathrm{~kg} \\
5 \mathrm{~kg}\end{array}$ \\
\hline $\begin{array}{l}\text { LB Agar (Lennox) Powder Growth } \\
\text { Media, pH } 7\end{array}$ & $\begin{array}{l}12109-05 \\
12109-1 \\
12109-5 \\
\end{array}$ & $\begin{array}{l}500 \mathrm{~g} \\
1 \mathrm{~kg} \\
5 \mathrm{~kg}\end{array}$ \\
\hline $\begin{array}{l}\text { Soybean-Casein Digest Medium } \\
\text { (TSB), USP }\end{array}$ & $\begin{array}{l}12114-05 \\
12114-1 \\
12114-5\end{array}$ & $\begin{array}{l}500 \mathrm{~g} \\
1 \mathrm{~kg} \\
5 \mathrm{~kg}\end{array}$ \\
\hline $\begin{array}{l}\text { Soybean-Casein Digest Agar } \\
\text { Medium (TSA), USP }\end{array}$ & $\begin{array}{l}12115-05 \\
12115-1 \\
12115-5\end{array}$ & $\begin{array}{l}500 \mathrm{~g} \\
1 \mathrm{~kg} \\
5 \mathrm{~kg}\end{array}$ \\
\hline Yeast Extract & $\begin{array}{l}12110-05 \\
12110-1 \\
12110-5\end{array}$ & $\begin{array}{l}500 \mathrm{~g} \\
1 \mathrm{~kg} \\
5 \mathrm{~kg}\end{array}$ \\
\hline Tryptone & $\begin{array}{l}12111-05 \\
12111-1 \\
12111-5\end{array}$ & $\begin{array}{l}500 \mathrm{~g} \\
1 \mathrm{~kg} \\
5 \mathrm{~kg}\end{array}$ \\
\hline Agar, Bacteriological Grade & $\begin{array}{l}12112-05 \\
12112-1 \\
12112-5\end{array}$ & $\begin{array}{l}500 \mathrm{~g} \\
1 \mathrm{~kg} \\
5 \mathrm{~kg}\end{array}$ \\
\hline $\begin{array}{l}\text { Other Reagents and Lab } \\
\text { Accessories }\end{array}$ & Catalog No. & Quantity \\
\hline 20 bp DNA Ladder & $17020-40$ & $40 \mu \mathrm{g}$ \\
\hline
\end{tabular}

\begin{tabular}{|c|c|c|}
\hline $\begin{array}{l}\text { Other Reagents and Lab } \\
\text { Accessories...Continued }\end{array}$ & Catalog No. & Quantity \\
\hline 100 bp DNA Ladder & $17100-40$ & $40 \mu \mathrm{g}$ \\
\hline $1 \mathrm{~kb}$ DNA Ladder & $17200-100$ & $100 \mu \mathrm{g}$ \\
\hline $\begin{array}{l}\text { UltraClean }(\mathbb{B} \text { Agarose, Molecular } \\
\text { Biology Grade }\end{array}$ & $\begin{array}{l}15003-50 \\
15003-100 \\
15003-500 \\
15003-1000\end{array}$ & $\begin{array}{l}50 \mathrm{~g} \\
100 \mathrm{~g} \\
500 \mathrm{~g} \\
1 \mathrm{~kg}\end{array}$ \\
\hline UltraClean $(8)$ MS-8 Agarose & $\begin{array}{l}15515-50 \\
15515-100 \\
15515-500\end{array}$ & $\begin{array}{l}50 \mathrm{~g} \\
100 \mathrm{~g} \\
500 \mathrm{~g}\end{array}$ \\
\hline UltraClean $(B)$ Forensic Agarose & $\begin{array}{l}15505-50 \\
15505-100 \\
15505-500\end{array}$ & $\begin{array}{l}50 \mathrm{~g} \\
100 \mathrm{~g} \\
500 \mathrm{~g}\end{array}$ \\
\hline UltraClean (8) Low Melt Agarose & $\begin{array}{l}15005-50 \\
15005-100 \\
15005-500\end{array}$ & $\begin{array}{l}\frac{\mathrm{g} g}{50 \mathrm{~g}} \\
100 \mathrm{~g} \\
500 \mathrm{~g}\end{array}$ \\
\hline UltraClean(8) Low Melt Sieve Agarose & $\begin{array}{l}15004-50 \\
15004-100 \\
15004-500\end{array}$ & $\begin{array}{l}50 \mathrm{~g} \\
100 \mathrm{~g} \\
500 \mathrm{~g}\end{array}$ \\
\hline Ethidium Bromide Solution & $\begin{array}{l}15006-1 \\
15006-10\end{array}$ & $\begin{array}{l}1 \mathrm{ml} \\
10 \mathrm{ml}\end{array}$ \\
\hline $\begin{array}{l}\text { Ethidium Bromide Destaining Tea } \\
\text { Bags }\end{array}$ & $15007-25$ & 25 bags \\
\hline $\begin{array}{l}\text { Bromophenol Blue Gel Loading } \\
\text { Buffer }\end{array}$ & $\begin{array}{l}15008-1 \\
15008-5\end{array}$ & $\begin{array}{l}1 \mathrm{ml} \\
5 \times 1 \mathrm{ml}\end{array}$ \\
\hline $\begin{array}{l}\text { Bromophenol Blue/Xylene Cyanol } \\
\text { Gel Loading Buffer }\end{array}$ & $\begin{array}{l}15009-1 \\
15009-5\end{array}$ & $\begin{array}{l}1 \mathrm{ml} \\
5 \times 1 \mathrm{ml}\end{array}$ \\
\hline TAE Buffer, 50X (Tris-acetate-EDTA) & $\begin{array}{l}15001-100 \\
15001-500 \\
15001-1000\end{array}$ & $\begin{array}{l}100 \mathrm{ml} \\
500 \mathrm{ml} \\
1 \text { liter }\end{array}$ \\
\hline TBE Buffer, 10X (Tris-borate-EDTA) & $\begin{array}{l}15002-100 \\
15002-500 \\
15002-1000\end{array}$ & $\begin{array}{l}100 \mathrm{ml} \\
500 \mathrm{ml} \\
1 \text { liter }\end{array}$ \\
\hline RNase-Free Gloves & $\begin{array}{l}1555-X S \\
1555-S \\
1555-M \\
1555-L\end{array}$ & $\begin{array}{l}\text { bag of } 100 \\
\text { bag of } 100 \\
\text { bag of } 100 \\
\text { bag of } 100\end{array}$ \\
\hline UltraClean $(8)$ Lab Cleaner & $\begin{array}{l}12095-250 \\
12095-500 \\
12095-1000\end{array}$ & $\begin{array}{l}250 \mathrm{ml} \\
\text { squeeze bottle } \\
500 \mathrm{ml} \text { spray } \\
\text { bottle } \\
1 \text { liter bottle }\end{array}$ \\
\hline $\begin{array}{l}\text { OmniTaq }{ }^{\text {TM }} \text { DNA Polymerase } \\
\text { Enzyme }\end{array}$ & $1224-250$ & $\begin{array}{l}250 \text { reactions } \\
(10 \text { U/ } / \mathrm{l})\end{array}$ \\
\hline $\begin{array}{l}\text { OmniTaq }^{\top \mu} \text { DNA Polymerase } 2 x \\
\text { Master Mix }\end{array}$ & $1226-250$ & $\begin{array}{l}250 \text { reactions } \\
(5 \times 1.25 \\
\mathrm{ml} / \text { /tube })\end{array}$ \\
\hline $\begin{array}{l}\text { Omni KlenTaq }{ }^{\top u} \text { DNA Polymerase } \\
\text { Enzyme }\end{array}$ & $1225-250$ & $\begin{array}{l}250 \text { reactions } \\
(25 \mathrm{U} / \mu \mathrm{l})\end{array}$ \\
\hline $\begin{array}{l}\text { Omni KlenTaq }{ }^{\top M} \text { DNA Polymerase } 2 x \\
\text { Master Mix }\end{array}$ & $1227-250$ & $\begin{array}{l}250 \text { reactions } \\
(5 \times 1.25 \\
\mathrm{ml} / \text { tube })\end{array}$ \\
\hline
\end{tabular}

Technical information: Toll free 1-800-606-6246, or 1-760-929-9911 Email: technical@mobio.com Website: www.mobio.com 
MO BIO

Laboratories, Inc.

Other Quality Products Available from MO BIO Laboratories, Inc.

For more product and detailed information go to www.mobio.com/catalog-request to request a catalog.

\begin{tabular}{|c|c|c|}
\hline $\begin{array}{l}\text { Other Reagents and Lab } \\
\text { Accessories...Continued }\end{array}$ & Catalog No. & Quantity \\
\hline DNase (RNase-Free) & $\begin{array}{l}15600-5 \\
15601-100\end{array}$ & $\begin{array}{l}5 \mathrm{mg} \\
2500 \text { units }\end{array}$ \\
\hline Proteinase K & $\begin{array}{l}1223-100 \\
1222-2\end{array}$ & $\begin{array}{l}100 \mathrm{mg} \\
2 \mathrm{ml}(20 \\
\mathrm{mg} / \mathrm{ml})\end{array}$ \\
\hline Ribonuclease A (25 mg/ml) & $\begin{array}{l}1202-1 \\
1202-5\end{array}$ & $\begin{array}{l}1 \mathrm{ml} \\
5 \mathrm{ml}\end{array}$ \\
\hline PCR Water & $\begin{array}{l}17000-1 \\
17000-5 \\
17000-10 \\
17000-11\end{array}$ & $\begin{array}{l}1 \mathrm{ml} \\
5 \times 1 \mathrm{ml} \\
10 \times 1 \mathrm{ml} \\
10 \mathrm{ml} \text { bottle }\end{array}$ \\
\hline Molecular Biology Grade Water & $\begin{array}{l}17012-200 \\
17012-5200\end{array}$ & $\begin{array}{l}200 \mathrm{ml} \\
5 \times 200 \mathrm{ml}\end{array}$ \\
\hline DEPC Treated Water & $\begin{array}{l}17011-200 \\
17011-5200\end{array}$ & $\begin{array}{l}200 \mathrm{ml} \\
5 \times 200 \mathrm{ml}\end{array}$ \\
\hline Endotoxin-Free Water & $\begin{array}{l}17013-10 \\
17013-50 \\
17013-100 \\
17013-500\end{array}$ & $\begin{array}{l}10 \mathrm{ml} \\
50 \mathrm{ml} \\
100 \mathrm{ml} \\
500 \mathrm{ml} \\
\end{array}$ \\
\hline Instrumentation and Accessories & Catalog No. & Quantity \\
\hline BagMixer( $400 \mathrm{VW}$ & 23112 & 1 unit \\
\hline BagFilter $(800 \mathrm{P}$ & $23113-500$ & Box of 500 \\
\hline BagPage $(8) 400$ & $23114-500$ & Box of 500 \\
\hline Precellys $₫ 24$ Homogenizer, $120 \mathrm{~V}$ & 13112 & 1 unit \\
\hline Ceramic Bead Tubes, $1.4 \mathrm{~mm}$ & $13113-50$ & 50 bead tubes \\
\hline Ceramic Bead Tubes, $2.8 \mathrm{~mm}$ & $13114-50$ & 50 bead tubes \\
\hline Glass Bead Tubes, $0.5 \mathrm{~mm}$ & $13116-50$ & 50 bead tubes \\
\hline Glass Bead Tubes, $0.1 \mathrm{~mm}$ & $13118-50$ & 50 bead tubes \\
\hline Metal Bead Tubes, $2.38 \mathrm{~mm}$ & $13117-50$ & 50 bead tubes \\
\hline $2.0 \mathrm{ml}$ Tough Tubes with Cap & $\begin{array}{l}13119-500 \\
13119-1000 \\
\end{array}$ & $\begin{array}{l}500 \\
1000 \\
\end{array}$ \\
\hline Carbide Bead Tubes, $0.25 \mathrm{~mm}$ & $13121-50$ & $\begin{array}{l}50 \times 0.5 \mathrm{ml} \\
\text { tubes }\end{array}$ \\
\hline Garnet Bead Tubes, $0.15 \mathrm{~mm}$ & $13122-50$ & $\begin{array}{l}50 \times 0.5 \mathrm{ml} \\
\text { tubes }\end{array}$ \\
\hline Garnet Bead Tubes, $0.70 \mathrm{~mm}$ & $13123-50$ & $\begin{array}{l}50 \times 2 \mathrm{ml} \\
\text { tubes }\end{array}$ \\
\hline $\begin{array}{l}\text { Garnet + 1/4 Ceramic } 15 \mathrm{ml} \text { Bead } \\
\text { Tubes, } 0.70 \mathrm{~mm}\end{array}$ & $13134-50$ & 50 tubes \\
\hline $\begin{array}{l}\text { Garnet + } 1 / 4 \text { Ceramic } 50 \mathrm{ml} \mathrm{Bead} \\
\text { Tubes, } 0.70 \mathrm{~mm}\end{array}$ & $\begin{array}{l}13144-10 \\
13144-50 \\
13144-100 \\
13144-500 \\
\end{array}$ & $\begin{array}{l}10 \text { tubes } \\
50 \text { tubes } \\
100 \text { tubes } \\
500 \text { tubes }\end{array}$ \\
\hline Glass $15 \mathrm{ml}$ Bead Tubes, $0.1 \mathrm{~mm}$ & $13135-50$ & 50 tubes \\
\hline
\end{tabular}

\begin{tabular}{|c|c|c|}
\hline $\begin{array}{l}\text { Instrumentation and } \\
\text { Accessories... Continued }\end{array}$ & Catalog No. & Quantity \\
\hline Glass $50 \mathrm{ml}$ Bead Tubes, $0.1 \mathrm{~mm}$ & $\begin{array}{l}13145-10 \\
13145-50 \\
13145-100 \\
13145-500\end{array}$ & $\begin{array}{l}10 \text { tubes } \\
50 \text { tubes } \\
100 \text { tubes } \\
500 \text { tubes }\end{array}$ \\
\hline Glass $15 \mathrm{ml}$ Bead Tubes, $1.0 \mathrm{~mm}$ & $13136-50$ & 50 tubes \\
\hline Ceramic $15 \mathrm{ml}$ Bead Tubes, $1.4 \mathrm{~mm}$ & $13137-50$ & 50 tubes \\
\hline Ceramic $50 \mathrm{ml}$ Bead Tubes, $1.4 \mathrm{~mm}$ & $\begin{array}{l}13147-10 \\
13147-50\end{array}$ & $\begin{array}{l}10 \text { tubes } \\
50 \text { tubes }\end{array}$ \\
\hline Metal $50 \mathrm{ml}$ Bead Tubes, $2.38 \mathrm{~mm}$ & $\begin{array}{l}13149-10 \\
13149-50 \\
\end{array}$ & $\begin{array}{l}10 \text { tubes } \\
50 \text { tubes }\end{array}$ \\
\hline PowerMix $15 \mathrm{ml}$ Bead Tubes & $13138-50$ & 50 tubes \\
\hline PowerMix $50 \mathrm{ml}$ Bead Tubes & $\begin{array}{l}13148-10 \\
13148-50\end{array}$ & $\begin{array}{l}10 \text { tubes } \\
50 \text { tubes }\end{array}$ \\
\hline $2 \mathrm{ml}$ Collection Tubes & $\begin{array}{l}1200-100-T \\
1200-150-T \\
1200-250-T\end{array}$ & $\begin{array}{l}100 \text { tubes } \\
150 \text { tubes } \\
250 \text { tubes }\end{array}$ \\
\hline $2 \mathrm{ml}$ Screw Cap Tubes & $12800-200-E$ & $\begin{array}{l}200 \text { tubes \& } \\
\text { caps }\end{array}$ \\
\hline $15 \mathrm{ml}$ Collection Tubes & $12700-\mathrm{T}$ & 25 tubes \\
\hline $50 \mathrm{ml}$ Centrifuge Tubes & $12600-\mathrm{T}$ & 25 tubes \\
\hline Spin Filters (in $1.9 \mathrm{ml}$ tubes) & $\begin{array}{l}1200-50-S F \\
1200-100-S F \\
1200-250-S F\end{array}$ & $\begin{array}{l}50 \text { filters } \\
100 \text { filters } \\
250 \text { filters }\end{array}$ \\
\hline Endotoxin-Free Centrifuge Tubes & $\begin{array}{l}12617-100 \\
12618-50 \\
12619-25\end{array}$ & $\begin{array}{l}100 \text { each } / 2 \mathrm{ml} \\
\text { tubes } \\
50 \text { each } / 15 \mathrm{ml} \\
\text { tubes } \\
25 \text { each } / 50 \mathrm{ml} \\
\text { tubes }\end{array}$ \\
\hline $15 \mathrm{ml}$ Midi Spin Filters & $12700-S F$ & 25 spin filters \\
\hline Vortex-Genie $(2) 2$ Vortex (120V) & $13111-\mathrm{V}$ & 1 unit \\
\hline Vortex-Genie $(2) 2$ Vortex (220V) & $13111-\mathrm{V}-220$ & 1 unit \\
\hline $\begin{array}{l}\text { Vortex Adapter, holds } 12(1.5-2.0 \mathrm{ml}) \\
\text { tubes }\end{array}$ & $13000-V 1$ & 1 unit \\
\hline Vortex Adapter, holds 6 ( $5 \mathrm{ml}$ ) tubes & $13000-V 1-5$ & 1 unit \\
\hline Vortex Adapter, holds $4(15 \mathrm{ml})$ tubes & $13000-V 1-15$ & 1 unit \\
\hline Vortex Adapter, holds $2(50 \mathrm{ml})$ tubes & $13000-\mathrm{V} 1-50$ & 1 unit \\
\hline $\begin{array}{l}\text { Vortex Adapter, holds } 24(1.5-2.0 \mathrm{ml}) \\
\text { tubes }\end{array}$ & $13000-V 1-24$ & 1 unit \\
\hline Power Supply w/Timer, (120V) & 16023 & 1 unit \\
\hline Power Supply w/Timer, (220V) & $16023-220$ & 1 unit \\
\hline Polycarbonate Single-sided Comb & $\begin{array}{l}16005 \\
16006 \\
16007 \\
16008 \\
\end{array}$ & $\begin{array}{l}1 \mathrm{~mm} \times 3 \text { well } \\
1 \mathrm{~mm} \times 8 \text { well } \\
1 \mathrm{~mm} \times 10 \text { well } \\
1 \mathrm{~mm} \times 12 \text { well }\end{array}$ \\
\hline
\end{tabular}

Technical information: Toll free 1-800-606-6246, or 1-760-929-9911 Email: technical@mobio.com Website: www.mobio.com 
Laboratories, Inc.

Other Quality Products Available from MO BIO Laboratories, Inc.

For more product and detailed information go to www.mobio.com/catalog-request to request a catalog.

\begin{tabular}{|c|c|c|}
\hline $\begin{array}{l}\text { Instrumentation and } \\
\text { Accessories... Continued }\end{array}$ & Catalog No. & Quantity \\
\hline Polycarbonate Dual-sided Comb & $\begin{array}{l}16013 \\
16014 \\
16015 \\
16016\end{array}$ & $\begin{array}{l}1 \mathrm{~mm} \times 8 \\
\text { well/16 well } \\
1 \mathrm{~mm} \times 10 \\
\text { well/14 well } \\
2 \mathrm{~mm} \times 8 \\
\text { well/16 well } \\
2 \mathrm{~mm} \times 10 \\
\text { well } 14 \text { well }\end{array}$ \\
\hline Teflon Single-sided Comb & $\begin{array}{l}16009 \\
16010 \\
16011 \\
16012 \\
\end{array}$ & $\begin{array}{l}1 \mathrm{~mm} \times 3 \text { well } \\
1 \mathrm{~mm} \times 8 \text { well } \\
1 \mathrm{~mm} \times 10 \text { well } \\
1 \mathrm{~mm} \times 12 \text { well }\end{array}$ \\
\hline Teflon Duat sided Comb & $\begin{array}{l}16017 \\
16018 \\
16019 \\
16020\end{array}$ & $\begin{array}{l}1 \mathrm{~mm} \times 8 \\
\text { well/16 well } \\
1 \mathrm{~mm} \times 10 \\
\text { well/14 well } \\
2 \mathrm{~mm} \times 8 \\
\text { well/16 well } \\
2 \mathrm{~mm} \times 10 \\
\text { well/14 well }\end{array}$ \\
\hline Mini Horizontal Gel System & 16001 & 1 each \\
\hline Mini Horizontal Gel Caster, 3 place & 16003 & 1 each \\
\hline Mini Horizontal Gel Tray & 16004 & 1 each \\
\hline 96 Well Plate Shaker (120V) & 11996 & 1 unit \\
\hline
\end{tabular}

\begin{tabular}{|l|l|l|}
\hline $\begin{array}{l}\text { Instrumentation and } \\
\text { Accessories... Continued }\end{array}$ & Catalog No. & Quantity \\
\hline 96 Well Plate Shaker (220V) & $11996-220$ & 1 unit \\
& & \\
\hline Plate Adapter Set & 11999 & 1 set \\
& & \\
\hline Tube Adapter Set & 11995 & 1 set \\
& & \\
\hline Vacuum Pump (120V) & & \\
\hline Vacuum Pump (220V) & & \\
\hline UltraVac'M Manifold & 11998 & 1 unit \\
\hline & $11998-220$ & 1 unit \\
\hline & 11997 & 1 unit \\
\hline
\end{tabular}




\section{Appendix D: Gel/PCR DNA Fragments Extraction Kit, IBI Scientific}




\section{Gel/PCR DNA Fragments Extraction Kit}

\section{For research use only}

$\begin{array}{ll}\text { Sample } & : \text { up to } 300 \mathrm{mg} \text { of agarose gel } \\ & \text { up to } 100 \mu \mathrm{l} \text { of PCR products } \\ \text { Recovery } & : \text { up to } 95 \% \\ \text { Format } & : \text { spin column } \\ \text { Operation time } & : 20 \text { minutes } \\ \text { Elution volume } & : 20-50 \mu \mathrm{l}\end{array}$

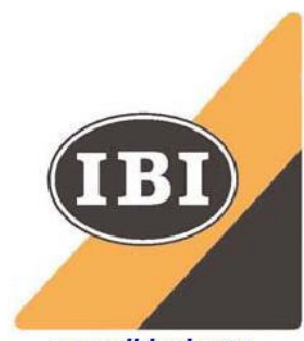

www.ibisci.com

Revised: $9 / 6 / 10$

\section{Introduction}

The Gel/PCR DNA Fragments Extraction Kit was designed to recover or concentrate DNA fragments (100 bp $\rightarrow 10$ $\mathrm{Kb})$ from agarose gel, PCR, or other enzymatic reactions. Chaotropic salt is used to dissolve agarose gel and denature enzymes. DNA fragments in the chaotropic salt are bound by the glass fiber matrix of the spin column (1). Contaminants are removed with a Wash Buffer (containing ethanol) and the purified DNA fragments are eluted by a low salt Elution Buffer or TE. Salts, enzymes and unincorporated nucleotides can be effectively removed from the reaction mixture without phenol extraction or alcohol precipitation. Typically, recoveries are up to $90 \%$ for Gel Extraction and up to $95 \%$ for PCR Clean up. The entire procedure can be completed in 20 minutes and the eluted DNA is ready for use in PCR, Fluorescent or Radioactive Sequencing, Restriction Enzyme Digestion, DNA Labeling and Ligation. For users who require a higher recovery from small base pair DNA fragments (50-200 bp) or large base pair DNA fragments (> $8 \mathrm{~Kb}$ ), see the order information below.

\section{Quality Control}

The quality of the Gel/PCR DNA Fragments Extraction Kit is tested on a lot-to-lot basis by isolating DNA fragments of various sizes from either aqueous solutions or agarose gel. The purified DNA is checked by electrophoresis.

\begin{tabular}{|c|c|c|c|}
\hline \multicolumn{4}{|c|}{ Kit Contents } \\
\hline Name & IB47010 & IB47020 & IB47030 \\
\hline DF Buffer & $3 \mathrm{ml}$ & $80 \mathrm{ml}$ & $240 \mathrm{ml}$ \\
\hline W1 Buffer & $2 \mathrm{ml}$ & $45 \mathrm{ml}$ & $130 \mathrm{ml}$ \\
\hline $\begin{array}{l}\text { Wash Buffer* } \\
\text { (Add Ethanol) }\end{array}$ & $\begin{array}{r}1 \mathrm{ml} \\
(4 \mathrm{ml})\end{array}$ & $\begin{array}{r}25 \mathrm{ml} \\
(100 \mathrm{ml})\end{array}$ & $\begin{array}{r}50 \mathrm{ml}+25 \mathrm{ml} \\
(200 \mathrm{ml})(100 \mathrm{ml})\end{array}$ \\
\hline $\begin{array}{l}\text { Elution Buffer } \\
\left.\text { (10 } \mathrm{mM} \text { Tris-HCl, pH } 8.5 \text { at } 25^{\circ} \mathrm{C}\right)\end{array}$ & $1 \mathrm{ml}$ & $6 \mathrm{ml}$ & $30 \mathrm{ml}$ \\
\hline DF Column & 4 pcs & $100 \mathrm{pcs}$ & $300 \mathrm{pcs}$ \\
\hline $2 \mathrm{ml}$ Collection Tube & 4 pcs & $100 \mathrm{pcs}$ & 300 pcs \\
\hline
\end{tabular}

*Add absolute ethanol (see the bottle label for details) to the Wash Buffer prior to initial use.

\begin{tabular}{|c|c|c|}
\hline \multicolumn{3}{|c|}{ Order Information } \\
\hline Product Name & Package size & Cat. No. \\
\hline $\begin{array}{l}\text { Gel/PCR DNA Fragments } \\
\text { Extraction Kit }\end{array}$ & $100 / 300$ preps & IB47020/030 \\
\hline $\begin{array}{l}\text { Large DNA Fragments } \\
\text { Extraction Kit }(>8 \mathrm{~Kb})\end{array}$ & $100 / 300$ preps & IB47071/072 \\
\hline $\begin{array}{l}\text { Small DNA Fragments } \\
\text { Extraction Kit }(50-200 \mathrm{bp})\end{array}$ & $100 / 300$ preps & IB47061/062 \\
\hline $\begin{array}{l}\text { 96-Well Gel/PCR DNA } \\
\text { Extraction Kit }\end{array}$ & $4 / 10 \times 96$ Wells & IB47040/050 \\
\hline $\begin{array}{l}\text { Vacuum Manifold } \\
\text { (Accessories) }\end{array}$ & $1 \mathrm{SET}$ & IB47500 \\
\hline
\end{tabular}

\section{Caution}

DF Buffer contains guanidine thiocyanate which is a harmful irritant. During operation, always wear a lab coat, disposable gloves, and protective goggles.

\section{References}

(1) Vogelstein, B., and Gillespie, D. (1979) Proc. Natl. Acad. Sci. USA 76, 615.

\section{Additional requirements}

microcentrifuge tubes, absolute ethanol 


\section{Gel Extraction Protocol}

Add absolute ethanol (see the bottle label for volume) to the Wash Buffer prior to initial use.

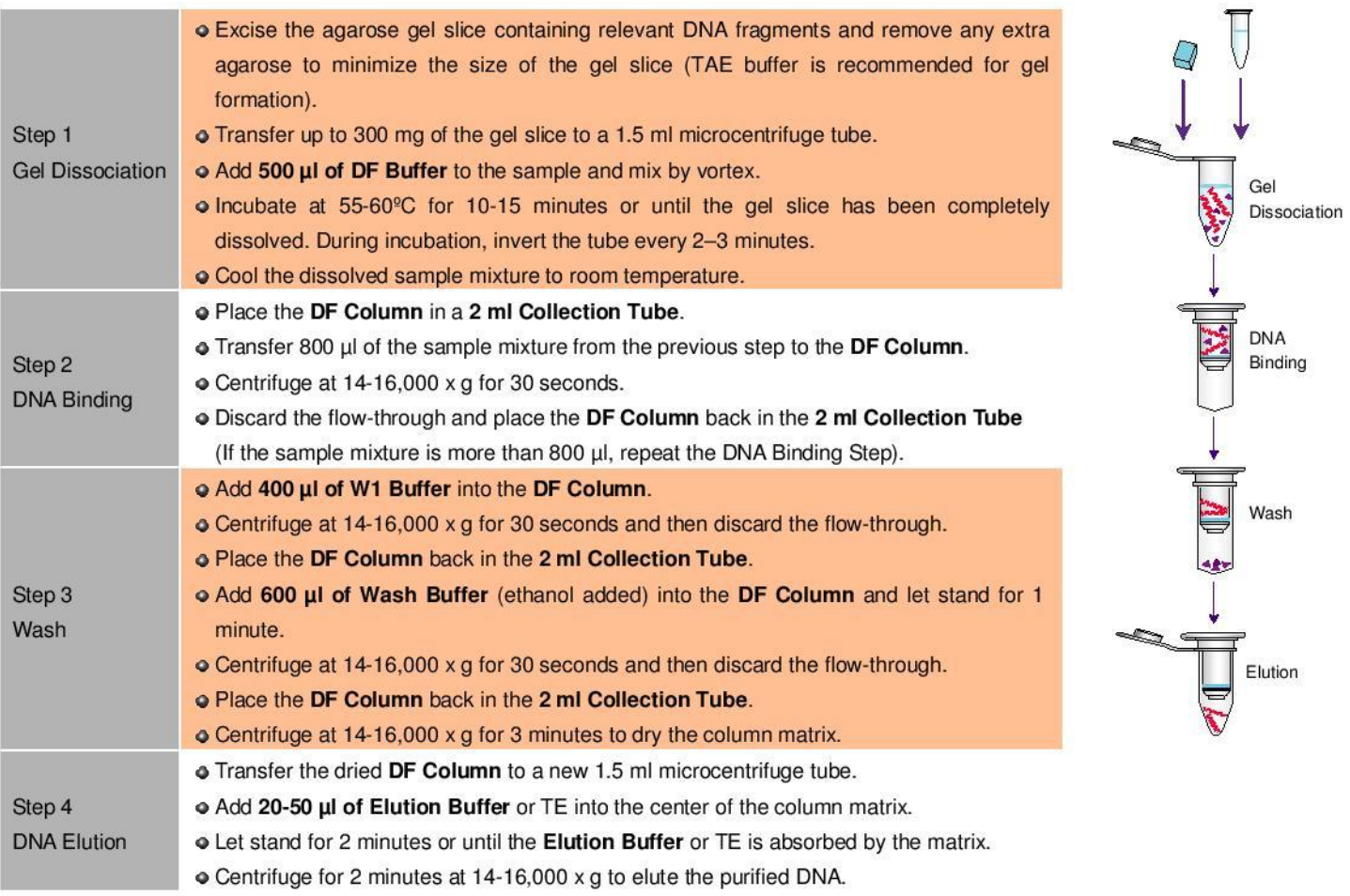

Gel Extraction (Sequencing) Protocol

Add absolute ethanol (see the bottle label for volume) to the Wash Buffer prior to initial use.

\begin{tabular}{|c|c|}
\hline $\begin{array}{l}\text { Step } 1 \\
\text { Gel Dissociation }\end{array}$ & $\begin{array}{l}\text { - Excise the agarose gel slice containing relevant DNA fragments and remove any extra agarose to minimize } \\
\text { the size of the gel slice (TAE buffer is recommended for gel formation). } \\
\text { - Transfer up to } 300 \mathrm{mg} \text { of the gel slice to a } 1.5 \mathrm{ml} \text { microcentrifuge tube. } \\
\text { - Add } 500 \mu \mathrm{l} \text { of DF Buffer to the sample and mix by vortex. } \\
\text { - Incubate at } 55-60^{\circ} \mathrm{C} \text { for } 10-15 \text { minutes or until the gel slice has been completely dissolved. During incubation, } \\
\text { invert the tube every } 2-3 \text { minutes. } \\
\text { - Cool the dissolved sample mixture to room temperature. }\end{array}$ \\
\hline $\begin{array}{l}\text { Step } 2 \\
\text { DNA Binding }\end{array}$ & $\begin{array}{l}\text { Place the DF Column in a } 2 \mathrm{ml} \text { Collection Tube. } \\
\text { - Transfer } 800 \mu \mathrm{l} \text { of the sample mixture from Step } 1 \text { to the DF Column } \\
\text { - Centrifuge at } 14-16,000 \times \mathrm{g} \text { for } 30 \text { seconds. } \\
\text { - Discard the flow-through and place the DF Column back in the } 2 \mathrm{ml} \text { Collection Tube (If the sample mixture } \\
\text { is more than } 800 \mu \mathrm{l} \text {, repeat the DNA Binding Step). }\end{array}$ \\
\hline $\begin{array}{l}\text { Step } 3 \\
\text { Wash }\end{array}$ & $\begin{array}{l}\text { - Add } 600 \mu \mathrm{l} \text { of Wash Buffer (ethanol added) into the DF Column and let stand for } 1 \text { minute. } \\
\text { - Centrifuge at } 14-16,000 \times \mathrm{g} \text { for } 30 \text { seconds and then discard the flow-through. } \\
\text { Place the DF Column back in the } 2 \mathrm{ml} \text { Collection Tube. } \\
\text { - Add } 600 \mu \mathrm{l} \text { of Wash Buffer (ethanol added) into the DF Column and let stand for } 1 \text { minute. } \\
\text { - Centrifuge at } 14-16,000 \times \mathrm{g} \text { for } 30 \text { seconds and then discard the flow-through. } \\
\text { Place the DF Column back in the } 2 \mathrm{ml} \text { Collection Tube. } \\
\text { - Centrifuge at } 14-16,000 \times \mathrm{g} \text { again for } 3 \text { minutes to dry the column matrix. }\end{array}$ \\
\hline $\begin{array}{l}\text { Step } 4 \\
\text { DNA Elution }\end{array}$ & $\begin{array}{l}\text { - Transfer the dried DF Column to a new } 1.5 \mathrm{ml} \text { microcentrifuge tube. } \\
\text { - Add } 20-50 \mu \text { l of Elution Buffer or TE into the center of the column matrix. } \\
\text { - Let stand for } 2 \text { minutes or until the Elution Buffer or TE is absorbed by the matrix. } \\
\text { - Centrifuge for } 2 \text { minutes at } 14-16,000 \times \text { g to elute the purified DNA. }\end{array}$ \\
\hline
\end{tabular}




\section{PCR Clean Up Protocol}

Add absolute ethanol (see the bottle label for volume) to the Wash Buffer prior to initial use.

\begin{tabular}{|l|}
\hline Step 1 \\
Sample Prep. \\
\hline Step 2 \\
DNA Binding \\
\hline Step 3 \\
Wash \\
\hline \\
\hline Step 4 \\
DNA Elution
\end{tabular}

- Transfer up to $100 \mu \mathrm{l}$ of a reaction product to a 1.5 microcentrifuge tube.

- Add 5 volumes of DF Buffer to 1 volume of the sample and mix by vortex.

- Place a DF Column in a $2 \mathbf{~ m l}$ Collection Tube.

- Transfer the sample mixture from step 1 to the DF Column and Centrifuge at $14-16,000 \times \mathrm{g}$ for 30 seconds.

- Discard the flow-through and place the DF Column back in the $2 \mathrm{ml}$ Collection Tube.

- Add $600 \mu \mathrm{l}$ of Wash Buffer (ethanol added) into the center of the DF Column and let stand for 1 minute.

- Centrifuge at $14-16,000 \times \mathrm{g}$ for 30 seconds.

- Discard the flow-through and place the DF Column back in the $2 \mathrm{ml}$ Collection Tube.

- Centrifuge again for 3 minutes at $14-16,000 \times \mathrm{g}$ to dry the column matrix.

- Transfer the dried DF Column to a new $1.5 \mathrm{ml}$ microcentrifuge tube.

- Add 20-50 $\mu$ l of Elution Buffer or TE into the center of the column matrix.

- Let stand for 2 minutes or until the Elution Buffer or TE is completely absorbed by the matrix.

- Centrifuge for 2 minutes at $14-16,000 \times \mathrm{g}$ to elute the purified DNA.

\section{Troubleshooting}

\begin{tabular}{|c|c|}
\hline Problem & Possible Reasons/Solution \\
\hline \multirow[t]{3}{*}{ Low Yield } & $\begin{array}{l}\text { Gel slice did not dissolve completely } \\
\text { - The Gel slice was too big. If using more than } 300 \mathrm{mg} \text { of gel slice, separate it into multiple tubes. } \\
\text { - Raise the incubation temperature to } 60^{\circ} \mathrm{C} \text { and extend the incubation time. }\end{array}$ \\
\hline & $\begin{array}{l}\text { Incorrect DNA Elution Step } \\
\text { - Ensure that the Elution Buffer is completely absorbed after being added to the center of the DF Column. }\end{array}$ \\
\hline & $\begin{array}{l}\text { Incomplete DNA Elution } \\
\text { If the DNA fragments are larger than } 10 \mathrm{~Kb} \text {, use preheated Elution Buffer }\left(60-70^{\circ} \mathrm{C}\right) \text { in the Elution Step to improve } \\
\text { the elution efficiency. }\end{array}$ \\
\hline \multirow{2}{*}{$\begin{array}{l}\text { Eluted DNA } \\
\text { doesn't perform } \\
\text { well in } \\
\text { downstream } \\
\text { applications. }\end{array}$} & $\begin{array}{l}\text { Residual ethanol contamination } \\
\text { - Following the Wash Step, dry the DF Column with additional centrifugation at } 14-16,000 \times \mathrm{g} \text { for } 5 \text { minutes or } \\
\text { incubate at } 60^{\circ} \mathrm{C} \text { for } 5 \text { minutes. }\end{array}$ \\
\hline & $\begin{array}{l}\text { DNA was denatured (a smaller band appeared on gel analysis) } \\
\text { Incubate the eluted DNA at } 95^{\circ} \mathrm{C} \text { for } 2 \text { minutes, and then cool down slowly to re-anneal the denatured DNA. }\end{array}$ \\
\hline Low A260/A230 & In the wash step, repeat the $600 \mu \mathrm{l}$ of Wash Buffer addition and let stand for 1 minute. \\
\hline
\end{tabular}




\section{Appendix E: Quality Scores for Next- Generation Sequencing}




\section{Quality Scores for Next-Generation Sequencing}

Assessing sequencing accuracy using Phred quality scoring.

\section{Introduction}

A next-generation sequencing experiment consists of a series of discrete steps that uniquely contribute to the overall quality of a data set. Sequencing quality metrics can provide important information about the accuracy of each step in this process, including library preparation, base calling, read alignment, and variant calling. Base calling accuracy, measured by the Phred quality score ( $Q$ score), is the most common metric used to assess the accuracy of a sequencing platform. It indicates the probability that a given base is called incorrectly by the sequencer.

Historically used to determine Sanger sequencing accuracy, Phred originated as an algorithmic approach that considered Sanger sequencing metrics, such as peak resolution and shape, and linked them to known sequence accuracy through large multivariate lookup tables. This method proved to be highly accurate ${ }^{1}$ across a range of sequencing chemistries and instruments, making it the quality scoring standard for commercial sequencing technologies.

While next-generation sequencing metrics vary from those of Sanger sequencing (e.g., no electropherogram peak heights), the process of generating a Phred quality scoring scheme is largely the same. Parameters relevant to a particular sequencing chemistry are analyzed for a large empirical data set of known accuracy. The resulting quality score lookup tables are used to calculate a quality score for de novo next-generation sequencing data (in real time on Illumina platforms), possessing an equivalent meaning to the historical metrics familiar to most Sanger sequencing users.

\section{Calculating Phred Quality Scores}

$\mathrm{Q}$ scores are defined as a property that is logarithmically related to the base calling error probabilities $(\mathrm{P})^{2}$.

\section{$Q=-10 \log _{10} P$}

For example, if Phred assigns a $Q$ score of $30(Q 30)$ to a base, this is equivalent to the probability of an incorrect base call 1 in 1000 times (Table 1). This means that the base call accuracy (i.e., the probability of a correct base call) is $99.9 \%$. A lower base call accuracy of $99 \%$ (Q20) will have an incorrect base call probability of 1 in 100 , meaning that every $100 \mathrm{bp}$ sequencing read will likely contain an error. When sequencing quality reaches $\mathrm{Q} 30$, virtually all of the reads will be perfect, having zero errors and ambiguities. This is why Q30 is considered a benchmark for quality in next-generation sequencing. By comparison, Sanger sequencing systems generally produce base call accuracy of $\sim 99.4 \%$, or $\sim$ Q203. Low $Q$ scores can increase false-positive variant calls, which can result in inaccurate conclusions and higher costs for validation experiments.

\section{Illumina Data Quality}

Illumina $Q$ score calculations have been shown to be very similar to the actual data quality observed in human genome sequencing ${ }^{4}$. Figure 1 shows that predicted and empirical quality scores from a HiSeq 2000

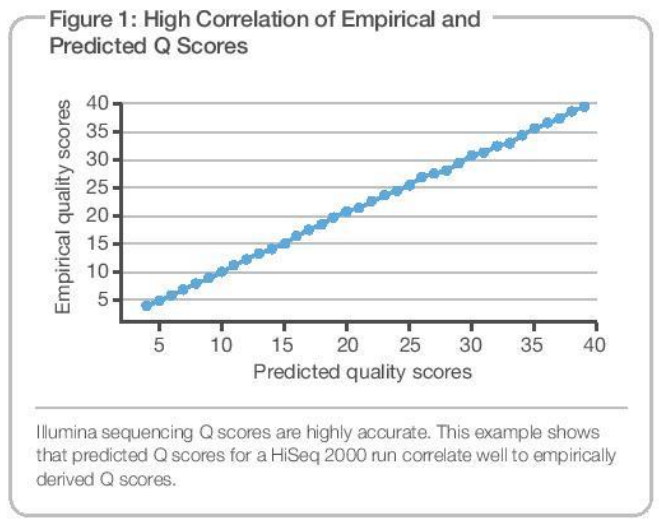

run are well correlated. Q scores can reveal how much of the data from a given run is usable in a resequencing or assembly experiment. Sequencing data with lower quality scores can result in a significant portion of the reads being unusable, resulting in wasted time and expense. PhiX quality scores for the $\mathrm{MiSeq}^{\circ}$ and $\mathrm{HiSeq}^{\circ}$ systems show that nearly all bases have scores $>\mathrm{Q} 30$ for single and paired-end reads (Figure 2). Comparison of $E$. coli whole-genome sequencing data shows that this high data quality is consistent across both platforms (Table 2).

\begin{tabular}{|ccc|}
$\begin{array}{c}\text { Table 1: Quality Scores and Base Calling Accuracy } \\
\begin{array}{c}\text { Phred Quality } \\
\text { Score }\end{array}\end{array}$ & $\begin{array}{c}\text { Probability of } \\
\text { Incorrect Base Call }\end{array}$ & $\begin{array}{c}\text { Base Call } \\
\text { Accuracy }\end{array}$ \\
\hline 10 & 1 in 10 & $90 \%$ \\
\hline 20 & 1 in 100 & $99 \%$ \\
\hline 30 & 1 in 1,000 & $99.9 \%$ \\
\hline 40 & 1 in 10,000 & $99.99 \%$ \\
\hline 50 & 1 in 100,000 & $99.999 \%$ \\
\hline
\end{tabular}

\begin{tabular}{|c|c|c|c|c|}
\hline \multirow[t]{2}{*}{ Metric } & \multicolumn{2}{|c|}{ MiSeq System } & \multicolumn{2}{|c|}{ HiSeq System } \\
\hline & Read 1 & Read 2 & Read 1 & Read 2 \\
\hline$\%$ Bases $Q \geq 30$ & 91.9 & 87.5 & 89.3 & 86.1 \\
\hline$\%$ Total Bases $Q \geq 30$ & \multicolumn{2}{|c|}{89.7} & \multicolumn{2}{|c|}{87.7} \\
\hline \multicolumn{5}{|c|}{$\begin{array}{l}\text { A whole-genome sequencing run ( } 2 \times 150 \mathrm{bp} \text { ) of } \mathrm{E} \text { coll } \mathrm{K} 12 \mathrm{MG} 1655 \text { performed } \\
\text { on the MiSeq system yielded } 1.7 \mathrm{~Gb} \text { of high--quality data. MSeq data were } \\
\text { trimmed to } 2 \times 100 \text { bp to allow for a direct comparison with } 2 \times 100 \text { bp reads } \\
\text { from the HiSeq } 2000 \text { plattorm. }\end{array}$} \\
\hline
\end{tabular}




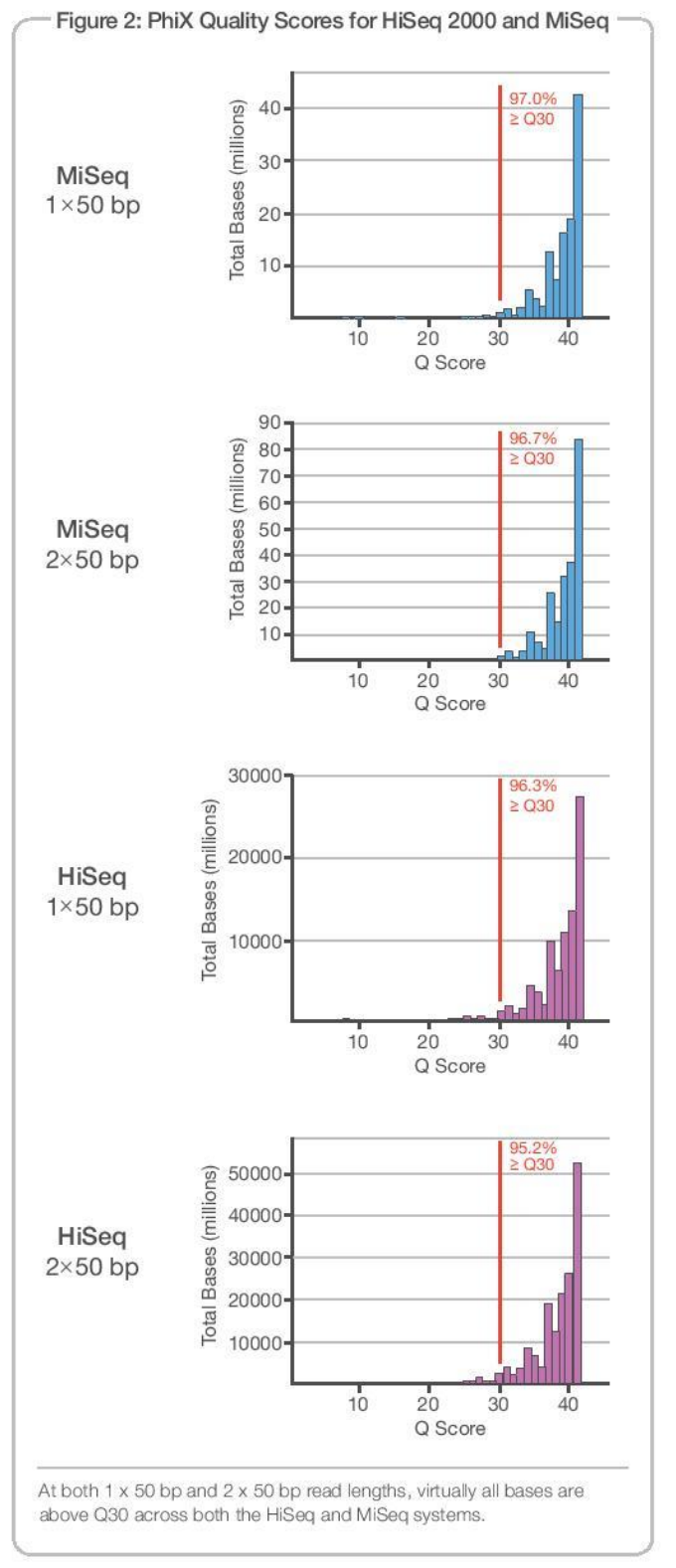

\section{Accurate Sequencing Chemistry}

Illumina sequencing by synthesis (SBS) technology delivers the highest percentage of error-free reads, with a vast majority of bases having quality scores above Q30. In many cases, even higher quality scores of Q35-Q40 are available. The latest version of the chemistry, TruSeq ${ }^{\text {TM }}$ SBS and Cluster Generation v3 reagents, have been optimized for accurate base calling even within difficult-to-sequence regions of the genome, such as repeats, homo polymers, and high GC regions. TruSeq $\sqrt{3}$ chemistry is available for the HiSeq and MiSeq systems. The unparalleled TruSeq accuracy is ideal for next-generation sequencing in clinical environments that demand the highest standard of quality. Since the release of the original Illumina Genome Analyzer ${ }^{\mathrm{TM}}$ system, SBS technology has been used in the widest range of sequencing applications, resulting in more than 2,000 peer-reviewed publications in just five years - a feat unmatched for any other life science technology.

SBS chemistry uses four fluorescently labeled nucleotides to sequence up to billions of clusters on the flow cell surface in parallel. During each sequencing cycle, a single labeled deoxynucleoside triphosphate (dNTP) is added to the nucleic acid chain. The dNTPs contain a reversible blocking group that serves as a terminator for polymerization, so after each dNTP incorporation, the fluorescent dye is imaged to identify the base and then enzymatically cleaved to allow incorporation of the next nucleotide. Since all four reversible terminator-bound dNTPs (A, C, T, G) are present as single, separate molecules, natural competition minimizes incorporation bias, which can be problematic with serial nucleotide incorporation chemistry used in Sanger sequencing. Base calls are made directly from signal intensity measurements during each cycle, greatly reducing raw error rates compared to other technologies. The result is highly accurate base-by-base sequencing that eliminates sequencecontext specific errors, enabling robust base calling across the genome, including repetitive sequence regions and homo polymers.

\section{Summary}

$Q$ scores are used to measure base calling accuracy, one of the most common metrics for assessing sequencing data quality. Low $Q$ scores can lead to increased false-positive variant calls, resulting in inaccurate conclusions and higher costs for validation experiments. Illumina's sequencing chemistry delivers unparalleled accuracy, with a vast majority of bases scoring Q30 and above. This level of accuracy is ideal for a range of sequencing applications, including clinical research.

\section{References}

1. Richterich P. (1998): Estimation of errors in "raw" DNA sequences: a validation study. Genome Res. 8(3):251-259.

2. Ewing B, Green P. (1998): Base-calling of automated sequencer traces using phred. II. Error probabilities. Genome Res. 8(3):186-194.

3. http://www3.appliedbiosystems.com/cms/groups/mcb_marketing/ documents/generaldocuments/cms_040402.pdf (as of 3/12/2012).

4. Fujimoto A, Nakagawa H, Hosono N, Nakano K, Abe T, et al. (2010) Whole-genome sequencing and comprehensive variant analysis of a Japanese individual using massively parallel sequencing. Nature Genetics. 42:931-936,

5. Morgan JE, Carr IM, Sheridan E, Chu CE, Hayward B, et al. (2010) Genetic diagnosis of familial breast cancer using clonal sequencing. Hum Mutat. 31(4):484-91.

Illumina, Inc. • 9885 Towne Centre Drive, San Diego, CA 92121 USA • 1.800.809.4566 toll-free • 1.858.202.4566 tel • techsupport@illumina.com・ Illumina.com FOR RESEARCH USE ONLY

O 2011 lllumina, Inc. All rights resenved.

Illumina, illuminaDx, BaseSpace, BeadArray, BeadXpress, cBot, CSPro, DASL, DesignStudio, Eco, GAllx, Genetic Energy, Genome Analyzer, Genomer. names contained herein are the property of their respective owners. Pub. No. 770-2011-030 Current as of 31 October 2011 